\title{
Automation Impact Study of Army Training Management
}

T. F. Sanquist

C. R. Schuller

M. C. McCallum

J. A. Underwood

P. J. Bettin
J. L. King

B. D. Melber

C. J. Hostick

D. A. Seaver

January 1988

Prepared for the U.S. Department of Energy under Contract DE-AC06-76RLO 1830

Pacific Northwest Laboratory

Operated for the U.S. Department of Energy

by Battelle Memorial Institute 


\title{
DISCLAIMER
}

This report was prepared as an account of work sponsored by an agency of the United States Government. Neither the United States Government nor any agency thereof, nor Battelle Memorial Institute, nor any of their employees, makes any warranty, expressed or implied, or assumes any legal liability or responsibility for the accuracy, completeness, or usefulness of any information, apparatus, product, or process disclosed, or represents that its use would not infringe privately owned rights. Reference herein to any specific commercial product, process, or service by trade name, trademark, manufacturer, or otherwise, does not necessarily constitute or imply its endorsement, recommendation, or favoring by the United States Government of any agency thereof, or Battelle Memorial Institute. The views and opinions of authors expressed herein do not necessarly state or reflect those of the United States Government or any agency thereof, or Battelle Memorial Institute.

\author{
PACIFIC NORTHWEST LABORATORY \\ operated by \\ BATTELLE MEMORIAL INSTITUTE \\ for the \\ UNITED STATES DEPARTMENT OF ENERGY \\ under Contract DE-AC06-76RLO 1830
}

\begin{tabular}{|c|c|}
\hline \multicolumn{2}{|c|}{$\begin{array}{l}\text { Printed in the United States of America } \\
\text { Available from } \\
\text { National Technical Information Service } \\
\text { United States Department of Commerce } \\
5285 \text { Port Royal Road } \\
\text { Springfield, Virginia } 22161\end{array}$} \\
\hline \multicolumn{2}{|c|}{$\begin{array}{l}\text { NTIS Price Codes } \\
\text { Microfiche A01 }\end{array}$} \\
\hline \multicolumn{2}{|c|}{ Printed Copy } \\
\hline Pages & $\begin{array}{l}\text { Price } \\
\text { Codes }\end{array}$ \\
\hline $001-025$ & $\mathrm{~A} 02$ \\
\hline $026-050$ & $\mathrm{~A} 03$ \\
\hline $051-075$ & A04 \\
\hline $076-100$ & A05 \\
\hline $101-125$ & A06 \\
\hline $126-150$ & $\mathrm{~A} 07$ \\
\hline $151-175$ & $\mathrm{~A} 0 \mathrm{~B}$ \\
\hline $176-200$ & A09 \\
\hline $201-225$ & A010 \\
\hline $226-250$ & A011 \\
\hline $251-275$ & A012 \\
\hline $276-300$ & A013 \\
\hline
\end{tabular}


AUTOMATION IMPACT STUDY OF ARMY TRAINING MANAGEMENT

T. F. Sanquist (a)

C. R. Schuller (a)

M. C. McCallum(a)

J. A. Underwood (a)

P. J. Bettin(a)

January 1988

Prepared for

the U.S. Department of Energy

under Contract DE-ACO6-76RLO 1830

Pacific Northwest Laboratory

Richland, Washington 99352

(a) Battelle Seattle Research Center Seattle, Washington 98105 
• 


\section{EXECUTIVE SUMMARY}

This automation impact study of Army Training Management (TM) was conducted by the Army Development and Employment Agency (ADEA) through Battelle Human Affairs Research Centers and Pacific Northwest Laboratory. The study was directed by Mr. Walt Hollis, the Deputy Undersecretary for Operations Research, Department of the Army. The main objectives were to identify the potential cost savings associated with automated TM, and to perform a cost-benefit analysis for an Army-wide automated TM system. A subsidiary goal was to establish baseline data for an independent evaluation of a prototype Integrated Training Management System (ITMS), to be tested in the fall of 1988 .

In order to meet these objectives, a structured analysis of TM doctrine was performed for comparison with empirical data gathered in a job analysis survey of selected units of the 9ID (MTZ) at Ft. Lewis, Washington. These observations will be extended to other units in subsequent surveys. The survey data concerning staffing levels and amount of labor expended on eight distinct TM tasks were analyzed in a cost effectiveness model. The main results of the surveys and cost effectiveness modelling are summarized below.

A comparison of survey results with TM doctrine, based on expert judgment, indicated that, in general, TM practice follows doctrine. However, there are specific inadequacies in practice that can ultimately have a profound impact on unit training and readiness. For example, most units operate within a narrowly-defined range of training program planning inputs. There were few reports of analyzing tasks in terms of wartime missions and previous training results. At the company level, only 26 percent of the respondents reported use of written guidance, and only 5 percent of the respondents reported using battalion guidance for identification of training objectives and tasks. Instead, company-level respondents tend to define missions and tasks in terms of historical and current planning, i.e., what they have trained on in the past, and what resources and time are currently available to them. This indicates that training is continually focused on short-term, event-driven responsiveness. 
Another key deficiency in current practice, related to those described above, is the low usage rate of training results in planning future activities. This indicates the lack of critical feedback, which is important for establishing and maintaining skills. The lack of input from the doctrinal sources that define unit missions and the lack of training feedback result in training programs that tend to be narrowly focused. Thus, a significant potential benefit of automated TM will be to align practice with doctrine, through the capability to more precisely define training requirements in terms of unit missions and proficiency status. Automation will facilitate this process by making documentation more readily available, by computationally resolving resource conflicts, and by providing training evaluation data that can be used to assess proficiency trends. It can be predicted that with the introduction of automated $T M$, the specific content of training programs will change for the better, i.e., will be tailored to unit needs rather than driven by schedules and resources. This type of change can be captured in an independent evaluation through appropriate measures of effectiveness (MOEs), such as comparisons of the training program content of two like units, one using automated $T M$, and the other using conventional TM procedures. Such measures address the results of training management, and are referred to as product-based measures.

A second general area where the survey identified inadequacies in the current TM process concerns how tasks are performed. Much paperwork is involved, such as repetitive forms generation and modification, with little faith in the final impact or accuracy of products. For example, only 13 percent of the respondents from companies surveyed reported using the training ammunition forecast as a resource input, and the ratings of accuracy obtained for many of the documents generated, such as schedules, were low. Further, critical documents were frequently missing, leading to some of the problems in planning discussed previously. The document retrieval and electronic message transmission capabilities of automation will help to alleviate some of these problems. The desirable characteristics for automated solutions to some specific TM tasks are described in Section 3.5 of this report. For purposes of independent evaluation, a number of specific task-based MOEs, or process-based measures, are discussed in Chapter 6 of this report. 
The staffing levels for TM tasks obtained in the survey were used as input for calculating the costs of TM as it is currently conducted. Numerous scenarios were examined, and are described in detail in Chapter 4. By extension of 9ID (MTZ) data to the entire active Army, it was estimated that TM as currently practiced requires 8208 man-years at a cost of $\$ 348$ million annually. Calculations for an automated system with labor reductions based on ITMS performance specifications and workload reduction factors from industrial studies showed that automated TM would entail 5683 man-years at a cost of $\$ 227$ million annually. The net savings would be 2525 man-years and $\$ 121$ million annually. Extended to a 10 year system life cycle, and incorporating new equipment, the present value dollar savings would be $\$ 720$ million. These savings figures are presented to company level, since the bulk of TM cost is associated with that echelon (49 percent). The man-year savings reflect resources that are currently devoted to coping with inefficiencies in the present TM system. When these inefficiencies are reduced or eliminated by automation, an additional 2525 man-years worth of labor can be devoted to mission essential training.

A similar cost reduction analysis of training-related consumable materials and vehicle depreciation indicates that substantial cost reductions will be obtained through automation. Since these costs were not directly measured in the present study, the 1986-87 Army budget was used as a bas is for calculation. This analysis indicates that a $1 \%$ cost reduction in training-related expenses and vehicle depreciation would result in a $\$ 312$ million savings annually.

The field test planned for the prototype ITMS in the fall of 1988 will provide an opportunity to evaluate some of the potential benefits and cost savings of automated TM. Chapter 5 presents a brief description of previous automation efforts leading up to the ITMS program, and examines the implications of using ATCCS common hardware for automated TM implementation. Chapter 6 provides a review of the major findings of this study, and discusses the general parameters of an independent evaluation that would address changes in unit performance as a result of automated $T M_{\text {; }}$ the focus here is on product-based measures. Since there will be difficulty in achieving a true test of unit performance differences resulting from automation, a variety of process-based issues are discussed. The underlying philosophy here is 
that by improving TM task performance through automation, the resulting training programs will be better linked to unit needs, thus resulting in a higher level of unit readiness. 
1.1 Background, Objectives \& Scope . . . . . . 1-1

1.2 Army Training Management: General Description . . . 1-4

1.3 Evaluating the Relationship of Training Management
to Readiness . . . 1-6

2.0 DOCTRINAL STUOY OF ARMY TRAINING MANAGEMENT $\cdot$. . . . $\quad$ 2-1

2.1 Document Review Process . . . . . . . . 2-1

2.2 Data Flow Diagrams . . . . . . . . . 2-2

2.3 Verification Process . . . . . . . . 2-2

2.4 Doctrinal Data Flow Diagrams . . . . . . . 2-2

2.4.1 Training Management Context . . . . . . 2-3

2.4.2 Level 1 - Training Management Processes . . . 2-3

2.4.3 Level 2 - Identification of Unit Missions and . 2-6
Goals

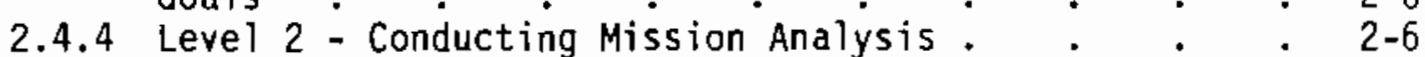

2.4.5 Level 2 - Conduct Training Estimate . . . . 2-9

2.4.6 Level 2 - Developing Training Strategy . . . 2-9

2.4.7 Level 2 - Task Training Status and Feedback . . 2-12

2.5 Organizational Analysis . . . . . . . . 2-12

2.6 Synopsis . . . . . . . . . . . 2-18

3.0 SURVEY AND JOB ANALYSIS OF CURRENT TRAINING MANAGEMENT

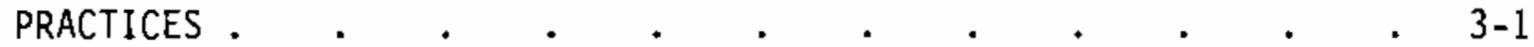

3.1 Introduction . . . . . . . . . . 3-1

3.2 Job Analysis Instrument Description . . . . . 3-1

3.3 Job Analysis Survey Results . . . . . . . 3-5

3.3.1 Study Sample . . . . . . . . . . 3-6

3.3.2 Job Performance . . . . . . . . 3-7

3.3.3 Scheduled Training Accomplished . . . . . 3-15

3.3.4 Problems, Solutions and Suggested Features 3-18

3.4 Comparison of Doctrine and Practice: Synopsis

of Results . . . . . . . . . 3-23

3.5 Improving Training Management through Automation : : ${ }^{*}$ 3-25

3.5.1 Candidate \#1: Resource Scheduling . . . . 3-26

3.5.2 Candidate \#2: Ammunition Forecasting . . . . 3-27

3.5.3 Candidate \#3: Preparing the Unit Readiness
Report. . 3-28

3.5.4 Candidate \#4: Obtaining Pubiications to Identify
Unit Missions, Goals and Tasks. . . $3-29$ 
CONTENTS (cont.)

$\underline{\text { Page }}$

3.5.5 Candidate \#5: Tracking Proficiency and

Turbulence Impacts

3.6 Methodological and Measurement Considerations . . . 3-33

4.0 INTEGRATED TRAINING MANAGEMENT SYSTEM COSTS

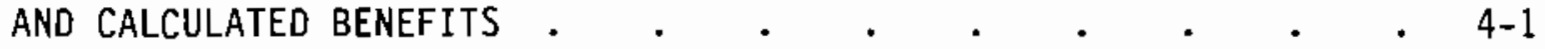

4.1 Introduction . . . . . . . . . . 4-1

4.1.1 Cost Benefit Analysis for Automated Office or
Management Systems . . . . 4-1

4.1 .2 Analytical Approach : . . . . . . $4-2$

4.1.3 The Model of Cost Effectiveness . . . . . 4-2

4.2 Manual Training Management System Cost Estimates . . . 4-3

4.2.1 Representative Unit Training Management Costs . . 4-4

4.2.2 Training Management System Labor Costs for the
Active Army . . 4-10

4.2.3 Army-Wide Manual Training Management Cost . . . 4-12

4.2.4 Training Management Cost by Task. . . . . 4-13

4.3 Automation Impact on Training Management . . . . . 4-21

4.3.1 Automation Impact on Type of Work . . . . 4-21

4.3.2 Summary of Labor Costs. . . . . 4-28

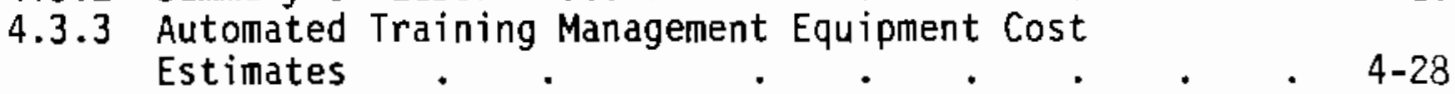

4.4 Automated System Cost Effectiveness . . . . . 4-31

4.5 Cost Impacts on Intangible Aspects of Army Operation . . 4-3.4

4.5.1 Cost Savings on Training-Related Consumables . . 4-36

4.5.2 Cost Savings on Equipment Depreciation . . . 4-37

4.5.3 Savings Resulting from Improved TM Performance. . 4-383

4.6 Synopsis of Potential Benefits . . . . . . . 4-43

5.0 automated training management $\quad . \quad$. . . . . . . . . . 5-1

5.1 Review of Mission Essential Needs Statement . . . . 5-1

5.2 Previous Automation Efforts . . . . . . . 5-1

5.3 The Prototype Integrated Training Management System . . 5-3

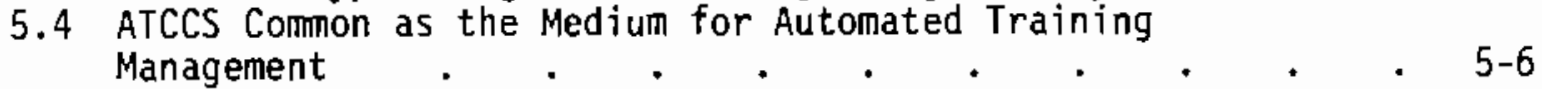


6.0 DISCUSSION OF RESULTS AND POTENTIAL MEASURES OF

EFFECTIVENESS • • • • • • • • . . . $6-1$

6.1 Review of Major Findings . . . . . . . . $6-1$

6.2 Cost Effectiveness and Evaluation . . . . . . 6-2

6.3 Evaluation Approaches and Candidate Measures of . . . 6- 6-3
Effectiveness. . . . .

6.3 .1 The Ideal Test . . . . . . . . 6- 6-3

6.3.2 The Practical Case . . . . . . 6-5

6.4 Conclusions . . . . . . . . . . . . 6-9

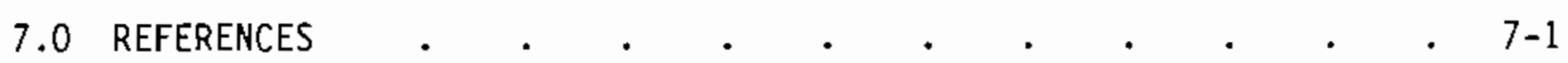

APPENDIX A. STRUCTURED INTERVIEW MATERIALS . . . . . . .

APPENDIX B. STRUCTURED INTERVIEW RESPONDENTS * . • . . . . B-1

APPENDIX C. SUMMARY OF CONTENT ANALYSIS + . . . . . . . . C-1

APPENDIX D. COMPARISON OF DOCTRINE AND PRACTICE . . . . . . $\quad$.

APPENDIX E. INPUT AND OUTPUT DOCUMENT TAXONOMY . . . . . E-I 


\section{FIGURES}

$\underline{\text { Page }}$

FIGURE 1.1. The Four Phases of Training Management . . . . . 1-5

FIGURE 2.1. Training Management Context . . . . . . . . 2-4

FIGURE 2.2. Leve] 1 - Training Management Processes . . . . 2-5

FIGURE 2.3. Level 2 - Identification of Unit Missions and Goals . . 2-7

FIGURE 2.4. Level 2 - Conducting Missions Analysis . . . . 2-8

FIGURE 2.5. Leve1 2 - Conducting Training Estimate . . . . 2-10

FIGURE 2.6. Level 2 - Developing Training Strategy . . . . . 2-11

FIGURE 2.7. Level 2 - Task Training and Feedback . . . . . 2-13

FIGURE 2.8. Interaction of Training Managenent Processes
Across Echelons . . . . . . . . . . . . 2-14

FIGURE 2.9. Interaction of Planning and Execution of Training
Across Echelons Over Time . . . . . . . . $2-16$

FIGURE 2.10. Company Level Training Management . . . . . . 2-17

FIGURE 3.1. Oata Sheet Completed by One Respondent . . . . . 3-4

FIGURE 3.2. Mean Proportion of Duty Time Spent on Each TM

Task by Respondents . . . . . . . . 3-10

FIGURE 3.3. Mean Proportion of Duty Time Spent on ATl TM
Tasks by Respondents at Each Echelon . . . . . . $3-12$

FIGURE 3.4. Mean Proportion of Duty Time Spent on Each TM
Work Type by Respondents . . . . . . . 3-14

FIGURE 3.5. Proportion of Respondents Who Use a Computer in
Performing TM Work . . . . . . . . . . $3-16$

FIGURE 4.1. Breakdown of Training Management Time Requirements . 4-14

FIGURE 4.2. Breakdown of Training Management Time Requirements . 4-16 


\section{TABLES}

Page

TABLE 3.1. Training Management Tasks Used in Job Study Survey

TABLE 3.2. Types of Work Categories Used in Job Study Survey . . . . . . . . . . . 3-5

TABLE 3.3. Summary of Job Analysis Survey Respondents . . . 3-6

TABLE 3.4. Summary of Survey Respondents' Training Management Experience . . . . . . . . 3-7

TABLE 3.5. Proportion of Respondents Performing Each Training Management Task . . . . . . 3-8

TABLE 3.6. Mean Proportion of Duty Time Performing Each Training Management Task . . . . . . . 3-9

TABLE 3.7. Mean Proportion of Duty Time Performing Each Type of Training Management Work

TABLE 3.8. Percent Respondents Who Perform Task and Use Computers . . . . . . . . . . . 3-13

TABLE 3.9. Summary of Training Scheduled and Accomplished Estimates . . . . . . . . . . 3-17

TABLE 3.10. Summary of "General Problems" Content Analysis . • . 3-19

TABLE 3.11. General Solutions: Summary of Results . . . . 3-20

TABLE 3.12. Percent Respondents Stating Each Automation Feature . . . . . . . . . 3-22

TABLE 4.1. U.S. Army Personnel Labor Costs . . . . . . . 4-6

TABLE 4.2. Representative Division Training Management Costs . . 4-7

TABLE 4.3. Representative Brigade Training Management Costs . . 4-8

TABLE 4.4. Representative Battalion Training Management Cost • . 4-8

TABLE 4.5. Representative Company Training Management Cost . . 4-9

TABLE 4.6. Representative Unit Training Management Costs . . . 4-9

TABLE 4.7. Army-Wide Divisions and Brigades . . . . . 4-10

TABLE 4.8. Breakdown of Representative Division and Brigade . . 4-11

TABLE 4.9. Total Active Army Units . . . . . . . . . . 4-11 
TABLE 4.10. Annual Active Amy Manual Training Management Cost . . 4-12

TABLE 4.11. Breakdown of Division Training Management Labor By Task (In Proportion of Duty Time) . . . . . . 4-17

TABLE 4.12. Brigade Training Management Labor by Task (In Proportion of Duty Time)

TABLE 4.13. Battalion Training Management Labor By Task (In Proportion of Duty Time) . . . . . . . 4-19

TABLE 4.14. Company Level Training Management Labor By Task (In Proportion of Duty Time) . . . . . . . 4-20

TABLE 4.15. Example Calculations for Determining Automated Training Management System Labor Requirements . . . 4-22

TABLE 4.16. Automated System Oivision Training Management Costs . . 4-25

TABLE 4.17. Automated System Brigade Training Management Costs . . 4-26

TABLE 4.18. Automated System Battalion Training Management Cost • . 4-27

TABLE 4.19. Automated Systems Company Level Training Management Cost . . . . . . . . . . 4-27

TABLE 4.20. Labor Costs for Automated Training Management System
from the Division Through Company Level . . 4-28

TABLE 4.21. A) Labor Savings in Thousands of Dollars for Each TM Task and Type of Work for Active Army Units • . . 4-29

8) Labor Savings in Man-Years for Each TM Task and Type
of Work for Active Army Units . . 4-29

TABLE 4.22. Per Unit Equipment and Supporting Software Costs for
Automating Training Management (BDM Corporation) . . 4-31

TABLE 4.23. Army-Wide Equipment/Supporting Software Costs for an Automated Training Management System . . . . 4-32

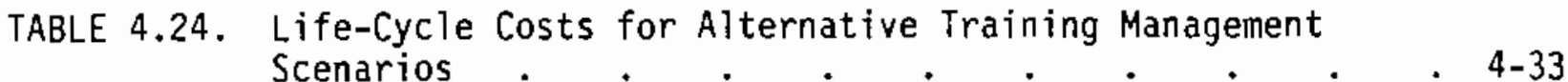

TABLE 4.25. Ranking of Training Management System Alternatives by Life-Cycle Cost Effectiveness . . . . . 4-35

TABLE 4.26. Potential Savings Resulting from a Percent Reduction in Cost of Training Resources . . . . 4-37 


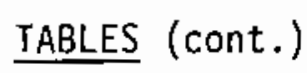

TABLE 4.27. Potential Savings Resulting from Extending the Life of Vehicles and Weapons

TABLE 4.28. Potential Improvements in Training References

Resulting from Automated TM . . . . . 4-40

TABLE 4.29. Potential Improvements in Training Guidance

Resulting from. Automated TM . . . . . 4-40

TABLE 4.30. Potential Improvements in Training Schedules

Resulting from Automated TM . . . . . . 4-41

TABLE 4.31. Potential Improvements in Training Evaluation

Resulting from Automation . . . . . . 4-41

TABLE 4.32. Potential Improvements in Training Ammunition

Resulting from Automation . . . . . . . 4-42

TABLE 4.33. Potential Improvements in Unit Status Reporting, Training Areas and Ranges, Training Aids Support and Training Funds Management . . . . . 4-42

TABLE 4.34. Potential Improvements in General Administration of TM Resulting from Automation . . . . . . 4-43

TABLE 5.1. Comparison of TM and ATCCS Requirements . . . . . 5-6 
$\infty$ 


\subsection{INTRODUCTION: AUTOMATION IMPACT \\ STUOY OF ARMY TRAINING MANAGEMENT}

The readiness of U.S. Army units depends on appropriate training-the development of individual and collective skills to perform missions. Effective skill building depends on proper training management (TM)--i.e., the processes used by commanders, their staffs, and others to plan and identify the requirements to conduct and evaluate training activities. TM is the process of developing training programs with the goal of combining resources, materials, guidance, and time to meet specific requirements. The study described in this report examines the costs and potential benefits associated with introducing computer-based automation to the process of Army training management.

The report is divided into six chapters. The first chapter provides background information concerning the study and discusses the relation of training management to unit readiness. Chapter 2 presents an analysis of how training management should be conducted according to Army doctrine. This provides a benchmark for comparison with an empirical study, described in Chapter 3, of how training management is currently conducted in a sample of units in the 9th Infantry Division (MTZ). Chapter 4 delineates the results of an analysis of the costs associated with such a system, and the potential benefits of automation. This model is developed for the 9ID (MTZ), and extended to the entire Ammy. The fifth chapter describes previous automation efforts and provides a description of a design prototype--the Integrated Training Management System (ITMS). The sixth and final chapter summarizes the study, offers conclusions regarding the probable impacts of automation on $T M$, and identifies potential independent evaluation issues.

\subsection{BACKGROUND, OBJECTIVES AND SCOPE}

The concept of automating the training management process originated in work conducted on training detractors at the U.S. Army Research Institute, Monterey, California (Hiller, 1982). The basic concept involves the use of automated data processing (ADP) systems to provide unit scheduling, establish training for units based on mission priorities, and the application of 
computed estimates of skill decline. Existing ADP systems do not work well, nor do they perform the needed TM functions. Properly implemented automated training management can help to resolve resource conflicts in TM, standardize the approach to training program development, and reduce administrative overhead, such as paperwork and message transmission.

The present study has been directed by the Deputy Undersecretary for Operations Research (DUSAOR) to examine the costs and benefits associated with automating training management, and is being executed by the Army Development and Employment Agency (ADEA) through Battelle Northwest (Carson, 1987). The requirements of the study are further defined in DA Message 011417 May ' 87 to ADEA. Specifically, the study is to (1) identify potential cost savings, and (2) perform a cost-benefit analysis for the objective system. A third objective defined in this message is the independent evaluation of the prototype ITMS. Toward that end, Battelle is providing input for the Independent Evaluation Plan (IEP).

The basic questions to be answered in this study are as follows:

- How does Army training management operate according to doctrine? (Chapter 2)

- Does the actual practice of training management follow doctrine? (Chapter 3)

- What areas in the TM, rocess appear to be most promising for automation? (Chapter 3)

- What are the costs of training management as it is conducted now? (Chapter 4)

- What are the costs and economic savings that will result from the introduction of automation? (Chapter 4)

- What are the functional characteristics of previous and current efforts for automating TM? (Chapter 5)

- What are Measures of Effectiveness (MOEs) that may be applied in an operational test of a prototype automated system that can be used to assess cost effectiveness? (Chapter 6)

The objectives in answering these questions are (1) to provide the Army with empirically-based information concerning the current costs of training management and a heuristic model for considering the cost effectiveness of 
automation; (2) to establish a framework, baseline data, and set of candidate measures for the test and evaluation of the prototype ITMS; and (3) to provide detailed data on staffing and information flow within and between echelons. These latter data will be particularly useful for establishing the functional architecture for the objective system.

The scope of the present study involved data collection within the 9ID (MTZ). A multi-comparison design was used in the study. First, TM according to doctrine was characterized through a review of existing and draft Army documents. The results were expressed as data flow diagrams of major functions, nodes, and data flow pathways, and were verified with doctrine writers at the Combined Arms Training Activity (CATA). The next set of data consisted of an extensive job analytic and information flow survey of training management in the 9ID (MTZ). These two approaches permit comparison of TM according to doctrine with how TM is actually performed currently in units. Additionally, a study of the functional characteristics of the Integrated Training Management System (ITMS) was performed. This system is a prototype being developed for ADEA by the BDM Corporation. Hardware configuration costs and administrative workload reduction factors associated with automation were examined in a cost effectiveness model developed for the 9ID (MTZ), and extended to the entire Army.

The present stury is primarily oriented toward developing a quantitative description and information flow model of TM. This provides the basis for making cost effectiveness calculations with a variety of different assumptions about how training management may best be automated. Further, it establishes a methodology for gathering additional data from Army units outside the 9ID to improve the generalizability of the results. Finally, the quantitative study of TM establishes a number of process-based measures (i.e., how TM is conducted) that can be employed in an operational test. When combined with product-based measures (i.e., the results of $T M$ ) of unit performance resulting from training, a comprehensive picture of training management effectiveness will result. Thus, the present report should be viewed as a companion study to an independent evaluation plan (IEP) for which Battelle is developing issues and criteria. 
The remainder of this chapter provides relevant background information for the analysis presented in Chapters 2 through 6 . First, a general description of the TM process is provided. This description sets the context for the detailed process flow analys is of doctrinally defined TM presented in Chapter 2. This presentation is followed by a discussion of the relationship of TM to unit readiness.

\subsection{ARMY TRAINING MANAGEMENT: GENERAL DESCRIPTION}

TM consists of four basic phases, as shown in Figure 1.1. This figure, based on FM 25-2 (Unit Training Management), shows that planning, resourcing, training, and evaluation comprise TM. The feedback and backward planning lines indicate that the phases occur concurrently and interact with one another. Thus, as actual training is being conducted, plans are being made for future programs.

As described in FM 25-100 (draft, Training the Force), TM is a "top-down' process, i.e., the training of each echelon focuses directly on the missions and support needs of the next higher echelon. The top-down approach is directed by a process known as "Battle Focus." The outcome of the battle focus process is a list of collective and individual tasks that are critical to a unit in meeting its wartime missions and goals. This list is known as the Mission Essential Task List (METL). Based on the ME*:? units compare their current task proficiency with their goals, and determine where training is needed to correct deficiencies. Within this process, priority tasks are selected by unit commanders, and training programs are designed around these tasks. Subsequent to planning, the training programs are provided resources and are conducted. The results of training are evaluated and used as feedback to the planning, resourcing, and training phases.

These phases occur at all levels and are staggered in time. Thus, while division may be planning for the subsequent quarter, company level units are executing training programs based on the current quarter's guidance. The high level of incerdependence of these processes within and across echelons points to coordination of information as a key requirement for smooth operation. Effective and timely inter-and intra-echelon coordination during the four TM phases will be a key impact of automated TM. 


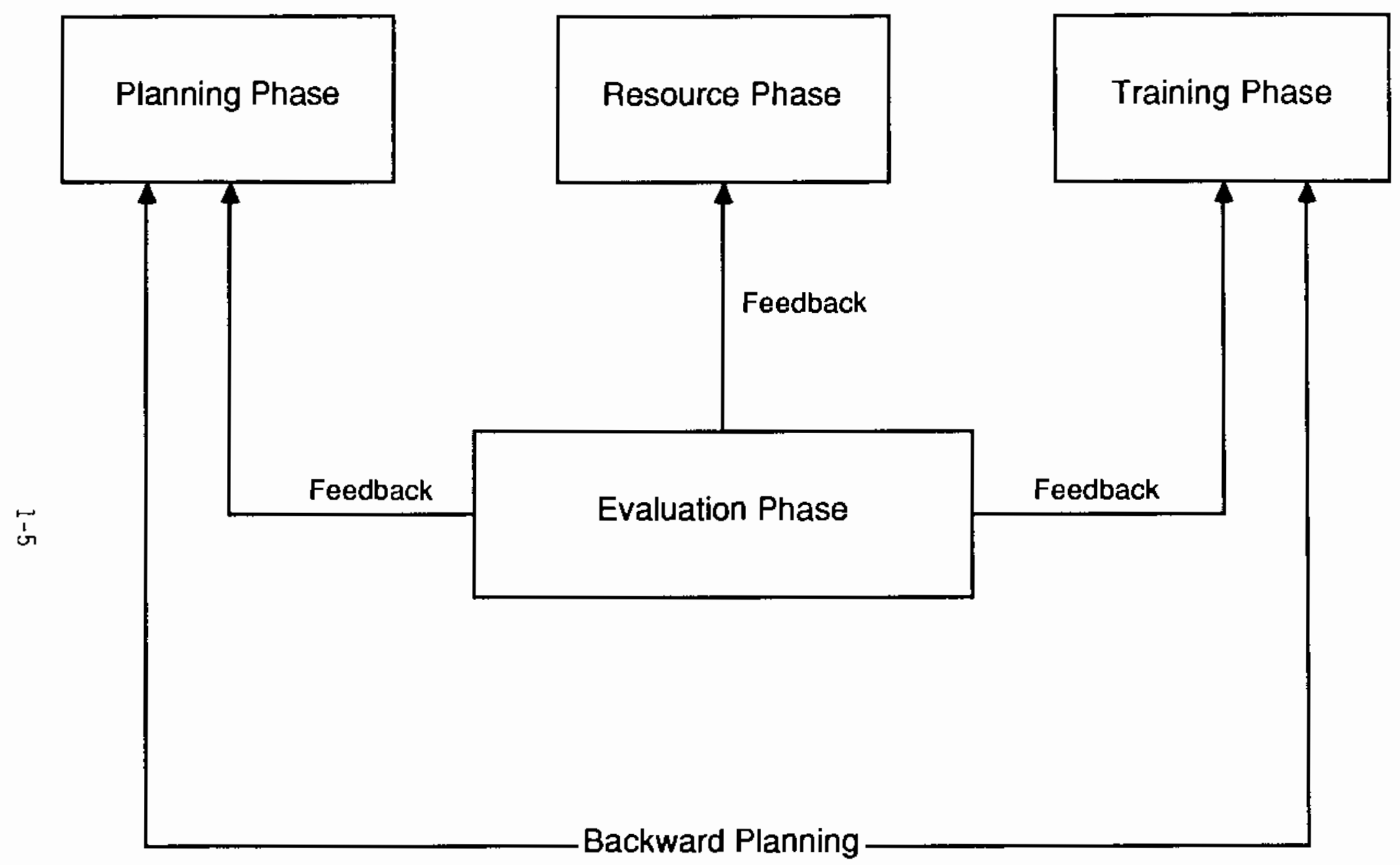

EIGURE 1.1. The Four Phases of Training Management 


\subsection{EVALUATING THE RELATIONSHIP OF TRAINING MANAGEMENT TO READINESS}

To determine whether automated TM enhances unit readiness, it is necessary to measure performance. Unit readiness can be considered to incluae the unit's capability to perform its various missions as defined by doctrine and higher echelon commands. Performance can be measured primarily through the ARTEP and AMTP or similar types of empirical comparisons of unit mission task performance with pre-established standards. Most ARTEP performance measures consist of a rating by experienced evaluators based on observations of team performance. The key to successful assessment of unit performance using this approach is the definition of objective standards against which unit performance can be compared. This definition process is difficult and the ARTEP has not been completely successful (word, 1987). AMTP development is intended to improve the definition of standards. As a consequence of these problems, use of ARTEP ratings to assess the effect of automated TM on unit readiness will yield ambiguous results.

Engagement simulation, as provided by the National Training Center (NTC), has introduced a higher-fidelity environment in which unit performance data can be collected. Large amounts of empirical data are collected (Fobes, 1984) and have the potential to support performance evaluation. Techniques for using these data, however, are not well-developed, although more attention is now being directed to this issue (Hiller, 1987; Battelle, 1987). Further, models are needed for aggregating specific mission or task performance into unit readiness measures. The current lack of such models to aggregate engagement simulation data and the highly subjective nature of ARTEP evaluation suggests that a direct assessment of the impact of automated TM on unit readiness will be difficult.

A more promising approach that is the basis for the work reported in this document focuses on the component activities of TM. Assuming that there are administrative and organizational inefficiencies that can be overcome via automation, it can be predicted that TM tasks will be performed more effectively. This should result in a measurable change in the missions and tasks that units are training for--presumably more closely related to their current training status and missions. It would be expected that 
training programs that are more commensurate with unit needs will result in a higher level of training readiness. 
.

ऽ. 


\subsection{DOCTRINAL STUDY OF ARMY TRAINING MANAGEMENT}

To provide a framework for the study of TM as currently practiced, and to help identify potential candidate tasks for automation. TM doctrine was modelled by means of structured analys is (Demarco, 1979). This form of analys is has been demonstrated to greatly facilitate the development of computer-based information management systems. The doctrinal baseline established by this analysis was compared with data concerning how TM is actualiy conducted by surveying a sample of units in the 9ID (MTZ) (Chapter 3).

\subsection{DOCUMENT REVIEW PROCESS}

The Army training management doctrinal review process began with a literature search of training management publications within ADEA and military libraries, and by visiting Army agencies and activities advocating various aspects of training management. Among the Training and Doctrine Command (TRADOC) and Army Materiel Command (AMC) agencies and activities visited were the Combined Arms Training Activity (CATA) at Fort Leavenworth, Kansas; Headquarters TRADOC at Fort Monroe, Virginia; and the Project Manager Army Communicative Services and Army Training Support Center (ATSC) at Fort Eustis, Virginia. Under the ITMS program, CATA represents the user as combat developer in formulating training management doctrine and concepts. Project Manager Army Communicative Services (PM ACS) represents the materiel developer responsible for producing an automated training management system to approved requirements.

General training-related references constituted the key source of background information about Army training management. Among the Army-level references were Unit Status Reporting (AR 220-1), and Training (AR 350-1). The principal TRADOC references were field manuals specifically addressing training: Iraining the Force (FM 25-100) (draft), Unit Training Management (FM 25-2), Training in Units (FM 25-3), and Training for Mobilization and War (FM 25-5). Other TRADOC publications researched included Iraining Ammunition (TC 25-3); How to Develoo Training Management Skills in the Unit (TC 25-7); and TRADOC regulations 11-7, 310-2, 350-4, 350-7, and 351-6. FORSCOM Pamphlet 350-31 provided background information on the Training 
Management Control System (TMACS) program. 9ID (MTZ) Training Program (Reg 350-1) provided specific division-level training guidance to the units in which the survey was conducted. Reports furnished by government contractors on the prototype Integrated Training Management System were also evaluated.

\subsection{DATA FLOW DIAGRAMS}

Data flow diagrams are structured analysis tools portraying the flow of information within complex systems. The partitioning of TM into subprocess levels allowed functional TM interfaces to be examined. Notational data flow diagram symbology used in the analysis process is as follows:

- A vector (called a data flow) portrays a data path. Each vector or arrow is labeled to show the type of data represented.

- A circle (called a process) portrays a transformation of data. Processes are numbered to indicate the level of data flow.

- A double straight line (open ended box) portrays a data set.

- A closed box portrays a data source. A data set is created as the result of a process, while a data source provides input to a process.

A minimum of three levels of data flow diagrams are commonly used to portray a system. The first, a context-level diagram, depicts the flow of data that is beyond the scope of analysis being conducted. The next, Level1 diagram, portrays the major processes within the system, with a limited presentation of data flow. The final, Level-2 set, specifies the flow of data between the discrete processes within the system.

\subsection{VERIFICATION PROCESS}

Data flow diagrams were developed as a means of describing the flow of training management information, as described in the doctrinal literature. They were reviewed with CATA on August 4, 1987, for concurrence with the modelling effort. The changes recommended were incorporated in a second draft which was then reviewed on August 10, 1987, by Headquarters TRADOC, Deputy Chief of Staff (DCS) Unit Training Oirectorate; ATSC Information Management Division; and PM ACS for additional validation. 


\subsection{DOCTRINAL DATA FLOW DIAGRAMS}

\subsubsection{Training Management Context}

Training management exists within the context of Army, major command (MACOM), and higher commander plans, goals, authorizations, guidance, and publications inputs. Figure 2.1 depicts the sources that provide input to the TM process as a whole. The Army (HQDA) and MACOMS (Training and Doctrine Command [TRADOC] and Forces Command [FORSCOM]) have assigned responsibilities within the training system. HQDA provides policy guidance on Army training in such areas as resourcing, evaluation, literature, and training aids. TRADOC publishes training support products implementing HQDA policies by describing what must be done in training. FORSCOM and subordinate headquarters are responsible for conducting training using TRADOC-furnished training support products. Training management leads to training plans and training events followed by an assessment of results. Training results are analyzed to assess unit mission readiness and to develop resource estimates such as budget information.

\subsubsection{Level 1 - Training Management Processes}

Army doctrine defines multiple TM processes operating concurrently across command echelons. Figure 2.2 depicts the major TM processes and elements of TM data. During Process 1 - Identify Unit Missions and Goals several sources, such as tables of organization and equipment (TOE) and operations plans (OPLANS), are reviewed by units, resulting in the development of a mission list and mission goals. At Process 2 - Conduct Mission Analysis, critical wartime tasks and mission training goals are analyzed using doctrinal literature such as How to Fight manuals and higher headquarters training guidance, resulting in the development of training objectives for each mission by task, condition, and standard.

Unit training objectives are subjected to a command and staff estimate during Process 3 - Conduct Training Estimate. Commanders and staff use several sources of training status in the estimate process, ranging from personal knowledge to lessons learned. This process results in a set of training requirements and a set of resource requirements that serve as input 


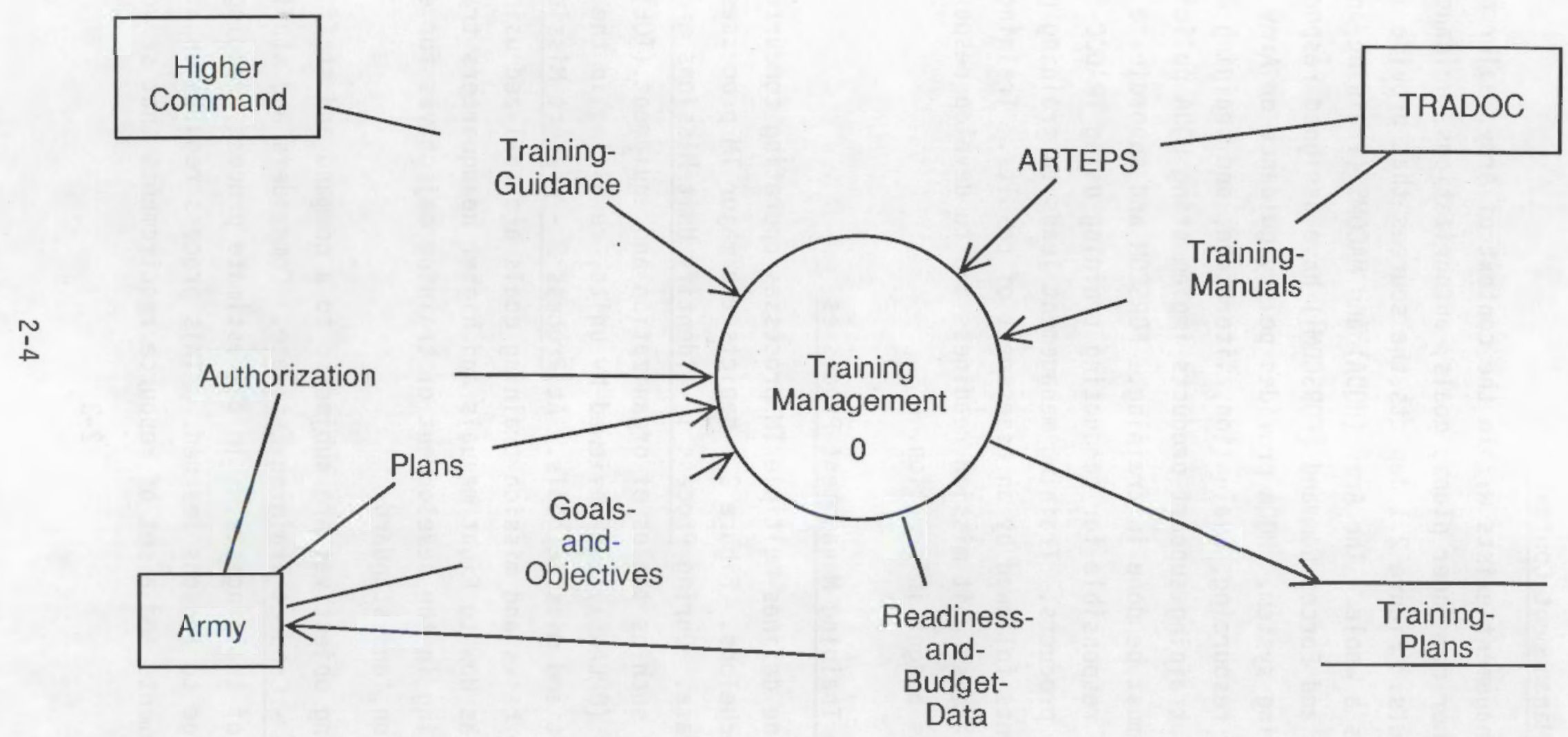

FIGURE 2.1. Training Management Context 


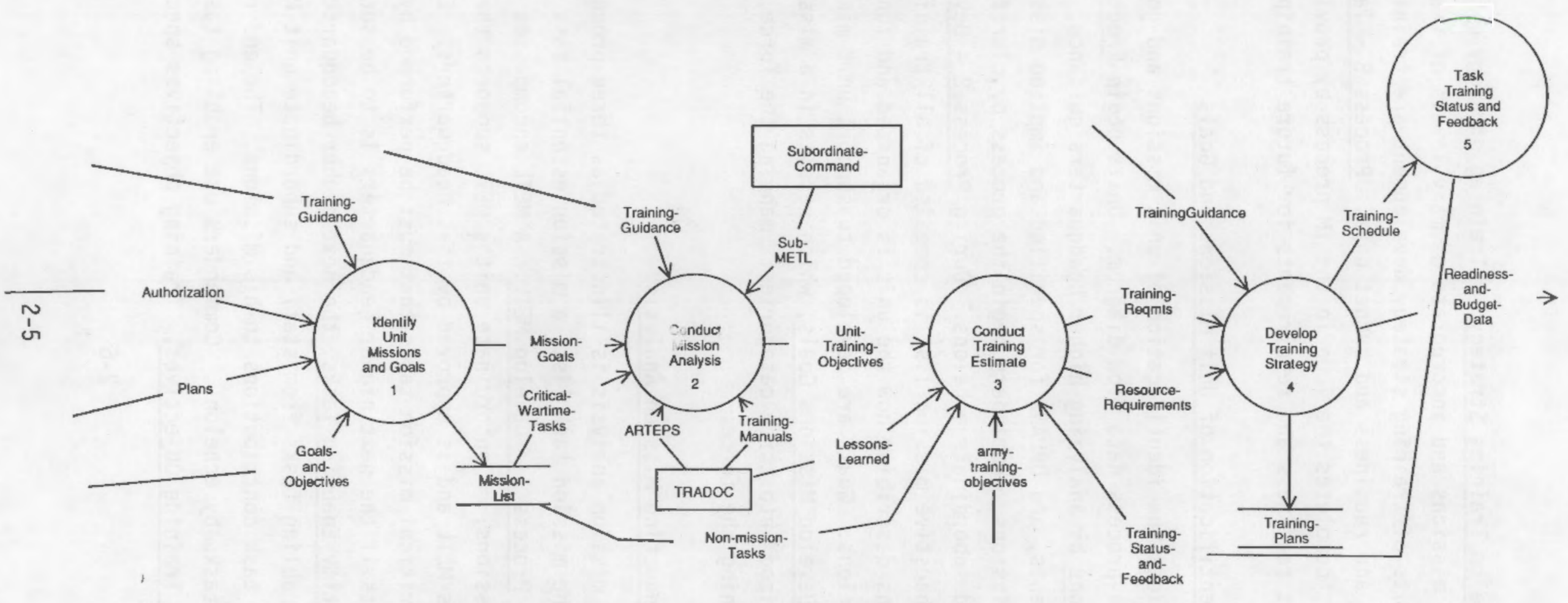

FIGURE 2.2. Level 1 - Training Management Processes 
to Process 4 - Develop Training Strategy. Training strategy must relate to a unit's wartime missions and incorporate as many levels of training as possible. The results of training strategy development are training plans, training schedules, and readiness and budget data. Process 5 - Task Training Status and Feedback, completes the loop in the TM process by providing data pertinent to current readiness and requirements for future training.

\subsubsection{Level 2 - Identification of Unit Missions and Goals}

Figure 2.3 depicts the identification of unit missions and goals in a more detailed, three-process data flow diagram. Units begin Process 1 Identify Unit Missions by analyzing higher headquarters guidance, goals, authorization documents, and OPLANS for specified and implied missions. In restating unit missions, commanders begin the process by clarifying their intent for staff and subordinate echelons. During Process 2 - Develop Mission List, an exhaustive mission list is compiled of all training and non-training missions describing how the unit is organized and functions under certain conditions. Goals are developed to support unit missions during Process 3 - Develop Missions Goals, which results in a mission goal list conmonly organized into three categories: manning the force, equipping the force, and training the force.

\subsubsection{Level 2 - Conducting Mission Analysis}

The conduct of mission analysis is illustrated as three processes in Figure 2.4. From the mission task list, a mission essential task list (METL) is developed during Process 1 - Develop METL. A METL encompasses all critical wartime missions. A subordinate unit's METL supports the next higher headquarter's METL and is approved by that headquarters. Enabling tasks are wartime critical mission tasks that must be performed by staff and subordinate units if the next higher headquarters is to be successful. In Process 2 - Identify Enabling Tasks, the next higher headquarters commander selects enabling tasks from staff and subordinate unit METLs that best describe their task contributions to his missions. The end result is a list of enabling tasks by echelon. Commanders use enabling tasks in Process 3 - Develop Training Objectives. Training objectives specify task, 


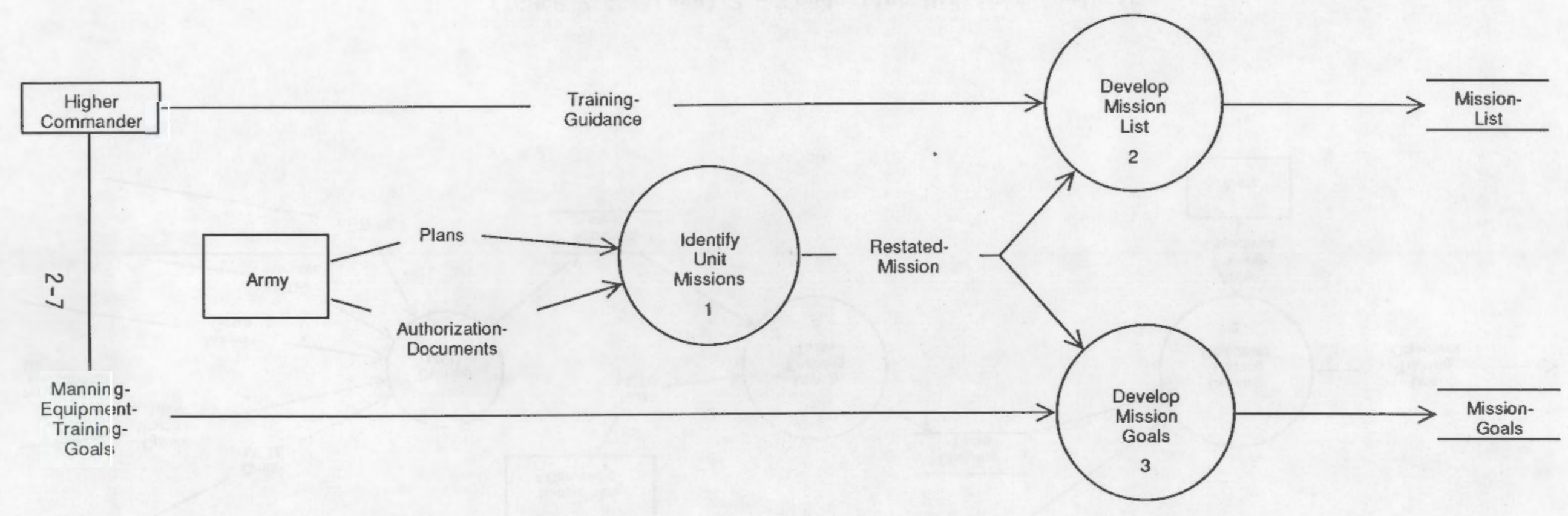

FIGURE 2.3. Level 2 - Identification of Unit Missions and Goals 


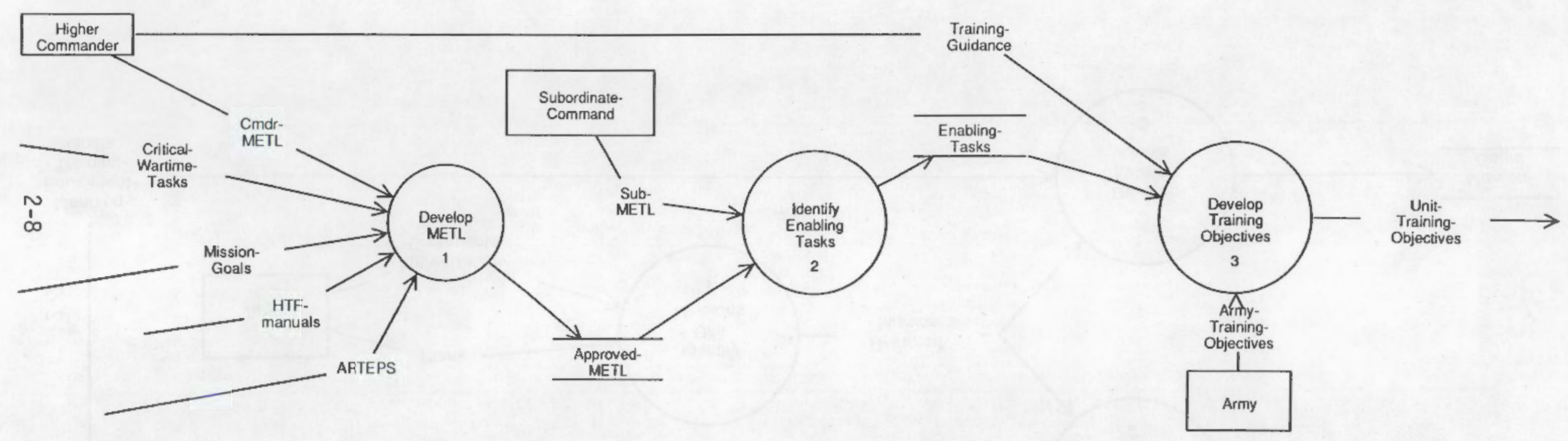

FIGURE 2.4. Level 2 - Conducting Missions Analysis 
condition, and standards for particular training outcomes derived from training guidance sources, including Army Training and Evaluation Program (ARTEP) documents, Army policies and procedures, Standards in Training Commission (STRAC) tables, Common Military Training References (CMTR) and plans.

\subsubsection{Level 2 - Conduct Training Estimate}

Figure 2.5 depicts the three processes and corresponding data flows that comprise the conduct of a training estimate. Linking training objectives to unit training programs is the training estimate, Process 1 - Identify Tasks for Training, and resource identification, Process 2 - Develop Training Requirements. In identifying tasks for training, units assess their current mission task status in light of previous lessons learned. Differences between training objectives and mission task status constitute potential training requirements. In addition to METL (enabling tasks) training requirements, directed training requirements, from equipping the force and manning the force missions, are incorporated. During Process 3 - Determine Resource Requirements, units begin looking at their programmed resources for facilities, ranges, ammunition, funds, etc.

\subsubsection{Level 2 - Developing Training Strategy}

Figure 2.6 illustrates the four processes that comprise the development of a training strategy. Commanders adopt training strategies for training their units at the most appropriate time. Training strategies incorporate higher headquarters training guidance, resource requirements and availability, mission task status, and training plans. Many of the documents used in conducting mission analysis, such as ARTEPs and STRAC tables, contain the means for identifying resources. Planning strategies are developed for various time periods; these are Process 1 - Issue Long-Range Planning (6-24 months), Process 2 - Issue Short-Range Planning (3-6 months), and Process 3 - Issue Near-Term Planning (3-12 weeks). Long-range planning sets a general direction for a training program. Normally, annual master planning calendars and long-range focus guidance are published. Resources are programmed in long-range planning. Short-range planning converts long-range planning 


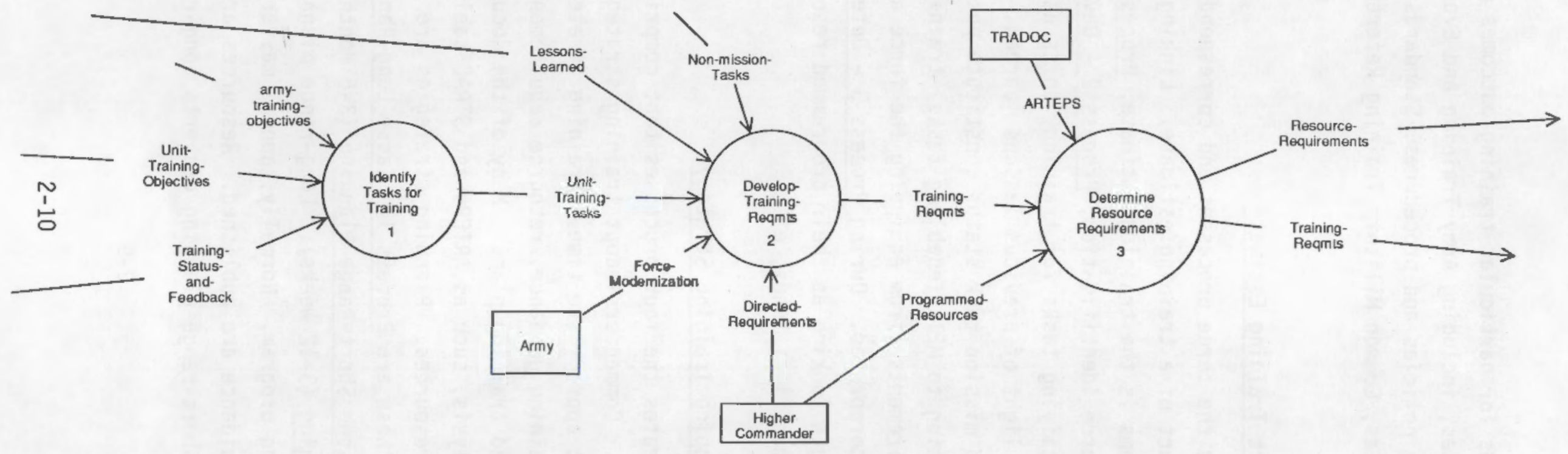

FIGURE 2.5. Level 2 - Conducting Training Estimates 


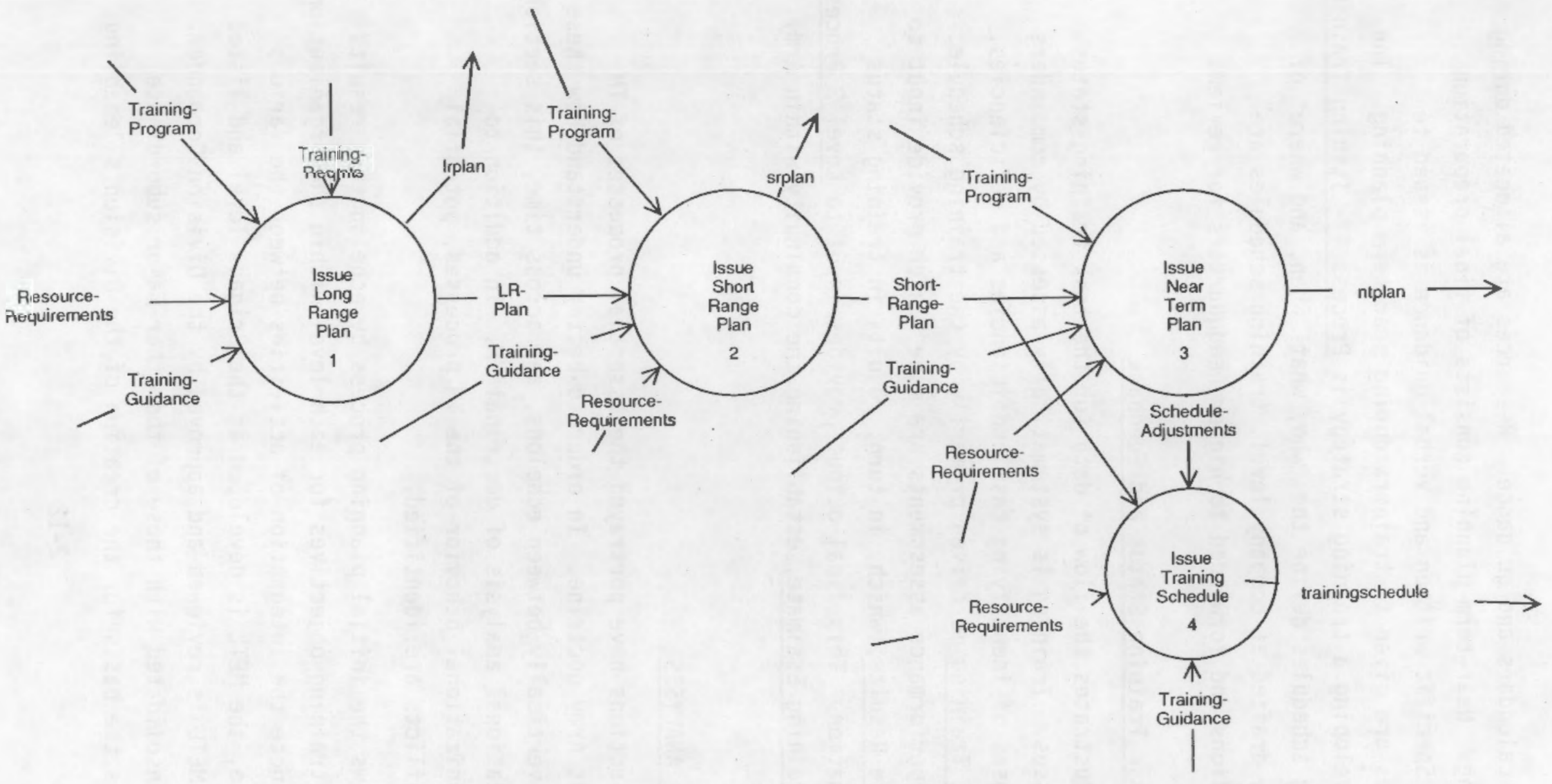

FIGURE 2.6. Level 2 - Developing Training Strategy 
into more detailed calendars and guidance. Resources are allocated during short-range planning. Near-term planning consists of final preparation before execution. Specific written and verbal guidance is issued to trainers. Resources are given to trainers during near-term planning. The last process in developing a training strategy is Process 4 - Issuing Training Schedule. Training schedules define the "who, what, when, and where" of training. Normally drafted at company level, training schedules are published by battalions and forwarded to higher headquarters for review.

\subsubsection{Level 2 - Task Training Status and Feedback}

Figure 2.7 illustrates the flow of data for the task training status and feedback processes. Training is systematically assessed by commanders and staff for purposes of identifying task proficiencies and deficiencies. Process 1 - Conduct Training is driven primarily by the training schedule. Formal or informal performance assessments are made, which provide input to Process 2 - Evaluate Results; which, in turn, results in training status and feedback information. This final output provides input to Level 2 Process - Conducting the Training Estimate, establishing the continuity within Army TM.

\subsection{ORGANIZATIONAL ANALYSIS}

The previous sections have portrayed the essential processes of TM according to current Army doctrine. In order to better understand how these processes interact vertically between echelons, and across time, this section presents an organizational analysis of doctrinal TM. In addition to portraying the organizational behavior of the TM processes, potential bottlenecks and conflicts are identified.

Figure 2.8 shows the initial planning process by echelon that results in the creation of training objectives for each level within the organization. It is important to note the integration of activities between the various levels. For example, the METL is developed at the Brigade level and listed in priority. This METL is reviewed and approved by the Division Commander. The METL is then consolidated with those of the other major subordinate commands and becomes the basis for the creation of the Division's "enabling 


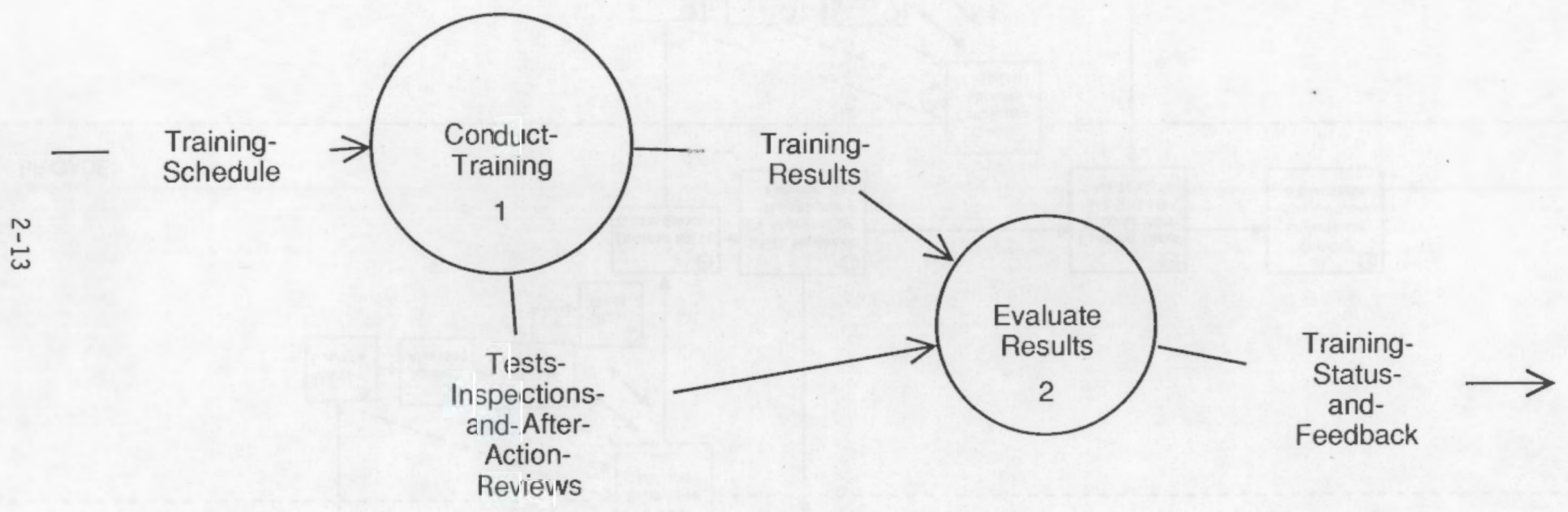

FIGURE 2.7. Level 2 - Task Training and Feedback 


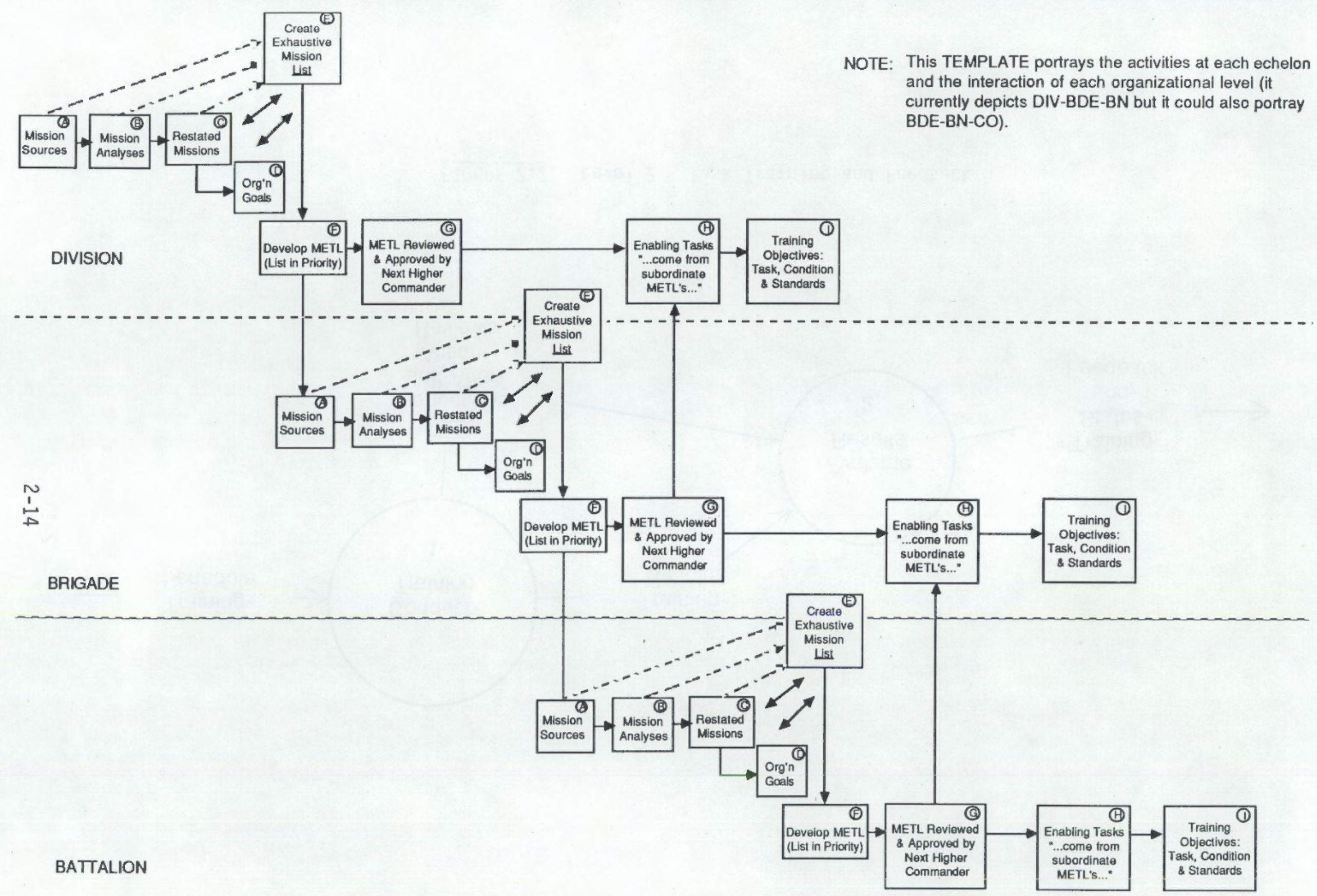


tasks." This sequence portrays one aspect of the vertical integration necessary for effective training management. The higher headquarters (in this case, the division) sends its METL to the Brigade, where it is included as one of the Brigade's mission sources. Following the mission analyses, the Brigade METL is created and subsequently sent back up to Division where it becomes an essential element of the Division's enabling tasks. A second planning sequence occurs as the Brigade METL is sent to the subordinate battalions for inclusion in their mission sources. Similarly, the Battalion METL is developed and subsequently approved and included as part of the Brigade's enabling tasks.

For a training management system to be adequately integrated, the system must take into account the significant relationships that exist among the various organizational levels. Although there is a degree of integration under the Army's current, non-automated system, the integration appears to consist primarily of training directives issued from higher headquarters (e.g., 350-1 series regulations) rather than the interactive process described in doctrine. TM must be interactive between echelons if it is to be effective; TM must facilitate the planning process by illuminating critical elements, articulating specific goals and objectives, and integrating the input from a variety of organizational sources.

Figure 2.9 portrays the TM functions of planning, and execution by echelon from division to battalion. The interaction of each echelon is depicted over time, with planning functions distinct from the actual conduct of training. The doctrine shows that guidance is generally issued in sufficient time for subordinate units to prepare their own training programs. However, this may not be the case when units are required to develop specific forecasts early in the fiscal year, or in training cycles that require long range projections (e.g., ammunition) or coordination with other organizations (e.g., off-post exercises).

Figure 2.10 portrays the sequence of activities for a typical companysize unit and illustrates a potential problem with respect to planning and coordination. According to doctrine, planning for training at the echelons above the company level occurs in a "leap-frog" manner where the Division, Brigade, and Battalion headquarters develop and issue training guidance and 


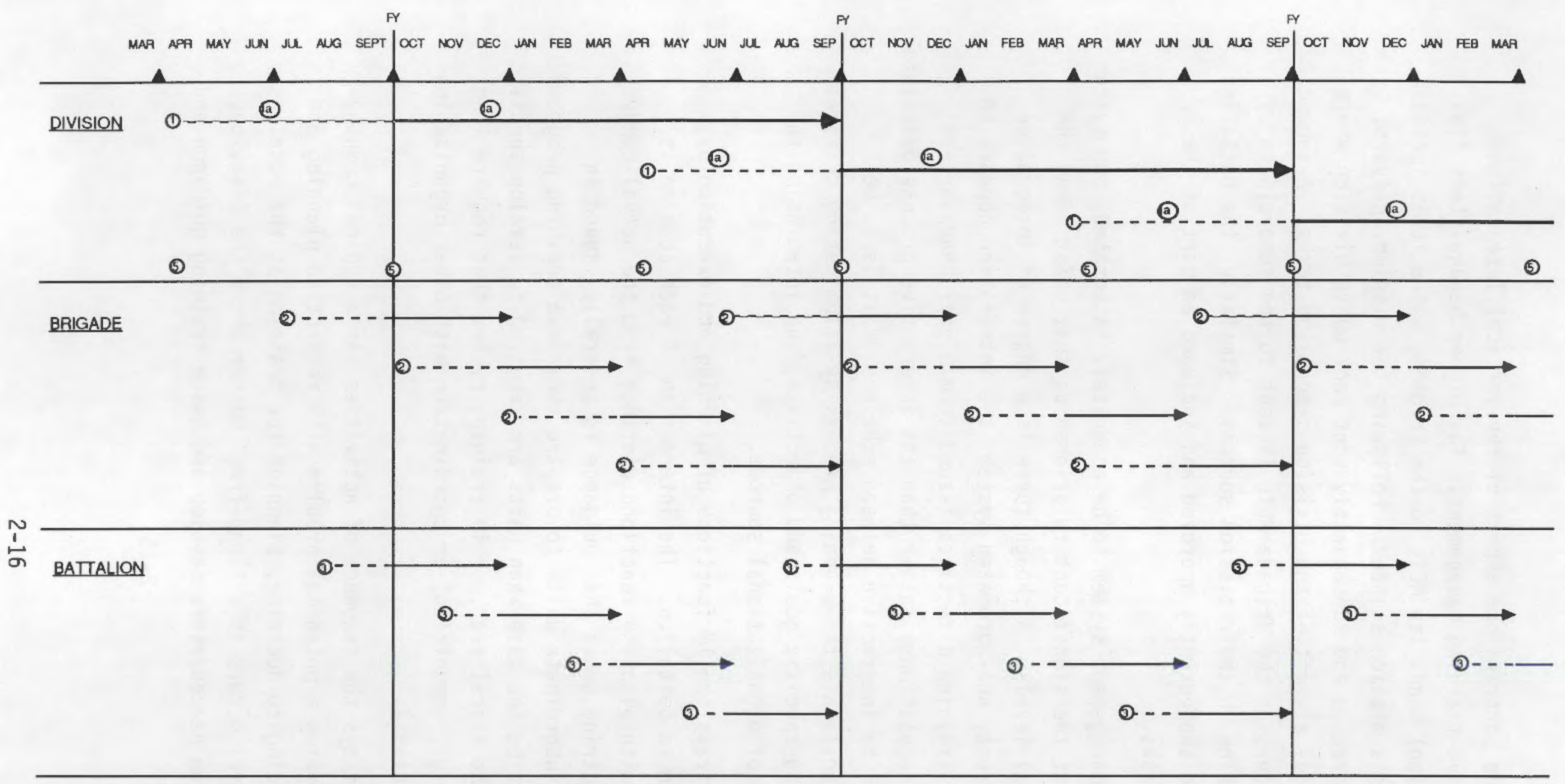

(1) Publication of division command training guidance for next fiscal year ( 180 days prior to $\mathrm{FY}$ )

(3) Review semiannually (100 days out)

(2) BDE publish quarterly training guidance (70 days prior to quarter)

(3) BN publish quarterly training guidance (30 days prior to quarter)

\begin{tabular}{c} 
LEGEND \\
-- Plan/Guidance Issued \\
\hline Execute
\end{tabular}

(4) CO drat training schedule (28 days prior to week of training); final training schedule (21 days prior to week of training)

(2) Brief CG (semiannually)--update if necessary 


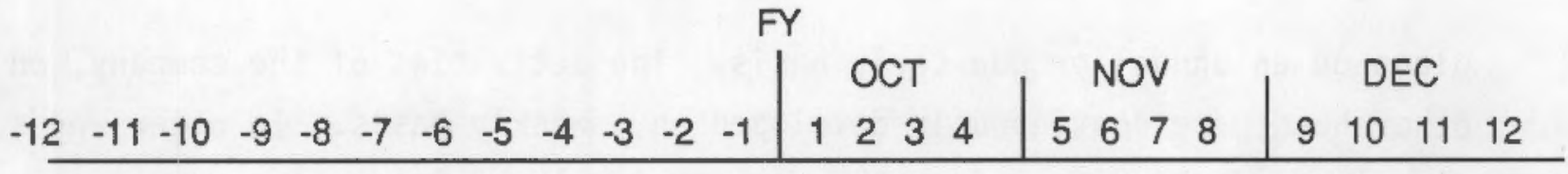

BDE

(a)

(a)

$\mathrm{BN}$

(b)

(b)

$\mathrm{CO}$

(C) (a) (d)
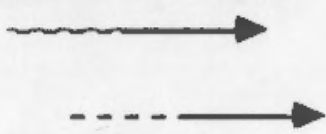

a. Brigade training guidance published.

b. Battalion training guidance published.

c. Ammunition forecast submitted.

d. Range usage should be forecast.

e. Training should be resourced.

f. Support requests (CS/CSS/AVN) submitted.

g. Company submit draft training schedule.

h. Company finalize training schedule.

i. Publish company training schedule.

j. "Lock-in" training.

FIGURE 2.10. Company Level Training Management 
plans on an annual or quarterly basis. The activities of the company, on the other hand, are continuously developed on a weekly basis. In other words, planning and coordination at the company level continues to move at a relatively rapid, yet stable, rate while the activities at the higher echelons occur in specific "spurts."

As a result of this problem, planning and coordination of training that is to be conducted by a company in the early weeks of a fiscal year (or quarter) must be done prior to the receipt of guidance from brigade and battalion. This usually occurs because of the relatively long lead times required for coordinating such activities as ammunition forecasting (120 days prior), Joint Air Attack Team (JAAT) training (90 days prior), and off-post training (received at division headquarters 90 days prior). In accordance with 9ID (MTZ) Reg 350-1, brigade training guidance is issued 70 days prior to the beginning of the quarter and battalion training guidance is issued 30 days prior. These lead times are inadequate to fulfill many of the forecasting and coordination activities necessary for a company involved in training management. Although this problem appears to exist in local regulations, training managers at the battalion and company levels seem to overcome it by developing continuous training guidance, which is processed and implemented through the weekly training meetings.

\section{$2.6 \underline{\text { SYNOPSIS }}$}

The foregoing structural analysis shows that there are distinct TM processes, sources of data, and outputs. They are connected in a logical manner that is designed to yield optimally trained units. The input from DA and MACOMS reflects policy-level guidance in response to national security considerations. Activities at the company level reflect more immediate training status and battalion objectives. The policy-level guidance affects lower echelons through an iterative, cascading process. In this manner, theoretically, company level training is directly influenced by high-level strategic guidance.

In order to determine the extent to which the interactive processes described above are put into practice, it is necessary to study how TM is actually conducted. The following chapter presents results from a survey 
of units of the 9ID (MTZ) that examines the procedures used to conduct TM in division through company levels. 


\subsection{SURVEY AND JOB ANALYSIS OF CURRENT \\ TRAINING MANAGEMENT PRACTICES}

\subsection{INTRODUCTION}

The basis for designing any automated system, particularly for the management of information, should derive in part from a quantitative study of the current system that is to be replaced. A quantitative needs assessment can be used to establish criteria for automating tasks, and can provide information concerning the current types and organizational distribution of work which may benefit from automation (Czaja, 1987). Additionally, data concerning the proportion of work that falls into various categories (e.g.. computing or retrieving information) can be of value when allocating function between human and machine (Kantowitz and Sorkin, 1987).

This chapter describes the methods and results of a job analytic survey made of selected units of the 9ID (MTZ). The purpose of the survey was to establish a design-oriented data base, as described above, and to provide empirical data for automation cost effectiveness calculations. Further, the job and task analytic information obtained will help to define scenarios for field testing in the independent evaluation effort.

The job analysis structured interview was administered to 70 members of selected units of the 910 (MTZ). The primary measures obtained include staffing for each echelon, percent time on various TM tasks, type of work performed, use of documents, and ratings of information accuracy and timeliness. Additionally, open-ended questions were posed to obtain information concerning perceived problems in TM and potential solutions. The subject population, data collection instruments and procedures, and the results are described below.

\subsection{JOB ANALYSIS INSTRUMENT DESCRIPTION}

There were two broad objectives in conducting the job analysis. The first objective was to provide estimates of the time currently spent by 9ID (MTZ) personnel on TM that would support the subsequent cost effectiveness analysis of TM automation. The second objective was to provide descriptive and quantitative data characterizing current TM duties and procedures within 
the 9ID (MTZ) that would support the development of an independent evaluatior plan (IEP), as well as the identification of current TM procedures that are candidates for automation.

Due to the global nature of our job study objectives, a structured interview format for conducting the job analysis was adopted, rather than a self-administered job survey questionnaire format. Structured interview formats allow for more thorough explanation of questions and issues to respondents than self-administered surveys. In addition, an interview format allows an in-depth discussion of specific areas of concern that arise during the course of discussion. Structured interviews can be contrasted with open-ended interviews, where a list of general issues are raised and interviewees are free to determine the format of their responses. In a structured interview, both the interviewer's questions and interviewee's format of responses are defined by interview protocols and response forms, allowing the systematic coverage of issues, as well as a standardized interpretation of responses obtained from interviewees.

Three separate sets of materials were prepared for conducting the structured interviews: interviewer scripts, data sheets completed by the interviewer and respondent, and a set of answer keys that could be used by respondents in answering the more highly structured questions. All interview materials are reproduced in Appendix $A$.

TM staffing questions were organized around eight tasks that were based on the doctrinal study presented in Chapter 2. The eight TM task titles, which are defined in the survey materials, are listed in Table 3.1. The set of eight tasks provided the basic framework for obtaining estimates from respondents on the amount of time spent on TM. At separate points during the interview procedure, respondents were asked to (1) estimate the percent of their duty time, excluding time in the field, they spent on TM; (2) indicate which of the eight TM tasks they worked on as part of their job; (3) estimate the percent of their TM time spent on each of the eight tasks; and (4) estimate the percent of time spent on each TM task that was spent on each of seven types of work. The seven types of work defined in Table 3.2 are similar to taxonomies used in previous studies of office automation 
IABLE 3.1. Training Management Tasks Used in Job Study Survey

Task

Number

Task Title

1 Identify unit missions, mission goals, METL, and enabling (battle) tasks

2 Identify training objectives, tasks for training, and training program

3 Forecast, process, and monitor resource requirements and prepare budget information

4 Process long-range (6-24 month) training guidance

5 Process short-range (3-6 month) training guidance

6 Process near-term (3-12 week) training guidance

7 Process training schedule

8 Process information on task training status and report training readiness

(Czaja, 1987) and represent general areas where humans and computers have inherently different capabilities (Fitts, 1951).

Figure 3.1 presents a data sheet completed by one respondent in providing the set of work time estimates referred to above. For those tasks performed, the respondent was asked to write-in estimates of percentages of the time spent on the seven types of work.

Descriptive data on TM procedures were also obtained at several points during the interview. These data included responses to questions asking for the names of documents, forms, and other sources of information used in carrying out each task, as well as the names and destination of products generated in carrying out each task. After providing document names, respondents were asked to rate (1) the accuracy of information received and (2) whether this information was received in time to be of use. These ratings were made by reference to two 9-point, Likert-type response scales (see Appendix A). Subjects also rated each of their task products using two g-point response scales for (1) the accuracy of information produced 
4.3 DATA SHEET - TYPE OF WOHK

INI EAVIEWEA NUMBER: 212

TYPES OF WOAK

\begin{tabular}{|c|c|c|c|c|c|c|c|c|c|c|}
\hline $\begin{array}{l}\text { CIRECKIF } \\
\text { DCME }\end{array}$ & TASK & $\begin{array}{c}\text { Orxeussion } \\
\text { Ftanning }\end{array}$ & $\begin{array}{l}\text { Gelting } \\
\text { Dencuments } \\
\text { a Inta }\end{array}$ & $\begin{array}{c}\text { Copying } \\
\& \\
\text { Complingy }\end{array}$ & Analyzing & & $\begin{array}{l}\text { Compoting } \\
\text { Numiters }\end{array}$ & & $\begin{array}{l}\text { Prispaingy } \\
\text { Docournents }\end{array}$ & $\begin{array}{l}\text { Supranising } \\
\text { Oliacting. } \\
\text { Loading }\end{array}$ \\
\hline$\triangle 1$ & $\begin{array}{l}\text { 1. IDENIIFY UTM HISSIONS, GOALS } \\
\text { METL ND EMUBLWG INSKS }\end{array}$ & 20 & $+\ln$ & $+1 n$ & $+\mp \varnothing$ & + & 10 & + & 19 & $+\quad 2 \alpha$ \\
\hline & & & & .100 & ol oime on last & & & & & \\
\hline & IRANING PSTOGNWA, & 30 & $10 x$ & 10 & 10 & & $\not 2$ & & 30 & 105 \\
\hline 勾 & 3. FORECAST REOUNREREATS & $\cos x$ & 10 & $\ldots$ & $2 x$ & & $\varnothing$ & & $\varnothing$ & 165 \\
\hline & 4. LONG TUNGE GUIDNCE & 40 & 20 & $-\infty$ & $2 D$ & & $\varnothing$ & & 20 & 10 \\
\hline 5 & 5. SIDTT RWGE GLIONCE & 10 & $1 x$ & 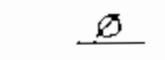 & $\underline{2 \not 2}$ & & 3 & & 10 & $2 x$ \\
\hline ] 6 . & 6. NEAP. TEFUA GUMONXE & $\leq \theta$ & 10 & $\not$ & 10 & & -2 & & $1.0 \alpha$ & $3 x$ \\
\hline 3 & 3. ISSUE IANNIIXS SCLEEOUE & ws & $\underline{Q S}$ & 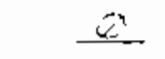 & 35 & & $a$ & & $\Omega$ & 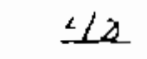 \\
\hline - & - OETERMINE TRUIPANG STATLS & \lrcorner$\propto$ & 20 & -469 & 10 & & $2 \theta$ & & 20 & 10 \\
\hline & A. &  & — & $\underline{.}$ & $\ldots$ & & — & & 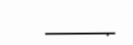 & 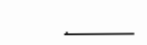 \\
\hline & 8 . & - & $\longrightarrow$ & - & $\ldots$ & & $\longrightarrow$ & & $\longrightarrow$ & $\longrightarrow$ \\
\hline c. & c. & & & & & & & & - & \\
\hline
\end{tabular}

FIGURE 3.1. Data Sheet Completed by One Respondent 
TABLE 3.2. Types of Work Categories Used in Job Study Survey

Work Type Category

1. Discussing and Planning

2. Obtaining Information

3. Compile Information

4. Analyze Information

5. Computing Numbers

6. Preparing Documents

7. Supervising 0thers
Definition

Discussing and planning ways to obtain, process, and document training management information

obtaining documents and information

Copying and compiling information from available source documents

Analyzing and interpreting documents and information

Computing numerical data

Preparing task documents, including document revisions

Supervising, directing, and leading others in carrying out a task.

and (2) the time available to meet the task production schedule in a timely manner.

Data directed at the identification of TM problems and candidates for automation were obtained during the interview by asking (1) for statements of the three biggest problems personally faced in TM work, (2) for any suggestions for improving TM, (3) for any specific problems in the performance of each task, (4) for suggestions for improving TM through automation, and (5) for a report on current uses of automation by the respondent. In addition, respondents were asked to estimate the degree of discrepancy between scheduled training and training conducted.

\subsection{JOB ANALYSIS SURVEY RESULTS}

The major results of the job ar.alysis survey are presented in this section. The topics covered are the study sample; patterns of respondents' job performance; scheduled training accomplished by units; and respondents' 
identification of TM problems, TM solutions, and suggested features of an automated TM system.

\subsubsection{Study Sample}

Seventy structured job interviews were conducted during a five-week period between September 14 and October 16, 1987. The time required to conduct an interview varied from a minimum of 30 minutes to a maximum of four hours. Table 3.3 provides a summary of personnel interviewed. A complete listing of personnel interviewed during the conduct of structured job analysis interviews is provided in Appendix B.

TABLE 3.3. Summary of Job Analys is Survey Respondents

\begin{tabular}{|c|c|c|c|}
\hline Echelon & Unit & Officers & Enlisted \\
\hline Installation & Range Control Office & $(1)^{\star}$ & 1 \\
\hline Division & 9ID G-3 Training Office & 3 & 6 \\
\hline Brigade & 3rd Brigade G-3 office & 6 & 4 \\
\hline Battalion & $2 / 60 \mathrm{CAB}(\mathrm{H})$ & 2 & 1 \\
\hline & $3 / 11 \mathrm{FA}$ & 3 & 3 \\
\hline & $3 / 47$ CAB (L) & 2 & 3 \\
\hline & 99 SB & 2 & 4 \\
\hline Company & $2 / 60 \mathrm{CAB}(\mathrm{H}) \mathrm{COs}$ & 3 & 3 \\
\hline & 3/11 FA BTs & 5 & 5 \\
\hline & $3 / 47 \mathrm{CAB}$ (L) $\mathrm{COS}$ & 4 & 4 \\
\hline & $99 \mathrm{SB}$ COS & 2 & 2 \\
\hline & 3rd BDE HHC & $3 \frac{1}{4}$ & $3 \frac{0}{6}$ \\
\hline
\end{tabular}

*GS-11 Civilian

The job study survey respondents had an extensive and varied background in TM. Table 3.4 provides summary data pertinent to respondents' TM experience, divided by echelon and officer versus enlisted personnel. Examination of this table reveals that the average years in the Army for the separate groupings ranged from 6.6 years for battalion officers to 15.5 years for battalion enlisted personnel. The mean number of TM-related jobs held by respondents varied from 1.1 for company enlisted respondents to 4.7 TM-related jobs for division officers. The average number of years respondents had held TM-related jobs ranged from 4.0 years for battalion officers to 8.8 years for battalion enlisted personnel. Comparison of the 
respondent groups in this sample reveals that battalion enlisted respondents have a relatively long tenure in the Army (an average of 15.5 years) and have held a relatively large number of TM-related Army jobs. The reader should note that this finding may be isolated to the present sample, rather than representative of a trend within the Army.

TABLE 3.4. Summary of Survey Respondents' Training Management Experience

\begin{tabular}{|c|c|c|c|c|c|c|}
\hline \multicolumn{2}{|c|}{ ECHELON } & \multirow{2}{*}{$\begin{array}{l}N \\
3 \\
6 * \star\end{array}$} & \multirow{2}{*}{$\begin{array}{c}\text { Mean Yrs. } \\
\text { In Army } \\
\\
10.0 \\
9.7\end{array}$} & \multirow{2}{*}{$\begin{array}{c}\text { Mean No. } \\
\text { TM Jobs } \\
4.7 \\
1.7\end{array}$} & \multirow{2}{*}{$\begin{array}{c}\text { Mean Yrs. } \\
\text { TM Jobs } \\
\\
8.3 \\
3.7\end{array}$} & \multirow{2}{*}{$\begin{array}{c}\text { Years On } \\
\text { Present Job } \\
0.4 \\
1.2\end{array}$} \\
\hline Division* & $\begin{array}{l}\text { Officer } \\
\text { Enlisted }\end{array}$ & & & & & \\
\hline Brigade & $\begin{array}{l}\text { Officer } \\
\text { Enlisted }\end{array}$ & $\begin{array}{l}6 \\
4\end{array}$ & $\begin{array}{l}6.8 \\
9.8\end{array}$ & $\begin{array}{l}2.5 \\
1.3\end{array}$ & $\begin{array}{l}3.8 \\
2.8\end{array}$ & $\begin{array}{l}0.5 \\
0.7\end{array}$ \\
\hline Battalion & $\begin{array}{l}\text { Officer } \\
\text { Enlisted }\end{array}$ & $\begin{array}{r}9 \\
11\end{array}$ & $\begin{array}{r}6.6 \\
15.5\end{array}$ & $\begin{array}{l}2.2 \\
2.3\end{array}$ & $\begin{array}{l}4 \\
8.8\end{array}$ & $\begin{array}{l}0.6 \\
1.2\end{array}$ \\
\hline Company & $\begin{array}{l}\text { Officer } \\
\text { Entisted }\end{array}$ & $\begin{array}{l}15 \\
14\end{array}$ & $\begin{array}{l}6.8 \\
8.0\end{array}$ & $\begin{array}{l}2.5 \\
1.1\end{array}$ & $\begin{array}{l}5.5 \\
4.7\end{array}$ & $\begin{array}{l}0.7 \\
0.8\end{array}$ \\
\hline
\end{tabular}

\subsubsection{Job Performance}

\subsubsection{TM Task Performance}

Table 3.5 presents the proportion of officer and enlisted respondents from each echelon who perform each of the eight TM tasks. Review of this table suggests specialization at higher echelons, as indicated by the performance of five of the eight tasks by division-level enlisted respondents and the performance of four of eight tasks by brigade-leve 1 enlisted respondents. With the exception of these two cases and the lack of performance of Task 7 by division-level officers, all other tasks are performed by some portion of the respondents interviewed.

The basic trends of task performance depicted in Table 3.5 involve the emphasis and distribution of TM work at division/brigade and battalion/company 
levels. At the division/brigade level, management and oversight are the primary TM functions. Here, officers are involved in all phases of training management, whereas enlisted involvement is limited to particular TM tasks. In contrast, operational-level activities predominate $T M$ functions at the battalion/company level. Here, there are more comparable distributions of tasks performed by enlisted and officer personnel, suggesting more substantial delegation of TM duties.

TABLE 3.5. Proportion of Respondents Performing Each Training Management Task

Task Number

$\begin{array}{lccccccccc}\text { Echelon* } & N & 1 & 2 & 3 & 4 & 5 & 6 & 7 & 8 \\ \begin{array}{c}\text { Oivision } \\ \text { Officers }\end{array} & 3 & 0.67 & 0.33 & 1.00 & 0.67 & 0.67 & 0.33 & 0.00 & 0.33 \\ \text { Enlisted } & 8 & 0.00 & 0.00 & 0.63 & 0.25 & 0.00 & 0.25 & 0.25 & 0.17 \\ \begin{array}{c}\text { Brigade } \\ \text { Officers } \\ \text { Enlisted }\end{array} & 6 & 0.83 & 0.50 & 1.00 & 0.83 & 0.67 & 0.33 & 0.17 & 0.33 \\ \text { Battalion } & 4 & 0.00 & 0.25 & 1.00 & 0.00 & 0.00 & 0.00 & 0.25 & 0.50 \\ \text { Officers } & 9 & 0.67 & 0.78 & 0.89 & 0.89 & 0.89 & 0.89 & 0.67 & 0.89 \\ \text { Enlisted } & 11 & 0.27 & 0.36 & 0.64 & 0.27 & 0.27 & 0.27 & 0.27 & 0.55 \\ \text { Company } & & & & & & & & & \\ \text { Officers } & 15 & 0.80 & 0.87 & 0.67 & 0.40 & 0.93 & 1.00 & 0.93 & 0.87 \\ \text { Enlisted } & 14 & 0.14 & 0.43 & 0.57 & 0.14 & 0.43 & 0.64 & 0.93 & 0.64\end{array}$

*Includes two Personnel from Range Control office.

The mean proportion of duty time spent performing each TM task is presented for each of the echelons in Table 3.6. Throughout this section, mean estimates of duty time are provided. The reader should note that for later purposes of system evaluation, estimate variability, as well as central tendency, must be considered. However, for the purposes of estimating the parameter of TM duty time, mean estimates are most appropriate. Inspection of this table reveals several patterns of results. Review of the means for separate echelons and tasks indicates that values range from a low of .008 


\section{TABLE 3.6. Mean Proportion of Duty Time Performing Each Training Management Task}

Task Number

$\begin{array}{lccccccccc}\text { Echelon } & \mathrm{N} & 1 & 2 & 3 & 4 & 5 & 6 & 7 & 8 \\ \text { Division* } & 11 & .008 & .026 & .361 & .052 & .034 & .035 & .070 & .013 \\ \text { Brigade } & 10 & .058 & .029 & .296 & .039 & .049 & .055 & .038 & .032 \\ \text { Battalion } & 20 & .030 & .046 & .109 & .028 & .051 & .078 & .058 & .049 \\ \text { Company } & 29 & .010 & .041 & .051 & .009 & .039 & .079 & .086 & .076 \\ \text { Mean } & 70 & .022 & .038 & .152 & .025 & .043 & .068 & .067 & .052\end{array}$

*Includes two personnel from Range Control office.

for divisional-level personnel performing Task 1 (Identify unit missions, mission goals, METL, and enabling tasks) to a high of .361 for divisionlevel personnel performing Task 3 (Forecast, process, and monitor resource requirements and prepare budget information).

The bottom row of Table 3.6 presents the mean proportion of duty time spent by respondents on each of the eight TM tasks. These values are also depicted graphically in Figure 3.2. Review of Figure 3.2 reveals that respondents spend relatively minor portions of their duty time on Task 1 , Task 2 (Identify training objectives, tasks for training, and training program), Task 4 (Process long-range training guidance), and Task 5 (Process short-range training guidance). Relatively moderate portions of respondents' duty time are spent on Task 6 (Process near-term training guidance), Task 7 (Process training schedule), and Task 8 (Process information on task training status and report training readiness). Finally, it is apparent that a relatively large portion of respondents' duty time, 15.2 percent on the average, is spent on Task 3 (Forecast, process, and monitor resource requirements and prepare budget information). However, reference back to Table 3.6 reveals that this is due, in large part, to the major role of Task 3 in division and brigade TM work. 


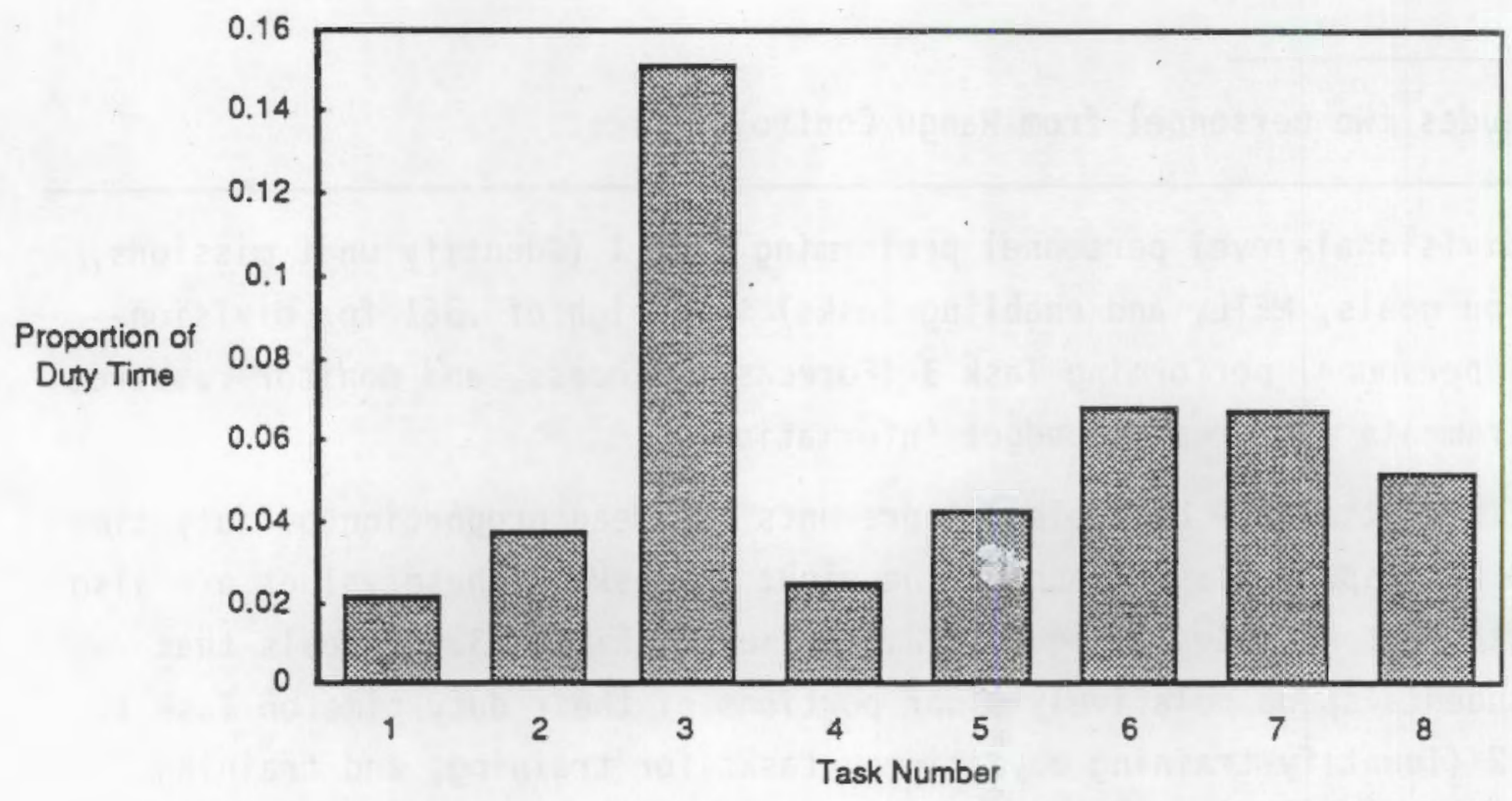

FIGURE 3.2. Mean Proportion of Duty Time Spent on Each TM Task By Respondents 


\subsubsection{TM Duty Time}

A comparison of TM duty time can be made between echelons, as shown in Figure 3.3. These values are the mean proportion of duty time spent on $T M$, adjusted for each respondent's reported number of days in the field. The figure illustrates that division- and brigade-level respondents reported spending an average of approximately 60 percent of their time on TM; whereas battalion- and company-level respondents reported spending an average of approximately 45 percent and 39 percent of their duty time on TM, respectively.

\subsubsection{TM Work Types}

Table 3.7 presents the job study findings for the mean proportion of duty time spent by respondents in the performance of each type of work, combined across the eight separate TM tasks. Some general trends are apparent after inspection of this table. Looking at the separate values between echelons and types of work, it can be seen that values range from a low of .020 for company personnel computing numbers to a high of .183 for brigadelevel personnel discussing and planning. There are two basic trends in these data: (1) brigade level emphasis of planning types of work, and (2) division level emphasis on analysis and reporting. The means in the right-hand column of Table 3.7 provide a summary across echelons, with

\section{TABLE 3.7. Mean Proportion of Duty Time Performing Each} Type of Training Management Work

\section{Work Type Category Division* Brigade Battalion Company Mean}

1. Discussing \& Planning

2. Obtaining Information

$\begin{array}{lll}.067 & .183 & .099\end{array}$

$\begin{array}{lll}.074 & .093 & .056\end{array}$

$.073 \quad .053$

$.104 \quad .055$

.050

.095

.048

.062

.137

.089

.027

.097

.054

.083

.071

.049

.077

.046

.054

.020

.066

.042

.064

.038

.089

7. Supervising Others

*Includes two personnel from Range Control Office. 


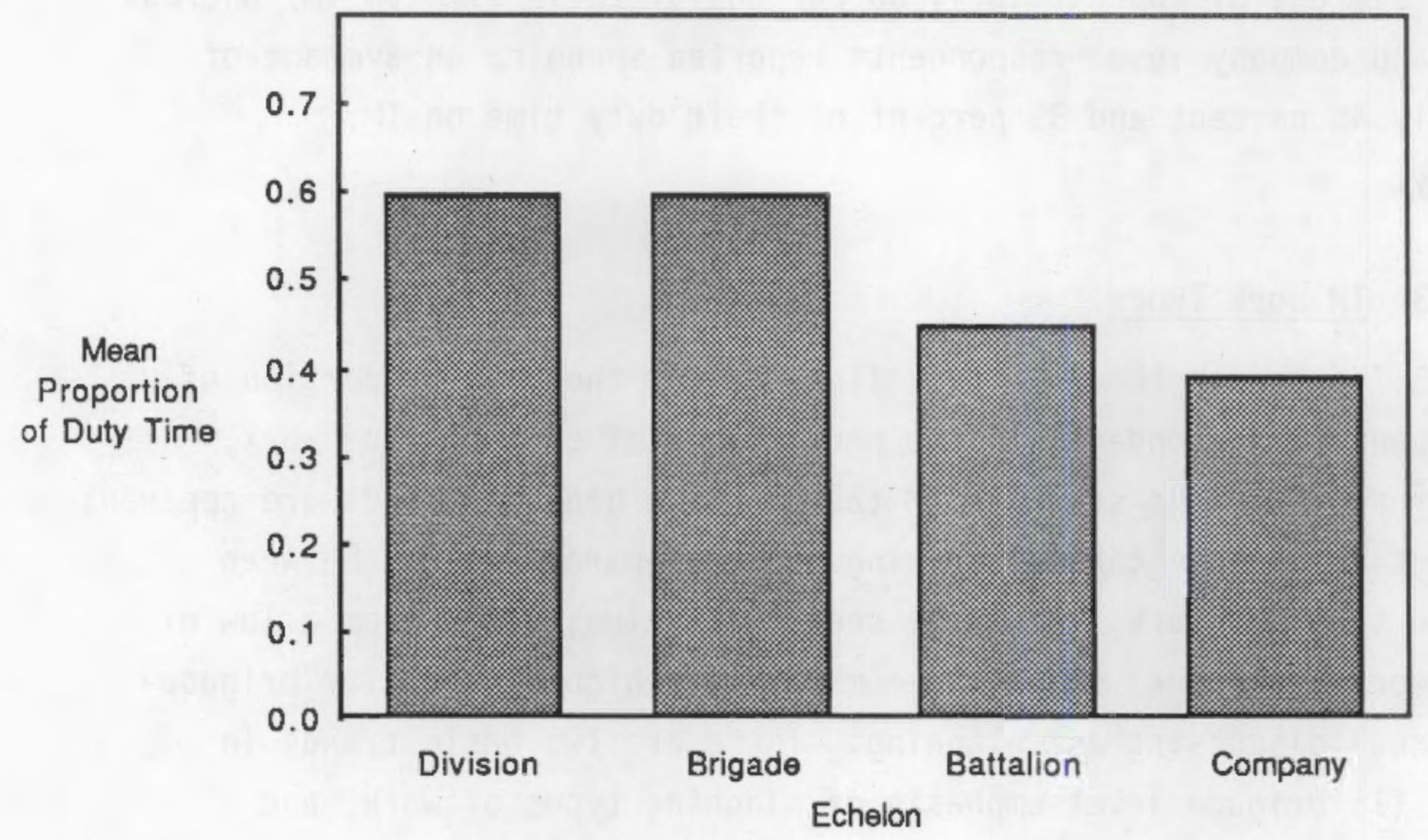

FIGURE 3.3 Mean Proportion of Duty Time Spent on All TM Tasks by Respondents at Each Echelon 
individual respondents weighted equally in computing these means. These values are also depicted in Figure 3.4. Inspection of these values indicates that relatively comparable portions of respondents' duty time are spent on all seven types of work, with Type 1 (discussing and planning) and Type 6 (preparing documents) taking relatively more time than other types of work.

\subsubsection{Computer Use in TM}

The proportion of respondents who perform training management tasks and use a computer to assist them in their work is presented in Table 3.8. The eight columns of values in this table provide a breakdown by echelon, officers, and enlisted personnel for the use of computers by those who perform each task (entries with dashes indicate that no respondents in the category reported performance of the task). Review of the entries in Table 3.8 reveals there are only four cases where none of the respondents reported using a computer to aid them in their training management task work, as indicated by 0.00 entries. All of these cases of work without the use of computers

TABLE 3.8. Percent Respondents Who Perform Task and Use Computers

\section{TASK}

\begin{tabular}{llcccccccc} 
Echelon & & 1 & 2 & 3 & 4 & 5 & 6 & 7 & 8 \\
Oivision* & Officer & 1.00 & 1.00 & 1.00 & 1.00 & 1.00 & 0.00 & -- & 1.00 \\
& Enlisted & -- & -- & 0.80 & 0.50 & -- & 1.00 & 1.00 & 1.00 \\
\multirow{2}{*}{ Brigade } & Officer & 0.80 & 1.00 & 1.00 & 1.00 & 1.00 & 1.00 & 0.00 & 1.00 \\
& Enlisted & -- & 0.00 & 0.50 & -- & -- & -- & 0.50 & -- \\
\multirow{6}{*}{ Battalion } & Officer & 0.80 & 0.86 & 0.63 & 0.50 & 0.50 & 0.38 & 0.50 & 0.75 \\
& Enlisted & 0.67 & 1.00 & 0.71 & 0.67 & 0.50 & 0.25 & 0.71 & 0.83 \\
Company & Officer & 0.17 & 0.31 & 0.40 & 0.50 & 0.50 & 0.40 & 0.36 & 0.31 \\
& Enlisted & 0.00 & 0.17 & 0.38 & 0.00 & 0.33 & 0.44 & 0.36 & 0.56
\end{tabular}

*Includes two personnel from Range Control office. 


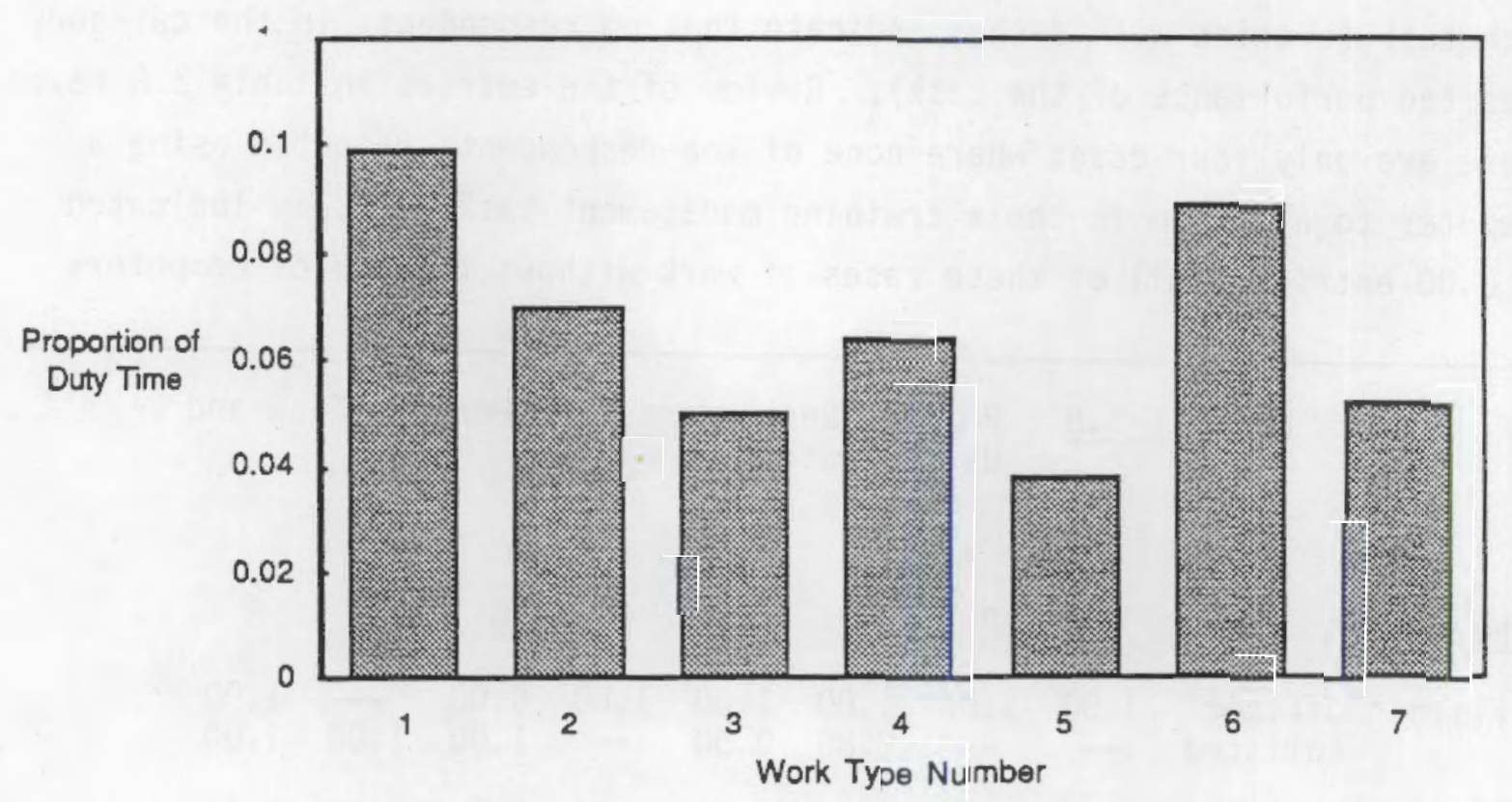

FIGURE 3.4. Mean Proportion of Duty Time Spent on Each TM Work Type by Respondents 
represent relatively few respondents. One division-level officer performs Task 6 (Process near-term training guidance) without the aid of a computer, one brigade-level enlisted respondent performs Task 2 (Identify training objectives, tasks for training, and training program) without a computer, and two company-level respondents perform Task 1 (Identify unit missions, mission goals, METL, and enabling tasks) and Task 4 (Process long-range training guidance) without computer assistance. In contrast to the few cases where computers are not used, there are fifteen cases where all respondents who perform a task use a computer to assist them in their TM work.

Figure 3.5 depicts the prevalence of computer use in TM among the survey sample. The measure used in this figure is the proportion of respondents who use a computer on one or more of the tasks they perform. All divisionand brigade-level officers in the sample use a computer to assist them in some facet of TM. There is a moderately-high level of computer use for TM among division-level enlisted respondents, as well as battalion officers and enlisted personnel. Finally, there is a moderate level of computer use among brigade-level enlisted personnel, and among company-level officers and enlisted personnel. The finding of a moderate level of computer use for TM among company-level personnel is noteworthy, since these units are not issued computers. Generally, there was a high prevalence of personallyowned computers in use for TM tasks at the company level, which suggests a requirement for automated TM at this level.

\subsubsection{Scheduled Training Accomplished}

This subsection presents estimates of the training that is actually conducted versus the training that had been scheduled. During the survey interview, participants were asked to respond to the question "Does your position allow you to compare the training that is actually conducted with the training that had been scheduled?" Participants were instructed to consider both individual and group training that was included in the quarterly schedule agreed upon by brigade and battalion staff in providing their responses. Thirty-eight participants indicated that their position allowed them to compare scheduled and accomplished training in this way. 


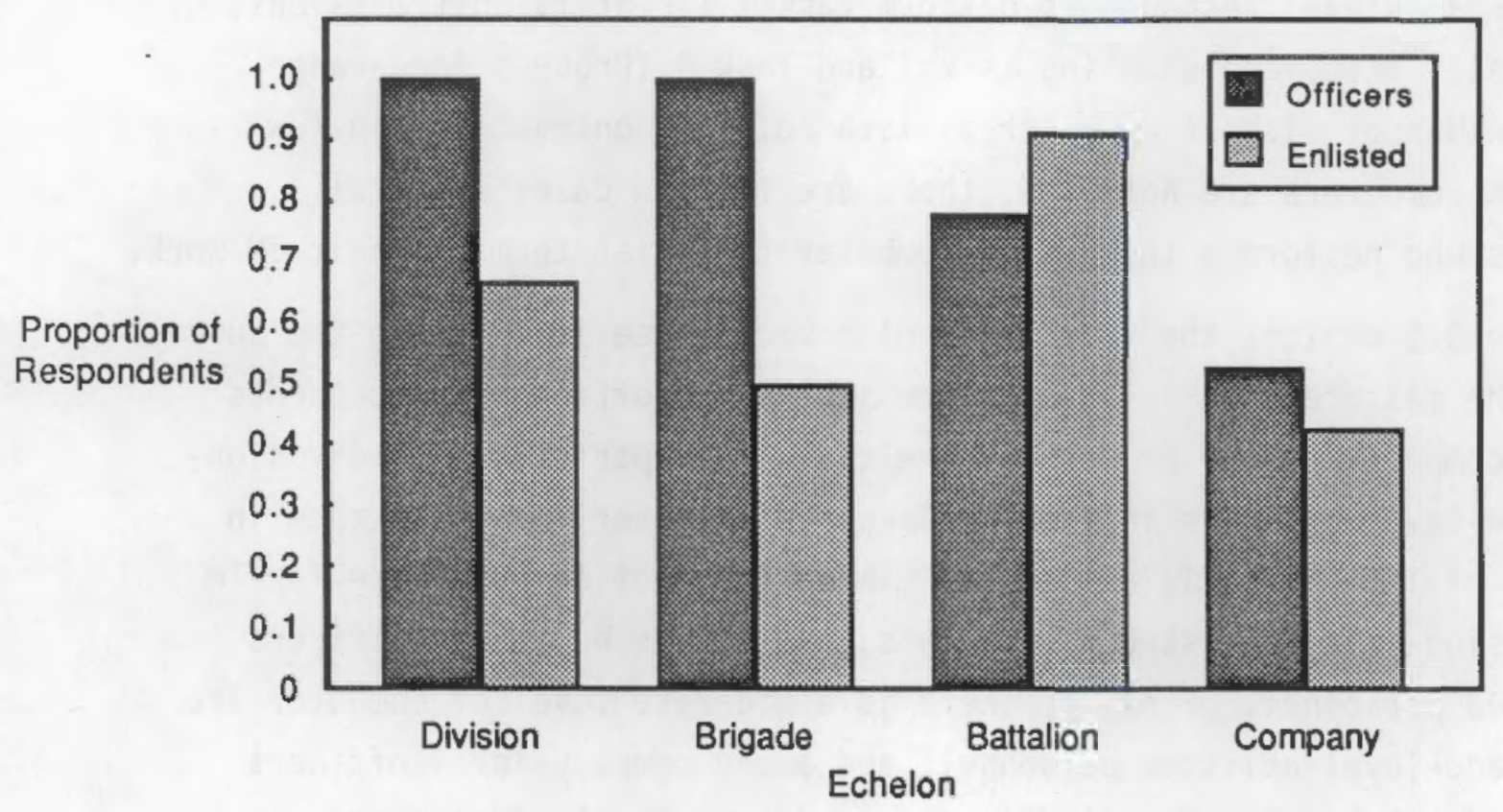

FIGURE 3.5. Proportion of Respondents Who Use a Computer in Performing TM Work 
Table 3.9 presents the mean percent estimates of scheduled and accomplished training provided by respondents, organized by echelon and officer versus enlisted status of the respondents. The first column of estimates in Table 3.9 is for the percent of scheduled training that was conducted as scheduled. Estimates for "Mean Percent as Scheduled" range from a low of 59 percent by company officers to a high of 93 percent by company enlisted personnel. (The reader should note that the company officer data could be argued to be the most valid subset of estimates, since these individuals are most familiar with both planned and executed training.) The bottom entry in the first column of estimates is the grand mean across all respondents, indicating an average estimate that 71.1 percent of training scheduled for a quarter is conducted as scheduled.

TABLE 3.9. Summary of Training Scheduled and Accomplished Estimates

\begin{tabular}{|c|c|c|c|c|c|c|}
\hline \multicolumn{2}{|l|}{ Echelon } & $\underline{N}$ & \begin{tabular}{l}
\multicolumn{1}{c}{ Mean } \\
Percent as \\
Scheduled \\
\end{tabular} & $\begin{array}{l}\text { Mean } \\
\text { Percent } \\
\text { Schedule } \\
\text { Changed }\end{array}$ & $\begin{array}{c}\text { Mean } \\
\text { Percent } \\
\text { Not } \\
\text { Conducted } \\
\end{array}$ & $\begin{array}{c}\text { Mean } \\
\text { Percent } \\
\text { Not } \\
\text { Scheduled } \\
\end{array}$ \\
\hline Division & $\begin{array}{l}\text { Officer } \\
\text { Enlisted }\end{array}$ & $\begin{array}{l}2 \\
0\end{array}$ & $\begin{array}{l}66 \\
--\end{array}$ & $\begin{array}{l}22 \\
--\end{array}$ & $\begin{array}{l}12 \\
--\end{array}$ & -- \\
\hline Brigade & $\begin{array}{l}\text { Officer } \\
\text { Enlisted }\end{array}$ & $\begin{array}{l}5 \\
0\end{array}$ & $\begin{array}{l}75 \\
--\end{array}$ & $\begin{array}{l}15 \\
--\end{array}$ & $\begin{array}{l}10 \\
--\end{array}$ & $\begin{array}{r}7 \\
--\end{array}$ \\
\hline Battalion & $\begin{array}{l}\text { Officer } \\
\text { Enlisted }\end{array}$ & $\begin{array}{l}8 \\
6\end{array}$ & $\begin{array}{l}77 \\
62\end{array}$ & $\begin{array}{l}14 \\
30\end{array}$ & $\begin{array}{l}9 \\
8\end{array}$ & $\begin{array}{l}17 \\
18\end{array}$ \\
\hline \multirow[t]{2}{*}{ Company } & $\begin{array}{l}\text { Officer } \\
\text { Enlisted }\end{array}$ & $\begin{array}{r}11 \\
-6 \\
-\end{array}$ & $\begin{array}{l}59 \\
93 \\
\end{array}$ & $\begin{array}{r}23 \\
6 \\
\end{array}$ & $\begin{array}{r}18 \\
1 \\
\end{array}$ & $\begin{array}{l}17 \\
10 \\
\end{array}$ \\
\hline & & N & 38 & 38 & 38 & 36 \\
\hline \multicolumn{3}{|c|}{$\begin{array}{l}\text { Grand Means } \\
\text { Across Respondents }\end{array}$} & $71.1 \%$ & $18.4 \%$ & $10.5 \%$ & $14.6 \%$ \\
\hline
\end{tabular}

The second column of estimates in Table 3.9 is for training that was conducted within the quarter scheduled, following a change in the scheduled training period. Across all respondents, it was estimated that 18.4 percent of training was conducted after changes in scheduling. The third column in Table 3.9 provides estimates for the scheduled training not conducted. 
Across participants, it was estimated that 10.5 percent of scheduled training was not conducted. The final column in Table 3.9 provides estimates of the percent of all training that was not included in a quarterly schedule. Across all respondents, it was estimated that 14.6 percent of all training was not planned on a quarterly schedule.

Although there is some variation in estimates of scheduled and accomplished training, the degree of general consensus is quite substantial. On the basis of these survey results, it would be reasonable to estimate that between 30 and 40 percent of conducted training results from a schedule change during the current quarter. This level of rescheduling represents a substantial training management burden at the battalion and company levels.

\subsubsection{Problems, Solutions and Suggested Features of Automation}

This subsection presents findings pertinent to general problems encountered by respondents in the conduct of $\mathrm{TM}$, solutions to these general problems suggested by respondents, and respondents' suggestions for improving training management through automation. The findings in each of these three areas are the result of a content analysis that consisted of four steps. First, all answers to open-ended questions were broken down into individual statements and transcribed, along with identifying information. Second, a scheme for classifying the set of statemonts was developed. Third, each answer was categorized using the classification scheme. The final, fourth step consisted of tabulating the frequency of response in each category.

\subsubsection{General TM Problems}

Table 3.10 presents the results of the content analysis of respondents' answers to the question "Would you describe the three biggest problems you face in your training management work?" The values in this table are the proportion of respondents from each echelon that provided a statement classified in the problem category listed in the left-hand column of the table. The problem categories in Table 3.10 are ordered in accordance with the right-hand column entries, which provide the average proportion across all echelons, where each echelon is weighted equally regardless of the number of respondents represented. The following discussion provides a brief review 
of the problems most commonly cited. Appendix $C$ provides a more detailed summary of comments.

TABLE 3.10. Summary of "General Problems" Content Analys is Proportion of Respondents Stating Each General Problem

\begin{tabular}{|c|c|c|c|c|c|}
\hline Problem Category & Division & Brigade & Battalion & Company & Mean \\
\hline Resource Availability & 0.38 & 0.40 & 0.16 & 0.45 & 0.35 \\
\hline Administrative Procedures & 0.25 & 0.30 & 0.42 & 0.14 & 0.28 \\
\hline Adherence to Procedures & 0.63 & 0.30 & 0.11 & 0.00 & 0.26 \\
\hline Training Distractors & 0.00 & 0.30 & 0.16 & 0.52 & 0.24 \\
\hline Resource Forecasts \& Requests & 50.13 & 0.40 & 0.16 & 0.07 & 0.19 \\
\hline Personne] Management & 0.13 & 0.30 & 0.11 & 0.10 & 0.16 \\
\hline Schedule Changes \& Conflicts & 0.13 & 0.10 & 0.16 & 0.24 & 0.16 \\
\hline Higher Command Guidance & 0. & 0.30 & 0.05 & 0.26 & 0.15 \\
\hline Communications & 0 . & 0.10 & 0.16 & 0.07 & 0.11 \\
\hline Time Availability & 0 . & 0.10 & 0 & 0.00 & 0.10 \\
\hline Training Planning & & 0.00 & 0.05 & 0.03 & 0.08 \\
\hline Resource Expenditures & & 0.10 & 0.00 & 0.00 & 0.03 \\
\hline Document Preparation & 0 . & 0.00 & 0. & 0.07 & 0.02 \\
\hline Individual Soldier Trai & 0 . & 0.00 & 0.00 & 0.07 & 0.02 \\
\hline
\end{tabular}

- Resource Availability was the TM problem most commonly cited across echelons. All types of training resources were mentioned by respondents, although problems about the lack of available ammunition and training areas were most frequently cited.

- Administrative Procedures ranked as the second most commonly mentioned problem across echelons. Such comments were most prevalent among battalion-level personnel. Several comments focused on excessive and unnecessary TM paperwork, the need to hand-carry forms to obtain approval, and the brief period of time available to process information.

- Adherence to Procedures was a problem most frequently identified by division-level personne 1 , who predominantiy stressed the lack of adherence to established TM procedures by subordinate units.

- Training Distractors was the most prevalent problem stated by companylevel respondents, who often focused on the last-minute nature of taskings imposed by division headquarters.

- Resource Forecasts and Requests were a frequently-cjted problem at the brigade level. Specific problems involved difficulties in monitoring ammunition expenditures and the difficulty of meeting last-minute requests for resources. 
- Personnel Management problems mentioned most frequently focused on short job tenure and mismatches between job assignments and personnel qualifications.

- Schedule Changes and Conflicts were frequently cited as a problem by company-level respondents, who identified changes imposed by higher headquarters.

- Higher Command Guidance was identified as a problem that involved lack of mission guidance and excessive burdens of directed training.

- Communications is a final problem to be mentioned in this discussion. Problems cited in this area involved poor coordination within units and excessive delays in notifying units about higher command orders.

\subsubsection{Suggested TM Improvements}

Table 3.11 provides the results from respondents who suggested solutions to TM problems in response to the open-ended question "Do you have any suggestions for improving training management?" As in the preceding table, entries under echelons provide the proportion of respondents providing each category of solution; and the right-hand column is an average of the four preceding entries, weighting echelons equally. Suggested solutions tended

\section{TABLE 3.11. General Solutions: Summary of Results}

\section{Proportion of Respondents Stating Each General Solution}

\begin{tabular}{lcccccc} 
Solution Category & Division & Brigade & Battalion & Company & Mean \\
\cline { 2 - 3 } $\begin{array}{l}\text { Training Management } \\
\text { Resources }\end{array}$ & 0.75 & 0.50 & 0.32 & 0.10 & 0.42 \\
$\begin{array}{l}\text { Training Man. } \\
\text { Procedures }\end{array}$ & 0.50 & 0.70 & 0.21 & 0.00 & 0.35 \\
$\begin{array}{l}\text { Communications } \\
\text { Personnel Management }\end{array}$ & 0.25 & 0.30 & 0.11 & 0.24 & 0.23 \\
Division Organization & 0.25 & 0.30 & 0.11 & 0.03 & 0.17 \\
Training Resources & 0.13 & 0.10 & 0.11 & 0.24 & 0.14 \\
Training Distractors & 0.00 & 0.00 & 0.16 & 0.41 & 0.14 \\
Higher Command Guidance & 0.13 & 0.00 & 0.21 & 0.17 & 0.13 \\
\hline
\end{tabular}


to focus on the same issues as those mentioned during the identification of problems, although a notably smaller number of solution categories were identified during the content analysis of these comments. Suggested solutions are briefly discussed below, and summarized in more detail in Appendix $C$.

- Training Management Resources were a solution most frequently cited by respondents in higher echelons. Many of these comments suggested ways to improve or introduce automated TM procedures.

- Training Management Procedures were also a solution predominantly cited by higher-echelon respondents. Comments in this category frequently identified the need to reduce paperwork or increase adherence to doctrinal procedures.

- Communications improvements were a solution cited by personnel at all echelon levels. Suggestions predominantly focused on quicker exchange and more centralized processing of information.

- Personnel solutions to TM problems included increased job tenure and increasing numbers of personnel to match Table of Organization and Equipment specifications.

- Division Organization solutions included decentralizing resource storage to reduce administrative requirements for procurement, and establishing central points of contact for clarification of TM problems.

- Training Resources solutions were most frequently cited by company-level respondents, who generally suggested an increase in available resources.

- Training Distractors reduction, especially reducing the level of taskings during non-support cycles and increasing the lead-time for tasking requests, were suggestions made exclusively by battalion- and companylevel respondents.

- Higher Command Guidance that was clearer, more current, and stressed the priority of training was suggested by battalion- and company-level respondents.

\subsubsection{Suggested Features of TM Automation}

Table 3.12 presents the results of the content analysis to the openended question "Do you have any suggestions for improving training management through automation?" In analyzing the responses to this question, suggestions were categorized into 18 separate categorics of automation features. As the summary of results in the table below indicates, there was a moderate level of consensus among respondents regarding the need for a number of automation features. However, many of the suggested features 
TABLE 3.12. Percent Respondents Stating Each Automation Feature

\begin{tabular}{|c|c|c|c|c|c|}
\hline Automation Feature & $\frac{\text { Division }}{(n=9)}$ & $\frac{\text { Brigade }}{(n=10)}$ & $\frac{\text { Battalion }}{(n=19)}$ & $\frac{\text { Company }}{(n=29)}$ & Mean \\
\hline Network Within Installation & 0.44 & 0.20 & 0.37 & 0.31 & 0.33 \\
\hline Resources & 0.22 & 0.30 & 0.37 & 0.21 & 0.27 \\
\hline Provide to Companies & 0.00 & 0.00 & 0.11 & 0.69 & 0.20 \\
\hline Training Records & 0.11 & 0.10 & 0.21 & 0.24 & 0.17 \\
\hline Scheduling & 0.11 & 0.00 & 0.26 & 0.17 & 0.14 \\
\hline Standardized Forms & 0.00 & 0.10 & 0.26 & 0.07 & 0.11 \\
\hline $\begin{array}{l}\text { Not Training Management - } \\
\text { Specific }\end{array}$ & 0.11 & 0.00 & 0.05 & 0.24 & 0.10 \\
\hline $\begin{array}{l}\text { Store TMs and Training } \\
\text { Requirements }\end{array}$ & 0.11 & 0.00 & 0.11 & 0.17 & 0.10 \\
\hline $\begin{array}{l}\text { Status Checking \& Decision } \\
\text { Making }\end{array}$ & 0.11 & 0.00 & 0.11 & 0.14 & 0.09 \\
\hline $\begin{array}{l}\text { Real-Time Updating of Data } \\
\text { Bases }\end{array}$ & 0.00 & 0.00 & 0.16 & 0.07 & 0.06 \\
\hline Integrate Functions & 0.00 & 0.10 & 0.11 & 0.00 & 0.05 \\
\hline Operator Training & 0.00 & 0.10 & 0.05 & 0.03 & 0.05 \\
\hline Ruggedized & 0.00 & 0.00 & 0.11 & 0.07 & 0.04 \\
\hline Easy to Use & 0.00 & 0.00 & 0.16 & 0.00 & 0.04 \\
\hline Store Regulations & 0.00 & 0.10 & 0.05 & 0.00 & 0.04 \\
\hline $\begin{array}{l}\text { Large, General-Purpose } \\
\text { Spreadsheet }\end{array}$ & 0.00 & 0.10 & 0.05 & 0.00 & 0.04 \\
\hline Taskings & 0.00 & 0.00 & 0.05 & 0.03 & 0.02 \\
\hline $\begin{array}{l}\text { Reduce Training Management } \\
\text { Labor }\end{array}$ & 0.00 & 0.00 & 0.05 & 0.03 & 0.02 \\
\hline
\end{tabular}


were recommended by only a few individuals. Following is a brief review of frequently suggested features of TM automation. A more thorough discussion is provided in Appendix $C$.

- Network within Installation was the most frequently suggested automation feature across echelons. These suggestions predominantly focused on the value of networking computers across echelons and providing a means of electronic mail to facilitate communications.

- Resources management was suggested by respondents in all echelons. The management of ammunition and training area information was commonly suggested.

- Provide to Companies was a feature of automation seldom identified explicitly. However, the prevalence of this comment among company-level respondents was so high (69 percent) that the result deserves mention.

- Training Records, i.e., automated record-keeping and reporting of individuals' training records, was a relatively frequent suggestion at all echelon levels. Specific training records most commonly mentioned were SQT, CTT, and ITEP.

- Scheduling automation was suggested as a means of improving TM, primarily by respondents at the battalion- and company-level. Respondents' suggestions focused on ways to improve the current program available on the GRID computer and make it available at all echelons.

- Forms was a final suggestion for automation. These suggestions commonly focused on the standardization of forms that could be stored electronically to reduce paper forms inventories and facilitate the oreparation of forms.

\subsection{COMPARISON OF DOCTRINE AND PRACTICE: SYNOPSIS OF RESULTS}

The results of the document usage section of the survey were analyzed to determine the extent to which TM doctrine and practice coincide. This was accomplished by determining the percentage of respondents reporting each document category as being used for input or in preparation of output for each of the eight TM tasks studied. Expert judgment was employed to determine the TM implications of document use statistics. The document categories and quantitative results are presented in Appendix D. This section presents the most significant findings of that analysis. The following major points emerged from the data:

1. There was no reported use of Army, FORSCOM, installation, or corps mission guidance above battalion level, and only 14 percent of company respondents cited using one of these mission guidance 
sources. A substantial percentage of respondents at all levels reported using TRADOC training references in defining battle tasks: 100 percent at division, 60 percent at MSC, 56 percent at battalion, and 57 percent at company. There was also a substantial level of reliance by respondents on division regulation 350-1 as a training directive (100 percent at division and MSC, 56 percent at battalion, and 29 percent at company), suggesting that unit missions are not the primary drivers of training programs, but that training programs are driven by what can be accomplished within the time and resources provided.

2. METL development is not uniform among units. Only 60 percent of the MSC respondents and 22 percent of the battalion respondents cited a METL as an output of identifying unit missions, goals, and enabling tasks. This lack of METL development can ultimately lead to a lack of standardization in unit skills.

3. Few units have formalized training task analysis procedures. This is particularly true at battalion and company level, where only 9 percent of the battalion respondents and 26 percent of the company respondents reported using training guidance from their next higher MSC. Battalion and company reliance on division training guidance was equally low, with 18 percent of battalion respondents and 21 percent of company respondents reporting use of this input. Finally, only 5 percent of the company respondents reported using their parent battalion's training guidance, reflecting a continuous focus on short-term, event-driven training. In contrast to the minimal usage of higher echelon guidance, the use of guidance documents from respondents' own units in planning training was very common (100 percent of division respondents, 75 percent of MSC respondents, and 27 percent of battalion respondents).

4. Companies are the primary source for initiating resource requests. This is indicated by 61 percent of the company respondents identifying range and training areas requests as output, as well as substantial percentages (39 percent and 33 percent) requesting training ammunition and general support services. This finding is significant in that companies do not have a position for handling these requests in their TO\&Es.

5. As training plans evolve from long-range to short-range to nearterm, the impact of external tasking becomes more significant. At division level, 25 percent of the respondents reported initiating subordinate unit planning with taskings during long-range planning, increasing to 33 percent during short-range planning and 50 percent during near-term planning. This increase in the output of taskings at division level suggests that higher headquarters cannot foresee requirements sufficiently in advance to preclude unit turbulence. A corresponding increase in the use of taskings as inputs by respondents was seen between short-range and near-term planning. During short-range planning, taskings served as input for 33 percent 
of division respondents, 25 percent of $M S C$ respondents, 18 percent of battalion respondents, and 5 percent of company respondents. By the time near-term planning had begun, there was an overall increase in the percentage of respondents using taskings as input, with 50 percent at division, 50 percent at MSC, 9 percent at battalion, and 8 percent at the companies.

6. The planning workload for training event execution shifts downward from MSC and battalion to company during near-term planning. At the MSC level, near-term planning outputs were limited to preparing training plans (50 percent of MSC respondents) and resource coordination documents (50 percent of respondents). Battalion staff efforts were also Timited primarily to publishing written instructions (73 percent of respondents) and coordinating resources (18 percent), along with a minor involvement in preparing the training schedule by 9 percent of respondents. Company staff, on the other hand, reported a wider breadth of activities, including providing input to battalion written instructions (4 percent of company respondents), preparing company near-term guidance (54 percent), requesting training ammunition (13 percent), requesting ranges ( 8 percent), requesting general support such as food and transportation (13 percent), and beginning preparation of the training schedule (29 percent). As in the case of company level initiation of resource requests, the lack of personnel and systems at the company level to support these activities reduces training effectiveness.

7. Few units have procedures for analyzing and incorporating training results. Rates of using training results are low, e.g., 45-50 percent at the company level. These low rates indicate that training lacks a feedback component, which is critical for skill building and maintenance.

The points discussed above reflect inadequacies in the present implementation of TM doctrine. Thus, while the surveys indicate that TM practice follows Army doctrine (e.g., increased resource coordination during short-range planning), the organization and practice of $T M$ tasks show specific inefficiencies. These inefficiencies, e.g., not considering previous training results when planning, can lead to serious deficiencies in training programs, and ultimately in unit readiness.

\subsection{IMPROVING TRAINING MANAGEMENT THROUGH AUTOMATION}

The TM tasks and work type taxonomy used as a data-gathering framework yields 56 distinct tasks. Some of these quite obviously are not, and will never be, candidates for automation. For example, discussing and planning. 
an activity that consumes the largest amount of time (10 percent) across all TM tasks, is an inherently human activity. However, 30 percent of the respondents' time is spent performing types of work that may be greatly facilitated by automation, i.e., obtaining information, compiling information, computing numbers, and preparing documents.

This section examines several tasks as prime candidates for automation, based on our interview data and observations. These several candidate tasks and the specific ways in which they can benefit from automation suggest some of the desired characteristics of a computer-based TM system.

\subsubsection{Candidate \#1: Resource Scheduling (e.g. Battle Simulation Facility)}

Resourcing a training activity occurs after the needs analysis confirms the requirement to conduct training on a particular objective and the decision is made to schedule it. This usually occurs three to six months prior to the scheduled training. Existing processes are cumbersome, labor intensive, and time consuming as outlined in the pre-determined, step-by-step procedure contained in App R, 9I0 Reg 350-1.

For example, if Company A, 2-60 Inf, wants to conduct training using the Fire Coordination Theater, a protracted request process is required. The company commander or his designated representative must get approval for the training from the Battalion S-3 section. A representative of $P$ Battalion 5-3 telephones the Battle Simulations Center to determine the availability of the desired facility. Upon determination of availability, an HFL 473 "facility request" form must be filled out and routed through higher command headquarters to the I Corps Battle Simulations Center. This process requires the form to be generated at the company, routed through the battalion S-3, through the brigade S-3, to the division G-3 section. Upon receipt of a facility request, 9 IO G-3 Training verifies the availability of the requested facility, and then retains a copy of the reques: until confirmation of scheduling has been received from the Battle Simulations Center. No facility is considured scheduled until a "completed and properly G-3 stamped HFL 473 facility request" (page R-1, 9ID Reg 350-1) has been received and logged by the Battle Simulations Center. 
Automated procedures coupled with established parameters will make this coordination significantly more efficient. Through the use of electronic mail, the request can be submitted and routed through all appropriate channels, received and scheduled by the Battle Simulations Center, and routed back to the requesting unit. This will save significant time and labor in the scheduling process, since it is recommended that such requests be hand carried. Additionally, the use of electronically-accessible schedules for such resources will permit longer-term plans to be made around resource availability. This will help to reduce the reactive nature of TM decision making. Additionally, such electronic schedules can be supplemented with waiting lists that will provide automatic notification to a unit if a pending request for a resource can be handled. The primary features of an ADP solution to the resourcing problem are (1) inter-echelon and interinstallation electronic mail, (2) resource schedules that can be displayed at the requesting unit, (3) a waiting list function, and (4) automatic feedback concerning resource availability.

\subsubsection{Candidate \#2: Ammunition Forecasting}

Ammunition management lends itself to automation as a means of inventory control and allocation. Each Major Subordinate Command (MSC) and separate battalion prepares and submits their annual ammunition requirement based on current training goals and objectives, Army regulations, and division guidelines. Subsequently, units are given ammunition allocations and assume responsibility for managing specific accounts that are maintained at the Division Ammunition Office. MSCs are required to sub-allocate ammunition to subordinate units and to monitor and manage the expenditures on a continuous basis. An automated information system that allows all users to be cognizant of the activities associated with each account will facilitate the efficient and effective expenditure of training ammunition. Units will know the current status of their accounts and can use this information to project training in the future and to control the actions of subordinate units.

Under the existing manual system, each MSC/Separate Battalion is required to submit monthly ammunition forecasts. With automation, the data required 
to complete this action can be more readily available and more accurate, since it can be timely. The forwarding from MSC to Division, the consolidation of data, and the providing of rollup information to the DAO can all be accomplished electronically.

An automated system can also facilitate adjusting training activities to compensate for insufficient anmunition in a particular unit (through cross-level allocations between sub-accounts) and to account for unforeseen training requirements. For example, should a range suddenly become available that would permit a unit to conduct a fire exercise for which sufficient ammunition had not been resourced, the computer could reallocate ammunition from another account that contains a surplus. Thus, computer-based ammunition handling can facilitate "opportunistic" training. The essential elements of computer-based ammunition management are (1) unit access to ammunition account data (information only), (2) consolidation of subordinate unit ammunition account information for MSC reporting, and (3) automatic reallocation between ammunition accounts with complementary resource requirements.

\subsubsection{Candidate \#3: Preparing the Unit Readiness Report}

Preparation of the Unit Readiness Report involves transcribing and compiling numerous pieces of data concerning subordinate unit status, e.g., percent of the unit trained in required areas such as weapons qualification, NBC proficiency, and CTT. Obtaining all of this information in a timely manner currently requires many phone calls, visits to staff sections, and the exchange of numerous, oftentimes incomplete, subordinate unit reports. As new information is received, the report must be revised by hand.

With appropriate computational options, battalion users can request summary statistics that can be embedded in the report. The report can also be generated by the computer, transmitted to upper-echelons, and an image stored for future reference. The key features of an ADP solution are

(1) access to subordinate unit data, (2) ability to create summary statistics,

(3) report generation and storage, and (4) electronic reporting to upper echelons. 


\subsubsection{Candidate \#4: Obtaining Publications to Identify Unit Missions,}

Goals and Tasks

In planning a training program, TM personnel require access to a large volume of information, including ARTEPs, Field Manuals, Battle Books, task lists, and training guidance. While individual specialty TM personnel, such as the NBC training officer, tend to have immediate access to several key publications, it is usually the case that critical publications are missing. This is compounded by the general unavailability of these documents anywhere on post. A further difficulty exists in relating the doctrinally defined mission critical tasks to current training status.

An effective computer-based solution to this problem can entail online access to all relevant training and training management publications. Such a capability must be supplemented by an appropriate indexing function to permit directed searches. Finally, automated correlation of mission critical tasks with current training status facilitates the construction of training programs. The desirable features of automated document access and retrieval include (1) on-line access to a complete, updated library of relevant material; (2) capability for directed document search, based on key word and phrase input; and (3) automatic extraction of unit mission critical tasks and correlation with current training status.

This latter capability may represent one of the most important potential benefits of automation, since the readiness of units depends on training. By algorithmically establishing training parameters, a unit's needs will be less heavily influenced by the schedule and resource constraints that presently drive much of a unit's activities.

\subsubsection{Candidate \#5: Tracking Proficiency and Turbulence Impacts}

A critical part of evaluating unit performance is monitoring trends in performance proficiency. This requires reference to the historical record of unit proficiency worksheets, and extraction of data for particular tasks of interest. A number of meaningful analyses could result from such data, such as the impact of turbulence on task performance. However, this task is cumbersome without a computer. 
Automation can track measurement of proficiency and personnel available through a combination of a performance data base and links with SIDPERS. It can also track turbulence, which has a significant effect on training readiness (see Dyer, 1986, for a review of other studies). Based on the results of research, models could be developed and incorporated into algorithms that would quantify the effects of turbulence on training readiness. This would not only facilitate the determination of training readiness, but would also define for unit commanders the effects of personnel assignments under their control and allow them to better manage their personnel. The elements of a proficiency tracking system would involve a historical data base of unit performance, (2) ability to extract trends on particular exercises of interest, and (3) ability to compare proficiency data with unit turbulence statistics.

The five automation candidates described above are but a few of literally hundreds of individual TM tasks that can benefit from automation. Two additional candidates are worthy of note: (1) construction of the training schedule, and (2) resolution of resource conflicts. An automated approach to these tasks that permits manual intervention can greatly reduce the iterative paperwork now required in these tasks.

A more comprehensive listing of candidate tasks and a description of desirat?a automated system features would require a complete TM job inventory and detailed task analysis for all echelons and positions. This is beyond the scope of the global job analysis undertaken in this study. However, it is clear that for the TM tasks studied, increases in task efficiency would take place with automation as well as a closer match between training program!s and unit needs. The potential labor cost savings of these efficiencies are addressed in the following chapter.

\subsection{METHODOLOGICAL AND MEASUREMENT CONSIDERATIONS}

The results of the study reported here are based on a job analysis of a small sample and on self-report of quantities. These procedures are appropriate, given the exploratory nature of the current work, and the need to establish baseline conditions. However, caution must be exercised when considering the generalizability of the data to other units. It is likely 
that the overall pattern of results would be similar, but with variance in specific instances. For example, while a substantial number of un-networked personal computers were found in use in the 91D (MTZ), this same pattern may not be observed in other units. Similarly, while a specific set of TM problems was observed in the present sample, a different set of problems may be manifest in other units. Thus, while it is important to understand the main trends in time spent on the job within and across units, it is also important to observe the variation in patterns of TM performance. This would be possible with a larger sample of units that is more representative of the Army, including, for example, heavy divisions, light divisions, units meeting rapid deployment missions, National Guard units, and U.S. Army, Europe.

A second area to consider in the current study is the exclusive use of self-report to estimate TM costs. Such data are the best available for measuring jobs performed and times spent on them, short of video-based activity analysis. However, it is possible to complement the cost estimates based on subjective report with objective data obtained from documents maintained within the units or at installations. These would include documents such as training ammunition forecasts and requests, master planning calendars, training device resource forecasts and requests, and records of activities performed. The goal would be to use such data to obtain (1) objective cost figures for training events accomplished and (2) quantities reflecting the effectiveness of $\mathrm{TM}$ by measures of predicted activity versus what is actually accomplished.

The use of a larger sample and a design incorporating objective data from unit records are beyond the scope of the present study. It is clear that a more representative portrait of current Army TM and the potential benefits of automation could be obtained by further research with a wider range of units and additional sources of data. 

• 


\subsection{INTEGRATED TRAINING MANAGEMENT SYSTEM COSTS AND CALCULATED BENEFITS}

\subsection{INTRODUCTION}

\subsubsection{Cost Benefit Analysis for Automated Office or Management Systems}

Conducting a cost/benefit analysis for an office automation system or a management information system is a complex task. A review of the literature on cost/benefit studies of commercial office automation and management information systems (MIS) (Curley, 1984) reveals two major trends:

- Labor costs and benefits dominate virtually every office automation cost/benefit assessment.

- There are no consistently effective ways to measure the non-labor benefits associated with automation.

The most common form of automation cost/benefit analysis focuses on labor costs. There are two reasons for this. First, it is relatively easy to directly measure sub-units. The type of labor-related benefits that are most commonly used are (1) direct labor savings, where units of labor costs are reduced by introducing automation; and (2) cost avoidance analysis, where fewer hours of labor are required to do the automated job--but the total labo: hours within the organization remain the same.

The second reason for focusing on labor costs is that these costs are currently the most rapidly rising cost element in any labor intensive system (Strassman, 1985). The Army is not immune to this overall trend, since military personnel must be paid at rates that are at least roughly competitive with the private sector. Because of this, the Army should be generally concerned about the time certain tasks require. Since those tasks must be performed, the service is paying a penalty for not having them done with optimal efficiency. Cost avoidance analysis should lead to optimal decision making when there are other equally or more valuable tasks that can be performed using the time made available by an automated system. This assumption can apply to Army personnel involved in training management in that the time released from management can be used for actual training. 
The results that actually emerge when automated systems are put in place are often different than anticipated (Alexander, 1985). For example, users begin to perform functions that they could not do without automation. Also, secondary effects of increased efficiency in planning, organization and performance monitoring will often result in greater benefits in the form of increased use of facilities or resources that were previously underused.

What is essential for understanding the actual costs and benefits of an automated system is a study that compares the pre-automated or control environment with a test environment where automation has been introduced. This type of evaluation will be possible with automated training management, since the ITMS prototype will be placed in a test bed situation during the fall of 1988. When such a test is actually conducted, the actual cost/benefit effects associated with this system can be empirically evaluated.

\subsubsection{Analytical Approach}

The basic approach used in the following analysis was to derive analytically-based comparisons of the cost differentials between the current manual training management systems and two different automated training management scenarios. One automated system scenario assumes that no new compute. hardware is purchased to house the management system. The other scenario assumes that dedicated hardware is purchased to support the training management system. Cost data in this analysis are developed for tangible items only, i.e., labor costs and material costs are the basis for all comparisons.

\subsubsection{The Model of Cost Effectiveness}

The basic elements of comparison are labor costs associated with training management and the material costs associated with computer hardware, software, and support. To derive comparisons of the automated and non-automated cases, it was necessary to extrapolate current information to calculate a set of cost estimates. When it becomes possible to gather actual performance data on system use and operations once the ITMS prototype is operational, then the 
calculations developed here may be refined to account for empirically based data.

The initial step in conducting the cost analysis was to develop a labor cost calculation for the present training management system. Currently, there are no other significant tangible costs involved. The labor costs of managing Army training were computed for levels of command from division through company. From a combination of job analysis survey data and published information, a profile of TM labor costs was devised for each level of command. This estimate was then multiplied by the number of like units within the Army. This produced an estimate of the total labor cost of managing training at each level in the active Army.

Labor costs of training management were further broken down by the types of tasks involved at each level of command. This information was based on data obtained in the structured interview survey of 9ID (MTZ) units described in Chapter 3. The labor costs for each level of command in the Army were then extrapolated based on the survey data. The net estimated changes in the labor costs associated with automated and non-automated scenarios were based on factors from functional specifications for system performance and estimates of labor impacts on specific tasks derived from empirical studies of other automated systems.

Cost estimates for manuali $y_{y}$-operated training management systems are presented in Section 4.2. Automated system labor and equipment cost estimates are presented in Section 4.3 and the cost effectiveness of the automated system as compared to the manual system is presented in Section 4.4 .

\subsection{MANUAL TRAINING MANAGEMENT SYSTEM COST ESTIMATES}

Cost estimates for the current TM system are based on information obtained during the interviews of 9ID (MTZ) personnel. This information was used to characterize unit TM costs for division, brigade, battalion, and company personnel. Army-wide TM cost estimates were obtained by multiplying representative Army unit costs by 1986 U.S. Army Greenbook Data for the total number of units in the Continental U.S., the Pacific, and Europe. 
It should be emphasized that manual TM cost estimates presented in this chapter should be considered as approximate since they are based on data from the 9ID (MTZ) only. To increase the accuracy of these estimates, a representative cross-section of Amy units from other divisions will have to be obtained, which is beyond the scope of the current project.

Nevertheless, because of the similarity of structure in Army divisions, the estimates presented are sufficient for approximating the current costs of TM.

Representative unit TM costs are presented in Section 4.2.1, and fieldinc requirements are presented in Section 4.2.2. Resulting manual TM costs are contained in Section 4.2.3.

\subsubsection{Representative Unit Training Management Costs}

The determination of representative unit TM costs was accomplished by a three-step approach. The first step was to identify all 9ID personnei who participate in TM. The main sources for identifying participating personnel are:

- 9ID Unit Directory

- 9ID REg 350-1 (Training Management Plan)

- Available Unit Tables of Organization and Equipment

The result of this effort wi, a preliminary list of staff positions and grades for individuals conducting TM from the division through the company level. The next step for determining costs was to quantify the percent of time each individual spent performing TM duties. Initial estimates of the proportion of time spent on these duties were obtained by calculating the ratio of TM duties as a percentage of all assigned duties 1 isted in duties FM 101-5. For personnel not identified in FM 101-5, estimates for similar positions were used. The purpose of this effort was to ensure that an estimate of TM labor requirements for each staff position would be available if interview data could not be obtained. For those positions where interview data were available, the estimate of labor requirement based on FM 101-5 was replaced by the interviewee's response. In addition, the interviews resulted in modifications to the list of staff positions performing TM 
functions. For example, seven positions staffed by Special Duty personnel were added to the cost of TM staff requirements. It should be noted that a comparison of FM 101-5 duty estimates to actual interview data indicates that FM 101-5 data underestimate the fraction of the year individuals spend on TM. The result of this finding is that the use of FM 101-5 data provides a conservative estimate of labor requirements.

The final step in determining training management costs involved translating annual labor requirements into labor costs using FORSCOM-TRADOC cost planning factors (April 1986). These cost factors are provided in Table 4.1 and represent the total cost of personnel to the U.S. Army (e.g., basic pay plus retired pay accrual plus allowance for quarters). Although U.S. Army personnel costs would not be reduced by reducing TM labor requirements, these labor cost estimates do provide a baseline measure of the resources consumed by TM activities. The benefits that would result from reducing current TM labor requirements consist of (1) more labor available for non-TM duties, and (2) additional labor available for increasing TM effectiveness resulting in improved unit readiness.

Results of the analysis of unit TM costs are shown in Tables 4.2 4.6. The tables show the staff position, grade, fraction of time spent on $T M$, and estimated annual cost for each individual. The source of the estimate of time spent on $T M$ is also provided. Interview I.D. nuiwher refers to the interview data sheets.

Representative division TM costs are presented in Table 4.2. Annual TM resource requirements at the division level are 8.7 man-years or approximately $\$ 408,000$ in labor expenditures. This figure is probably a conservative estimate since no estimate has been included for time spent by commanders. Similarly, costs at the brigade level are presented in Table 4.3. Brigade level TM costs are estimated at 8 man-years or $\$ 361,000$ annually. Battalion level costs, shown by Table 4.4, total 6 man-years or $\$ 276,000$ per year. Company TM costs total 1.7 man-years or $\$ 66,000$ annually, and are presented in Table 4.5. Representative unit TM costs are summarized in Table 4.6. 
TABLE 4.1. U.S. Army Personnel Labor Costs

\begin{tabular}{|c|c|c|c|c|c|c|c|}
\hline & Pay Grado & $\begin{array}{c}\text { Annua I } \\
\text { Rate }\end{array}$ & $\begin{array}{l}\text { Wonthiy } \\
\text { Rate }\end{array}$ & $\begin{array}{l}\text { Neckly } \\
\text { Rate }\end{array}$ & $\begin{array}{l}\text { Daily } \\
\text { Rate } \\
\text { (7 Days) }\end{array}$ & $\begin{array}{c}\text { Daily } \\
\text { Rate } \\
\text { (5 Days) }\end{array}$ & $\begin{array}{l}\text { Hourly } \\
\text { Rate }\end{array}$ \\
\hline $0-6$ & Colonel & 98204.6 & 8184.0 & 1889.0 & 289.9 & 378.0 & 47.2 \\
\hline $0-5$ & Lt. Colonel & 82480.0 & 8873.0 & 1588.0 & 226.6 & 317.0 & 39.7 \\
\hline $0-4$ & Major & 87813.6 & 5651.0 & 1394.9 & 186.0 & 281.0 & 32.6 \\
\hline $0-3$ & Captain & 55604.0 & 4584 & 1658.0 & 151.6 & 212.0 & 26.4 \\
\hline $0-2$ & 1st Lieutenant & 41845.0 & 3487.0 & 885.6 & 115.6 & 161.0 & 20.1 \\
\hline $0-1$ & 2nd Lieutenant & 33292.9 & 2787 & 639.6 & 91.6 & 128.0 & 16.6 \\
\hline$E-9$ & Sgt. Major & 54584.0 & 4459.8 & 1950.0 & 150.0 & 210.6 & 26.2 \\
\hline$E-8$ & 1st Sgt., H. Sgt. & 45469.6 & 3789.0 & 874.6 & 125.6 & 175.0 & 21.9 \\
\hline$E-7$ & Sgt 1st Class, 5.7 & 38423.0 & 3202.9 & 739.9 & 165.0 & 148.6 & 18.5 \\
\hline$E-6$ & Staff Sgt., S.6 & 32878.6 & 2723.6 & $B 28.9$ & 99.6 & 126.8 & 15.7 \\
\hline$E-5$ & Sgt., S-5 & 27688.8 & 2367 & 532.6 & 76.0 & 168.0 & 13.3 \\
\hline$E-4$ & Corporal, S.4 & 22888 & 1997.9 & 448.9 & 83.6 & 88.6 & 11.6 \\
\hline$E-3$ & Privato 1st Class & 19823.0 & 1652. & 381.6 & 54.0 & 78.0 & 9.5 \\
\hline $\mathrm{E}-2$ & Privato & 18762.0 & 1559.0 & 360.0 & 51.6 & 72.8 & 9.6 \\
\hline
\end{tabular}


TABLE 4.2. Representative Division Training Management Costs

\begin{tabular}{|c|c|c|c|c|}
\hline Staff Position & Grade & $\begin{array}{c}\text { Data } \\
\text { Source }\end{array}$ & $\begin{array}{c}\text { Fraction of } \\
\text { Year on } \\
\text { Training } \\
\text { Management } \\
\end{array}$ & $\begin{array}{l}\text { Annual } \\
\text { Costs }\end{array}$ \\
\hline $\begin{array}{l}\text { AC of } S, G=1 \\
\text { Assistant }\end{array}$ & $\begin{array}{l}05 \\
\text { E9 }\end{array}$ & $\begin{array}{l}F M-101-5 \\
F M-101-5\end{array}$ & $\begin{array}{l}0.09 \\
0.09\end{array}$ & $\begin{array}{r}\$ 7,423.00 \\
4,913.00\end{array}$ \\
\hline $\begin{array}{l}\text { AC of } S, G-2 \\
\text { Assistant }\end{array}$ & $\begin{array}{l}05 \\
02\end{array}$ & $\begin{array}{l}\text { FM-101-5 } \\
F M-101-5\end{array}$ & $\begin{array}{l}0.05 \\
0.09\end{array}$ & $\begin{array}{l}4,124.00 \\
3,766.00\end{array}$ \\
\hline $\begin{array}{l}\text { G-3 Training } \\
\text { Division Training Resource Manager } \\
\text { G-3 Assistant } \\
\text { Assistant } \\
\text { G-3 Training NCO In Charge } \\
\text { Training Inspector } \\
\text { Division Anmunition NCO } \\
\text { Clerk Typist } \\
\text { Oraftsman } \\
\text { SSG }\end{array}$ & $\begin{array}{l}04 \\
03 \\
03 \\
03 \\
\text { E8 } \\
\text { E7 } \\
\text { E8 } \\
\text { E4 } \\
\text { E3 } \\
\text { E6 }\end{array}$ & $\begin{array}{l}\text { ID\# } 302 \\
\text { ID\# } 301 \\
\text { ID\#204 } \\
\text { ID\#204 } \\
\text { ID\# } 201 \\
\text { ID\#712 } \\
\text { ID\#205 } 205 \\
\text { ID\#202 } \\
\text { ID\# } 203 \\
\text { FM-101-5 }\end{array}$ & $\begin{array}{l}0.96 \\
0.88 \\
0.46 \\
0.46 \\
0.36 \\
0.98 \\
0.94 \\
0.56 \\
0.56 \\
0.29\end{array}$ & $\begin{array}{r}65,100.00 \\
48,403.00 \\
25,302.00 \\
25,302.00 \\
16,369.00 \\
37,655.00 \\
42,741.00 \\
12,816.00 \\
11,101.00 \\
9,474.00\end{array}$ \\
\hline $\begin{array}{l}A C \text { of } S, G 4 \\
\text { Assistant }\end{array}$ & $\begin{array}{l}05 \\
\text { E9 }\end{array}$ & $\begin{array}{l}F M-101-5 \\
F M-101-5\end{array}$ & $\begin{array}{l}0.11 \\
0.11\end{array}$ & $\begin{array}{l}9,073.00 \\
6,004.00\end{array}$ \\
\hline $\begin{array}{l}\text { Comptroller (a) } \\
\text { ACcounts officer } \\
\text { TMACS NCOIC }\end{array}$ & $\begin{array}{l}05 \\
02 \\
\text { E5 }\end{array}$ & $\begin{array}{l}\text { ID\#A } \\
\text { ID\#A } \\
\text { ID\#A }\end{array}$ & $\begin{array}{l}0.25 \\
0.25 \\
0.50\end{array}$ & $\begin{array}{l}20,620.00 \\
10,461.00 \\
13,843.00\end{array}$ \\
\hline $\begin{array}{l}\text { Division Chemical } \\
\text { NBC TNG NCO }\end{array}$ & $\begin{array}{l}05 \\
\text { E7 }\end{array}$ & $\begin{array}{l}F M-101-5 \\
F M-101-5\end{array}$ & $\begin{array}{l}0.17 \\
0.50\end{array}$ & $\begin{array}{l}14,022.00 \\
19,212.00\end{array}$ \\
\hline Total Annual Man-Years Per Division & & $=$ & 8.66 & \\
\hline Total Annual Cost Per Division & & $=$ & & $\$ 407,724.00$ \\
\hline (a) Data For Accounts Officer Used & & & & \\
\hline
\end{tabular}


TABLE 4.3. Representative Brigade Training Management Costs

Individual

Staff Position

Brigade Commander

S-3

Assistant $\mathrm{S}-3$

S-3 Operations Assistant

Assistant S-3 Air

Chemical officer

Operations Sergeant

NBC OPNS/Staff NCO

Training NCO

Operations Assistant

Ammo Officer (Special Duty)

Ammo NCO (Special Duty)

Training Schedules (Special Duty)

Master Gunner (Special Duty)

Schools NCO (Special Duty)

Total Annual Man Years Per Brigade Total Annual Cost Per Brigade
Fraction of

Year on

Training

Grade Source Management

0.28

0.40

0.75

0.17

0.62

0.59

0.61

0.29

0.43

0.29

0.88

0.47

0.47

0.88

0.88

Annual.

Custs

$\$ 27.497 .00$

27.125 .00

$41,253.00$

9.351.00

$34,102.00$

$32,452.00$

$33,296.00$

11.143 .00

$11,905.00$

$6,637.00$

$36,824.00$

$18,059.00$

$18,059.00$

$24,364.00$

$28,750.00$

8.01

$\$ 360,817.00$

IABLE 4.4. Representative Battalion Training Management Cost

\begin{tabular}{lc}
\multicolumn{1}{c}{$\begin{array}{c}\text { Individual } \\
\text { Staff Position }\end{array}$} & Grade \\
\cline { 1 - 1 } Battalion Commander & 05 \\
S-3 & 04 \\
S-3 Air & 03 \\
S-3 - Assistant & 03 \\
Chemical Officer & 02 \\
Operations Sergeant & $E 8$ \\
Operations Assistant & E6 \\
Fire Direction Officer & 03 \\
Training NCO & E6 \\
Operations Officer & 02 \\
Schools NCO & E6 \\
Assist. Security Manager & E6 \\
Supply Sergeant & E7 \\
Chemical NCO & E7 \\
\multicolumn{2}{c}{ Total Annual Man-Years Per Battalion } \\
Total Annual Cost Per Battalion
\end{tabular}

Fraction of

Year on

Training

Management

4nnual

Source

0.30

FM 101-5

0.48

ID $\$ 719,723,726$

0.76

ID\#718, 721

0.38

ID 403

ID\#216，103，105

0.56

0.57

ID\#212

0.19

ID\#104

0.84

ID\#713

0.59

ID 102,218

0.84

ID\#402

0.04

$\begin{array}{ll}7 & \text { ID\#714 } \\ 7 & \text { ID } \# 401\end{array}$

0.15

0.09

sosts

$24,744.00$

$32,550.00$

$41,803.00$

$20,901.00$

$23,433.00$

$13,641.00$

$18,622.00$

$10,451.00$

$27,443.00$

$24,689.00$

$27,443.00$

$1,307.00$

$5,763.00$

$3,458.00$

Total Annual Cost Per Battalion

$=6.09$

$=$

$\$ 276,248.00$ 
IABLE 4.5. Representative Company Training Management Cost

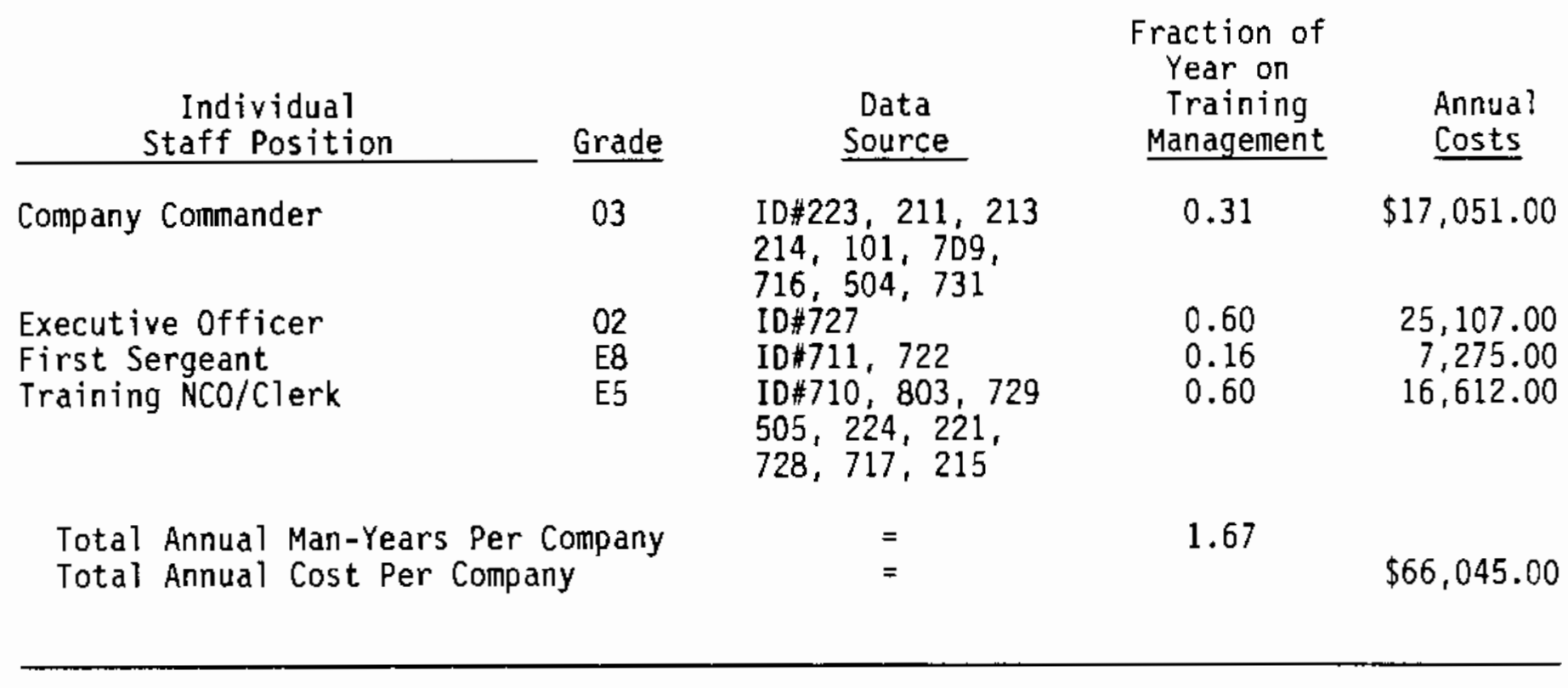

IABLE 4.6. Representative Unit Training Management Costs

$\begin{array}{lcc}\text { Unit } & \begin{array}{c}\text { Annual Man-Years } \\ \text { Required }\end{array} & \begin{array}{c}\text { Annual } \\ \text { Labor Cost }\end{array} \\ \text { Division } & 8.66 & \$ 407,724 \\ \text { Brigade } & 8.01 & 360,817 \\ \text { Battalion } & 6.09 & 276,248 \\ \text { Company } & 1.67 & 66,045\end{array}$




\subsubsection{Training Management System Labor Costs for the Active Army}

Army-wide labor costs for the current TM system were estimated by extrapolating the costs for the 9ID (MTZ) units to all active units. The 9ID (MTZ) interview process resulted in the determination of division, brigade, battalion, and company TM labor requirements. These unit labor requirements were multiplied by the total number of each unit Army-wide to determine total system costs. Using 1986 Army Greenbook data, the total number of divisions and brigades were estimated and are shown in Table 4.7. It should be noted that various Army support groups and regiments were treated as brigades, which is adequate for the purpose of this study.

To calculate the total number of companies and other echelons in the divisions and brigades shown in Table 4.7, a representative division and brigade were developed. The breakdown of the representative division and brigade is shown in Table 4.8 .

Multiplying the total number of divisions and brigades presented in Table 4.7 by the number of companies and other echelons contained within each, as presented in Table 4.8, yields the total number of units for the active Army, which will be used in subsequent calculations. These are shown in Table 4.9. There are 18 active Army divisions and 37 separate urigades/regiments, for an approximate brigade count of $37+18(3)=91$

TABLE 4.7. Army-Wide Divisions and Brigades

CONUS Fielding Requirements:

12.0 Divisions

13.0 Separate Brigades and Regiments

Pacific:

2.0 Divisions

2.0 Support Groups

Europe:

4.0 Divisions

22.0 Brigades, Regiments, and Groups 
TABLE 4.8. Breakdown of Representative Division and Brigade

Representative Division:

$\begin{array}{ll}\text { 3.0 Maneuver Brigades } & =9 \text { Battalions (5 Companies Each) } \\ & 3 \text { HHCs } \\ 1.0 \text { DISCOM } & 4 \text { Battalions (3 Companies Each) } \\ 1.0 \text { Divarty } & 1 \text { HHB } \\ & 4 \text { Battalions (5 Batteries Each) } \\ 1.0 \text { Signal Battalion } & =5 \text { CHB TGT Acquisition Battery } \\ 1.0 \text { AIRDEF Battalion } & =5 \text { Companies } \\ 1.0 \text { Engr. Battalion } & =5 \text { Companies } \\ 1.0 \text { Mil. Intel. Bn } & =5 \text { Companies } \\ 1.0 \text { Cav. Squadron } & =4 \text { Troops } \\ 1.0 \text { M.P. Company } & =1 \text { Company } \\ 1.0 \text { A.G. Company } & =1 \text { Company }\end{array}$

Representative Division Is Approximately Equivalent To:

3.0 Brigades

22.0 Battalions

108.0 Companies

Representative Brigade Is Approximately Equivalent To:

$1.0 \mathrm{HHC}$

3.0 Battalions

15.0 Companies

TABLE 4.9. Total Active Army Units

$$
\text { Unit } \quad \text { Number }
$$

Division

Brigade/Regiments/Groups

Battalion

Company
18.0

91.0

507.0

$2,536.0$ 
brigades, as shown by Table 4.9. Similarly, the total number of battalions is calculated by taking the number of battalions in divisions $(18 \times 22=$ $396)$ and adding the number of battalions in separate brigades/groups/regiments ( $37 \times 3=111)$, for a total battalion count of 507 . The number of companies is obtained by adding the number of companies in divisions $(18 \times 108=1,944)$ and adding the number of battalions in separate brigades/groups/ regiments ( $37 \times 16=592)$, for a total company count of 2,536 , as shown in Table 4.9.

\subsubsection{Army-Wide Manual Training Management Cost}

Combining the representative unit TM costs contained within Section 4.2.1 with the total number of units (presented in Section 4.2.2) results in a total Active Army cost estimate. This cost estimate is shown in Table 4.10 .

TABLE 4.10. Annual Active Army Manual Training Management Cost

\begin{tabular}{l}
\multicolumn{1}{c}{ Unit } \\
\hline Divisions \\
Brigades \\
Battalions \\
Companies
\end{tabular}

Total

\section{Annual Labor Requirements}

Man-Y̌ears

156

729

3,088

4,235

8,208 cost

$\$ 7,339,032$

$32,834,347$

$140,057,736$

$167,490,120$

$347,721,235$

The total annual cost of TM to the U.S. Army is approximately 8,200 manyears, which represent $\$ 348$ million dollars in labor. The magnitude of training management costs is apparent. Forty-eight percent of all training management costs occurred at the company level and forty percent of all costs occurred at the battalion level. Brigade- and division-level training management costs together represent 12 percent of total cost. 


\subsubsection{Training Management Cost by Task}

To assess areas of the TM process where advantages might be gained through automation, a job-task cost analys is of TM functions was conducted using the eight TM tasks identified in the doctrinal study:

1. Identify unit missions, goals, METL and enabling tasks

2. Develop training objectives, tasks for training, and training program

3. Forecast requirements

4. Long-range guidance

5. Short-range guidance

6. Near-term guidance

7. Issue training schedule

8. Determine training status

Respondents were asked to initially indicate what portion of their total job time was devoted to TM. The respondents were then asked to indicate in which of the eight tasks they worked, and what portion of their TM time was devoted to each task. A sample response form is shown in Figure 4.1. The example respondent who completed this form spenis 22 percent of his working year on TM. Within that 22 percent, roughly 10 percent of the TM time is spent planning unit missions. He spends roughly 30 percent forecasting requirements.

The survey requested a breakdown of each TM task into specific types of work. Each respondent was asked to specify the portion of the TM task spent on each of seven types of work activity:

- Discussing and Planning

- Getting Documents and Information

- Copying and Compiling

- Analyzing and Interpreting

- Computing Numbers

- Preparing Documents

- Supervising, Directing, Leading 
Check If

Done

$X$ 1. Identify Unit Missions, Goals, METL and Enabling Tasks

$x$ 2. Develop Training Objectives, Tasks for Training, and Training Program

$x$ 3. Forecast Requirements

4. Long-Range Guidance

$x$

5. Short-Range Guidance

6. Near-Term Guidance

7. Issue Training Schedule

8. Determine Training Status

$x$
Frequency

(Daily, Weekly, Monthly, Quarterly, Etc.)

Q-1

10

Q-1

10

$W-5$

30

D-1

15

D-1

15

D-1

15

$M-1$

5

FIGURE 4.1 Breakdown of Training Management Time Requirements (Example Data) 
An example of this work breakdown by task and work type is shown in Figure 4.2. In this case it can be seen that of the total time the respondent spends on Task 3 - Forecasting, 60 percent of that time is invoived in "0iscussion and Planning." This is equivalent to about 18 percent of his total TM time $(0.30$ multiplied by 0.60$)$ and about 4 percent of his total work year (0.18 multiplied by 0.22$)$.

This work breakdown by task has been conducted for all respondents in the survey. The data have been aggregated by command echelon, and are displayed in Tables 4.11 through 4.14. The results of this work breakdown by TM task are a set of data indicating the time that respondents at each level of command devote to TM, and the amount of time they spend doing each type of work to accomplish a given task. These tables provide an initial means for determining what job tasks might benefit most from automation at each command level. Some clear differences in the type of work and the job tasks emerged at each level.

The breakdown of division training management cost by task is shown in Table 4.11. For the individuals interviewed, 38 percent of the time spent at the division level was for Task 3 - Forecasting Requirements. The task requiring the next highest level of staff time is Task 7 - Issue Training Schedule, which accounts for 10 percent of division-level staff time.

Similarly, the breakdown of brigade-level TM labor requirements by task is shown in Table 4.12. Approximately 30 percent of all brigade-level labor is spent on Task 3 - Forecasting Requirement activities. The next highest task is Task 1 - Identifying Unit Missions, which accounts for 6 percent of brigade-level TM labor.

Battalion-level TM costs are shown in Table 4.13. As with division and brigade, Task 3 requires the most training management labor, an average of 11 percent.

Company-level costs are shown in Table 4.14. At this level, TM time is divided almost equally among all tasks. 


\begin{tabular}{|c|c|c|c|c|c|c|c|c|}
\hline $\begin{array}{c}\text { Cheek } \\
\text { One }\end{array}$ & Task & $\begin{array}{l}\text { Discussing } \\
\text { Planning }\end{array}$ & $\begin{array}{l}\text { Getting } \\
\text { Documents } \\
2 \text { Info. } \\
\end{array}$ & $\begin{array}{l}\text { Copying } \\
\text { Compiling }\end{array}$ & $\begin{array}{l}\text { Analyzing } \\
\text { Interpreting }\end{array}$ & $\begin{array}{c}\text { Computing } \\
\text { Numbers } \\
\end{array}$ & $\begin{array}{l}\text { Preparing } \\
\text { Docuinents }\end{array}$ & $\begin{array}{l}\text { Supervising } \\
\text { Directing, } \\
\text { Leading } \\
\end{array}$ \\
\hline & $\begin{array}{l}\text { 1. Identify Unit Missions, } \\
\text { Coals, UETL and } \\
\text { Enabling Tasks }\end{array}$ & 36 & 10 & 10 & 5 & 5 & 36 & 10 \\
\hline & $\begin{array}{l}\text { 2. Develop Training Objec- } \\
\text { tives, Tasks for Training, } \\
\text { and Training Program }\end{array}$ & 25 & 25 & 5 & 10 & 5 & 15 & 15 \\
\hline & 3. Forecast Requirenents & 68 & 10 & 5 & 5 & 10 & 10 & 5 \\
\hline & 4. Long-Range Guidance & & & & & & & \\
\hline & 5. Short-Range Guidance & 30 & 16 & 30 & 5 & 5 & 18 & 10 \\
\hline & 6. Near-Tors Guidance & 36 & 10 & 36 & 5 & $\mathbf{S}$ & 10 & 10 \\
\hline & 7. Issue Training Schedule & 10 & 10 & 30 & 30 & 5 & 10 & 5 \\
\hline & 8. Deteraine Training Status & 70 & 5 & 5 & 5 & 5 & 5 & $\Gamma$ \\
\hline & A. & & & & & & & \\
\hline & B. & & & & & & & \\
\hline & c. & & & & & & & \\
\hline
\end{tabular}

FIGURE 4.2. Breakdown of Training Management Time Requirements (Example Data) 
TABLE 4.11. Breakdown of Division Training Management Labor by Task (In Proportion of Duty Time)

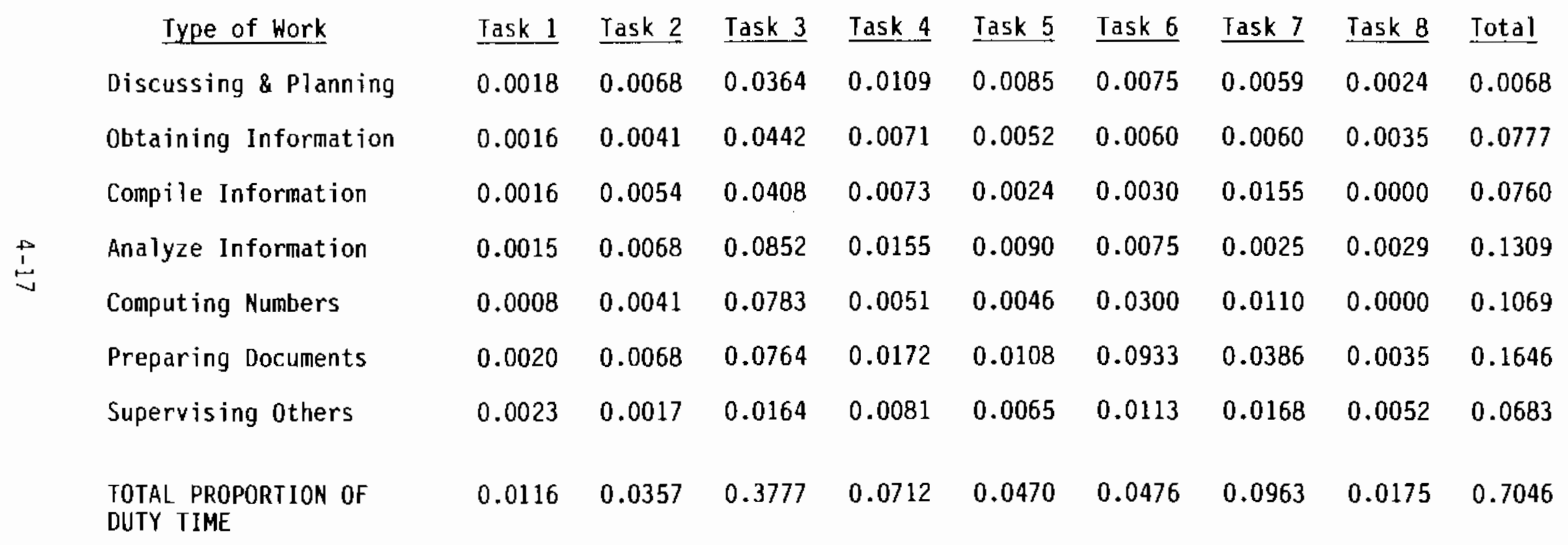


TABLE 4.12. Brigade Training Management Labor by Task (In Proportion of Duty Time)

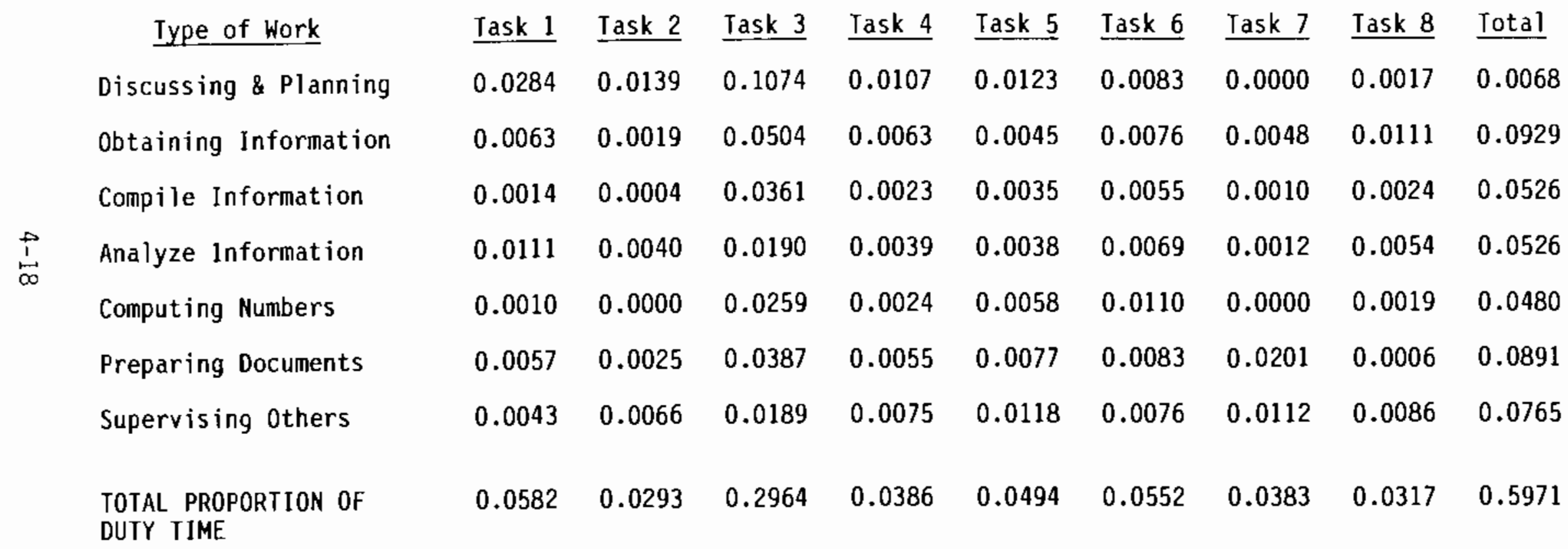


TABLE 4.13. Battalion Training Management Labor by Task (In Proportion of Duty Time)

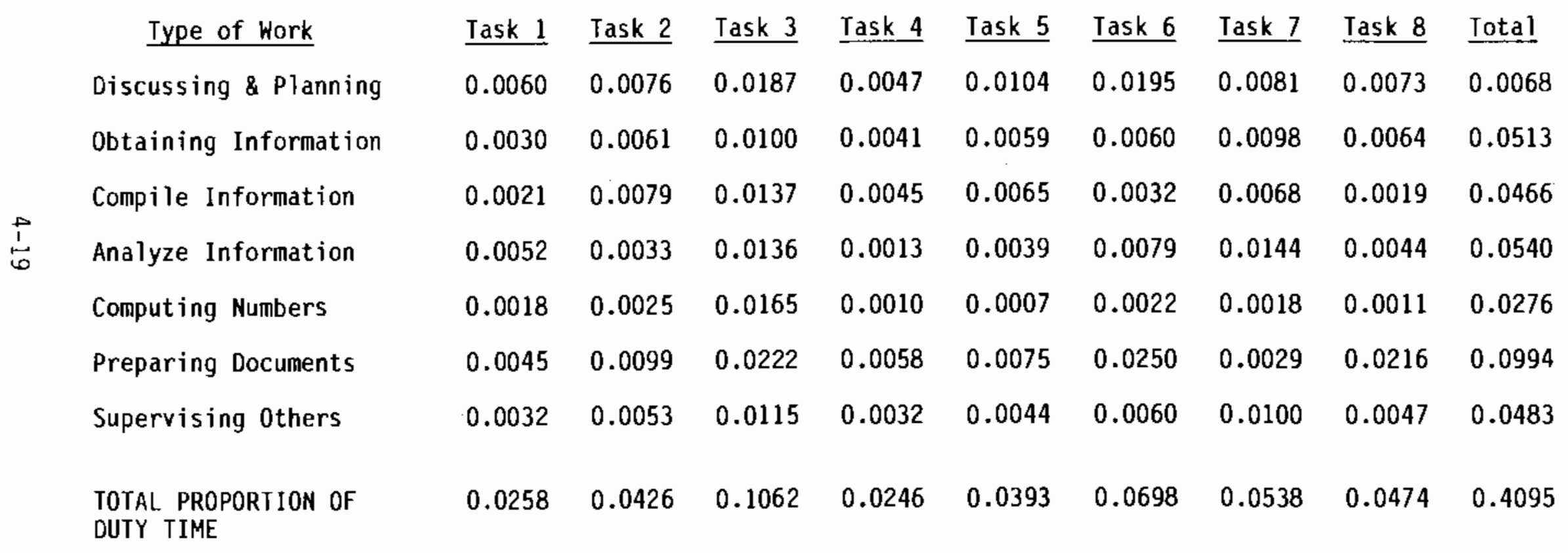


TABLE 4.14. Company Level Training Management Labor by Task (In Proportion of Duty Time)

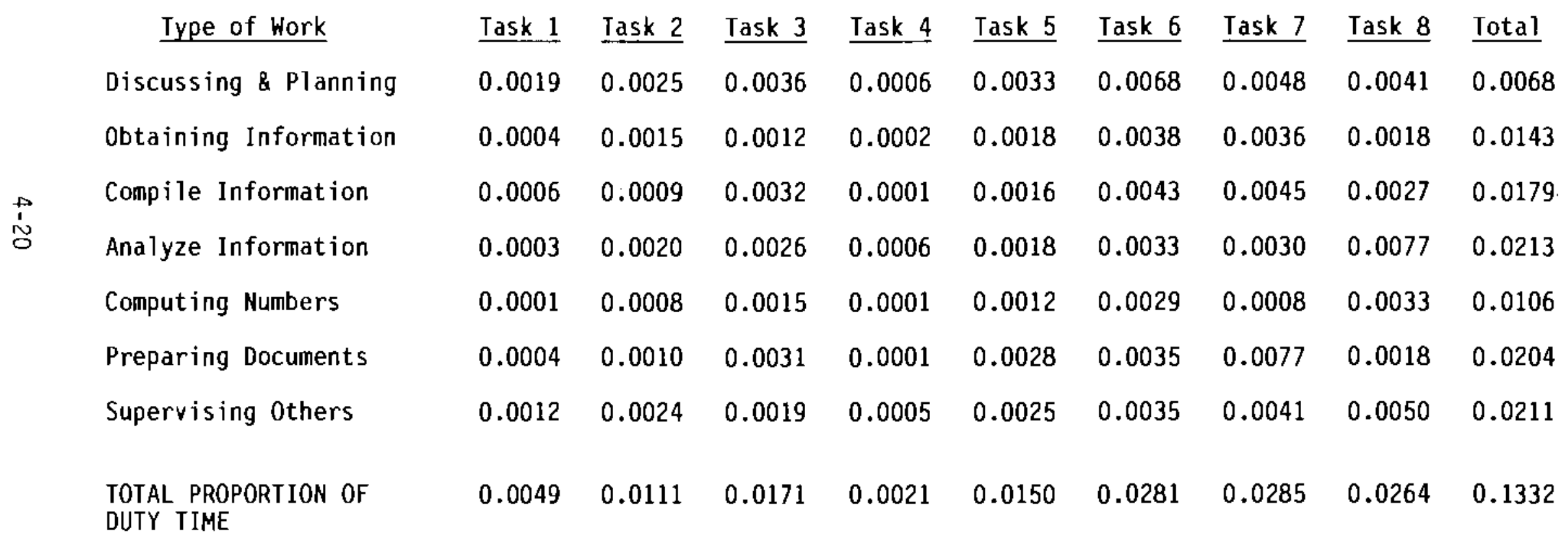




\subsection{AUTOMATION IMPACT ON TRAINING MANAGEMENT}

\subsubsection{Automation Impact on Type of Work}

The work type by task breakdown technique is the first step in isolating the aspects of TM that are most likely to show significant benefits from automation. The next step is to apply automation impact factors to the type of work/TM task matrix. An automation impact factor is an estimate of the overall change in labor requirements that would result by introducing automation to accomplish the work that is now done manually. These factors can be used to calculate the net change in labor cost that could be expected as a result of automating various tasks.

The automation impact factors used in this analysis are based on labor reduction rates reported in civilian applications that are generally comparable. In two instances, an ITMS system performance specification was used. The automation impact factors in each work task area are as follows:

- Planning and Discussion: 15 percent

- Getting Documents and Information: 15 percent

- Copying and Compiling: 75 percent

- Analyzing and Interpreting: 15 percent

- Computing Numbers: 100 percent

- Preparing Documents: 75 percent

- Supervising, Directing and Leading: No Change

These labor reduction factors are based on a survey of the literature on impacts of office automation and management information systems. Although the measured changes in productivity vary widely depending on the type of business being automated (Tapscott, 1982; Alexander, 1985), general productivity increases for most clerical activities increased between 15 percent (Booz, Allen, Hamilton, 1980) and 100 percent (Strassman, 1986). The 75 percent reduction in copying and compiling, and document preparation is based on the functional specification for the ITMS to reduce paperflow by 75 percent.

An example of how these labor reduction factors might potentially affect a particular respondent's work load is depicted in Table 4.15. This 


\section{TABLE 4.15. Example Calculations for Determining Automated Training Management System Labor Requirements}

Manual system annual labor requirements

for captain using example data $\quad=22$ percent of year

\begin{tabular}{|c|c|c|c|c|c|c|c|c|c|}
\hline $\begin{array}{c}\text { Check } \\
\text { One } \\
\end{array}$ & Task & $\begin{array}{l}\text { Discyssing } \\
\text { L Planning }\end{array}$ & $\begin{array}{l}\text { Cotting } \\
\text { Documents } \\
\text { Info. } \\
\end{array}$ & $\begin{array}{l}\text { Copying } \\
\text { Conpiling }\end{array}$ & $\begin{array}{l}\text { Analyzing } \\
\text { Interpreting }\end{array}$ & $\begin{array}{l}\text { Computing } \\
\text { Nunbers } \\
\end{array}$ & $\begin{array}{l}\text { Preparing } \\
\text { Documents }\end{array}$ & $\begin{array}{l}\text { Supervising, } \\
\text { Directing, } \\
\text { Leading } \\
\end{array}$ & $\begin{array}{l}\text { Time } \\
\text { Recuirement } \\
\text { (fiercent) } \\
\end{array}$ \\
\hline & $\begin{array}{l}\text { 1. Identify Unit Missions, } \\
\text { Coais, METL and } \\
\text { Enabling Tasks }\end{array}$ & $30(.85)$ & $10(.85)$ & $10(.25)$ & $5(.85)$ & $5(0)$ & $30(.25)$ & $19(1)$ & 58.3 \\
\hline & $\begin{array}{l}\text { 2. Develop Training objec- } \\
\text { tives, Tasks for Training, } \\
\text { and Training Progran }\end{array}$ & $25(.85)$ & $25(.85)$ & $5(.25)$ & $10(.85)$ & $5(\bar{b})$ & $15(.25)$ & $15(1)$ & 71.0 \\
\hline & 3. Forecast Requiresents & $60(.85)$ & $16(.85)$ & $5(.25)$ & $5(.85)$ & $5(0)$ & $10(.25)$ & $5(1)$ & 72.5 \\
\hline & 4. Long-Range Guidance & & & & & & & & \\
\hline & 5. Short-Range Guidance & $38(.85)$ & $19(.85)$ & $36(.25)$ & $5(.85)$ & $5(\theta)$ & $18(.25)$ & $18(1)$ & 58.25 \\
\hline & 8. Hear-Tern Guidance & $30(.85)$ & $10(.85$ & $30(.25)$ & $5(.85)$ & $5(\theta)$ & $10(.25)$ & $10(1)$ & 58.25 \\
\hline & 7. Issue Training Schedule & $10(.85)$ & $10(.85)$ & $35(.25)$ & $30(.85)$ & $5(8)$ & $16(.25)$ & $5(1)$ & 57.5 \\
\hline & 8. Deteruine Training Status & $70(.85)$ & $5(.85)$ & $5(.25)$ & $5(.85)$ & $5(0)$ & $5(.25)$ & $5(1)$ & 75.5 \\
\hline
\end{tabular}

A.

B.

c. 
IABLE 4.15. (cont.)

\begin{tabular}{|c|c|c|c|c|}
\hline $\begin{array}{l}\text { Check } \\
\text { One } \\
\end{array}$ & Task & $\begin{array}{l}\text { Porcent } \\
\text { TN Tine }\end{array}$ & $\begin{array}{l}\text { Fraction Required } \\
\text { Due to Autonation }\end{array}$ & $\begin{array}{l}\text { Autonated System } \\
\text { Tine Requirenent } \\
\text { (percent) } \\
\end{array}$ \\
\hline & $\begin{array}{l}\text { 1. Identify Unit Missions, } \\
\text { Coals, WEIL and } \\
\text { Enabling Tasks }\end{array}$ & 16 & $(.583)$ & 5.83 \\
\hline & $\begin{array}{l}\text { 2. Dovolop Training Objec- } \\
\text { tives, Tasks for Training, } \\
\text { and Training Progran }\end{array}$ & 10 & $(.71)$ & 7.1 \\
\hline & 3. Forecast Requirenents & 30 & $(.725)$ & 21.8 \\
\hline & 4. Long-Rango Guidanco & & & \\
\hline & 5. Short-Range Guidance & 15 & $(.583)$ & 8.75 \\
\hline & 8. Near-Tern Guidance & 15 & $(.583)$ & 8.75 \\
\hline & 7. Issue Training Schedulo & 15 & $(.575)$ & 8.63 \\
\hline & 8. Deteraine Training Status & 5 & $(.755)$ & $\frac{3.78}{84.84}$ \\
\hline
\end{tabular}

Autonated Systen Annual Labor Requirenent for Captain using Exauplo Data $=(22)(.65)=14.3$ percent of year 
respondent spends 22 percent of this total duty time on TM without automation support. His specific responsibilities are arrayed in the table with the amount of time he spends performing specific types of work (e.g., copying and compiling) to accomplish his duties. When the automation impact factors are applied to each cell of the matrix, the net change in the amount of time this person spends on TM can be calculated as a function both of his tasks and the type of work performed to complete the jobs.

In this example, automation will reduce the time needed to do the same job from 22 percent of annual time to 14.3 percent. If this respondent is an $0-3$, the savings of 0.08 man-year would be $\$ 4,400$.

Using this approach with the aggregated data from each echelon, automate: TM system labor requirements were calculated for division through company levels, and are presented in Tables 4.16 through 4.19. Automated system costs are presented as a percentage of manual system costs, i.e., 1.00 the percentage reduction due to automation. Expected costs for a division using an automated training management system are shown by Table 4.16. Division-level annual training management costs for an automated system are reduced from $\$ 407,000$ to $\$ 218,000$ per division. This $\$ 199,000$ reduction per division represents a 48 percent reduction in direct labor requirements. Brigade-level automated training management costs are presented in Table 4.17. Annual costs are reduced from $\$ 361,000$ to $\$ 241,000$ per brigade, representing a 33 percent reduction in labor requirements. Similarly, battalion-level training management costs for an automated system are presented in Table 4.18. Annual costs per battalion are reduced from $\$ 276,000$ to $\$ 169,000$ per year, representing a 39 percent reduction in labor requirements. Company TM costs, shown in Table 4.19, are reduced from $\$ 66,000$ to $\$ 46,000$, representing a 30 percent savings.

Combining unit training managenent costs for an automated system with the Army-wide fielding requirements presented in Section 4.1 .2 yields the total expected direct labor costs, which are presented in Table 4.20. Direct labor operating costs for an automated system total $\$ 227$ million pe:" year. An automated system would require 5,683 man-years of labor per year. This represents a savings of $\$ 121$ million per year in direct labor expenditures as compared to the current manual training management system. 
TABLE 4.16. Automated System Division Training Management Costs

\begin{tabular}{|c|c|c|c|c|c|}
\hline & & Manua $7 S_{3}$ & ystem & Automated & System \\
\hline $\begin{array}{c}\text { Individual } \\
\text { Staff Position }\end{array}$ & $\underline{\text { Grade }}$ & $\begin{array}{c}\text { Fraction of } \\
\text { Year on } \\
\text { Training } \\
\text { Management } \\
\end{array}$ & $\begin{array}{l}\text { Annual } \\
\text { Cost } \\
\end{array}$ & $\begin{array}{l}\text { Percentage } \\
\text { of Manual } \\
\text { System Cost }\end{array}$ & $\begin{array}{c}\text { Annual } \\
\text { Cost } \\
\end{array}$ \\
\hline $\begin{array}{l}A C \text { of } S, G 1 \\
\text { Assistant }\end{array}$ & $\begin{array}{l}05 \\
\text { E9 }\end{array}$ & $\begin{array}{l}0.09 \\
0.09\end{array}$ & $\begin{array}{r}\$ 7,423 \\
4,913\end{array}$ & $\begin{array}{l}0.54^{\star} \\
0.54^{\star}\end{array}$ & $\begin{array}{r}\$ 4,008 \\
2,653\end{array}$ \\
\hline $\begin{array}{l}A C \text { of } S, G 2 \\
\text { Assistant }\end{array}$ & $\begin{array}{l}05 \\
02\end{array}$ & $\begin{array}{l}0.05 \\
0.09\end{array}$ & $\begin{array}{l}4,124 \\
3,766\end{array}$ & $\begin{array}{l}0.54^{\star} \\
0.54^{\star}\end{array}$ & $\begin{array}{l}2,227 \\
2,034\end{array}$ \\
\hline $\begin{array}{l}\text { G-3 - Training } \\
\text { Division Training Resource Manager } \\
\text { G-3 - Assistant } \\
\text { Assistant } \\
\text { G-3 - Training NCO in Charge } \\
\text { Training Inspector } \\
\text { Division Ammunition NCO } \\
\text { Clerk Typist } \\
\text { Draftsman } \\
\text { SSG }\end{array}$ & $\begin{array}{l}04 \\
03 \\
03 \\
03 \\
\text { EB } \\
\text { E7 } \\
\text { EB } \\
\text { E4 } \\
\text { E3 } \\
\text { E6 }\end{array}$ & $\begin{array}{l}0.96 \\
0.88 \\
0.46 \\
0.46 \\
0.36 \\
0.98 \\
0.94 \\
0.56 \\
0.56 \\
0.29\end{array}$ & $\begin{array}{r}65,100 \\
48,403 \\
25,302 \\
25,302 \\
16,369 \\
37,655 \\
42,741 \\
12,816 \\
11,101 \\
9,474\end{array}$ & $\begin{array}{l}0.68 \\
0.5 \\
0.54 \\
0.54^{\star} \\
0.75 \\
0.48 \\
0.3 \\
0.54^{\star} \\
0.54^{\star} \\
0.54^{\star}\end{array}$ & $\begin{array}{r}44,268 \\
24,202 \\
13,663 \\
13,663 \\
12,277 \\
18,074 \\
12,822 \\
6,921 \\
5,995 \\
5,116\end{array}$ \\
\hline $\begin{array}{l}A C \text { of } S, G 4 \\
\text { Assistant }\end{array}$ & $\begin{array}{l}05 \\
\text { E9 }\end{array}$ & $\begin{array}{l}0.11 \\
0.11\end{array}$ & $\begin{array}{l}9,073 \\
6,004\end{array}$ & $\begin{array}{l}0.54^{\star} \\
0.54^{\star}\end{array}$ & $\begin{array}{l}4,899 \\
3,242\end{array}$ \\
\hline $\begin{array}{l}\text { Comptroller } \\
\text { ACcounts officer } \\
\text { TMACS NCOIC }\end{array}$ & $\begin{array}{l}05 \\
02 \\
\text { E5 }\end{array}$ & $\begin{array}{l}0.25 \\
0.25 \\
0.50\end{array}$ & $\begin{array}{l}20,620 \\
10,461 \\
13,843\end{array}$ & $\begin{array}{l}0.54^{\star} \\
0.54^{\star} \\
0.54^{\star}\end{array}$ & $\begin{array}{r}11,135 \\
5,649 \\
7,475\end{array}$ \\
\hline $\begin{array}{l}\text { Division Chemical } \\
\text { NBC TNG NCO }\end{array}$ & $\begin{array}{l}05 \\
\text { E7 }\end{array}$ & $\begin{array}{l}0.17 \\
0.50\end{array}$ & $\begin{array}{l}14,022 \\
19,212\end{array}$ & $\begin{array}{l}0.54^{\star} \\
0.54^{\star}\end{array}$ & $\begin{array}{r}7,572 \\
10,374\end{array}$ \\
\hline $\begin{array}{l}\text { Total Annual Man-Years per } D \\
\text { Total Annual Cost per Divisi } \\
\text { * } 0.54 \text { value used is the av } \\
\text { (1 - \% Reduction Due to } A \\
\text { value calculated from dat } \\
\text { division personnel. }\end{array}$ & $\begin{array}{l}\text { ivision = } \\
\text { on }= \\
\text { erage } \\
\text { utomation } \\
\text { a for }\end{array}$ & $\begin{array}{l}=8.66 \\
=8.6\end{array}$ & $\$ 407,724$ & $4.7^{\star \star}$ & $\$ 218,269$ \\
\hline ** Calculated by $(.54)(8.66)$ & & & & & \\
\hline
\end{tabular}


TABLE 4.17. Automated System Brigade Training Management Costs

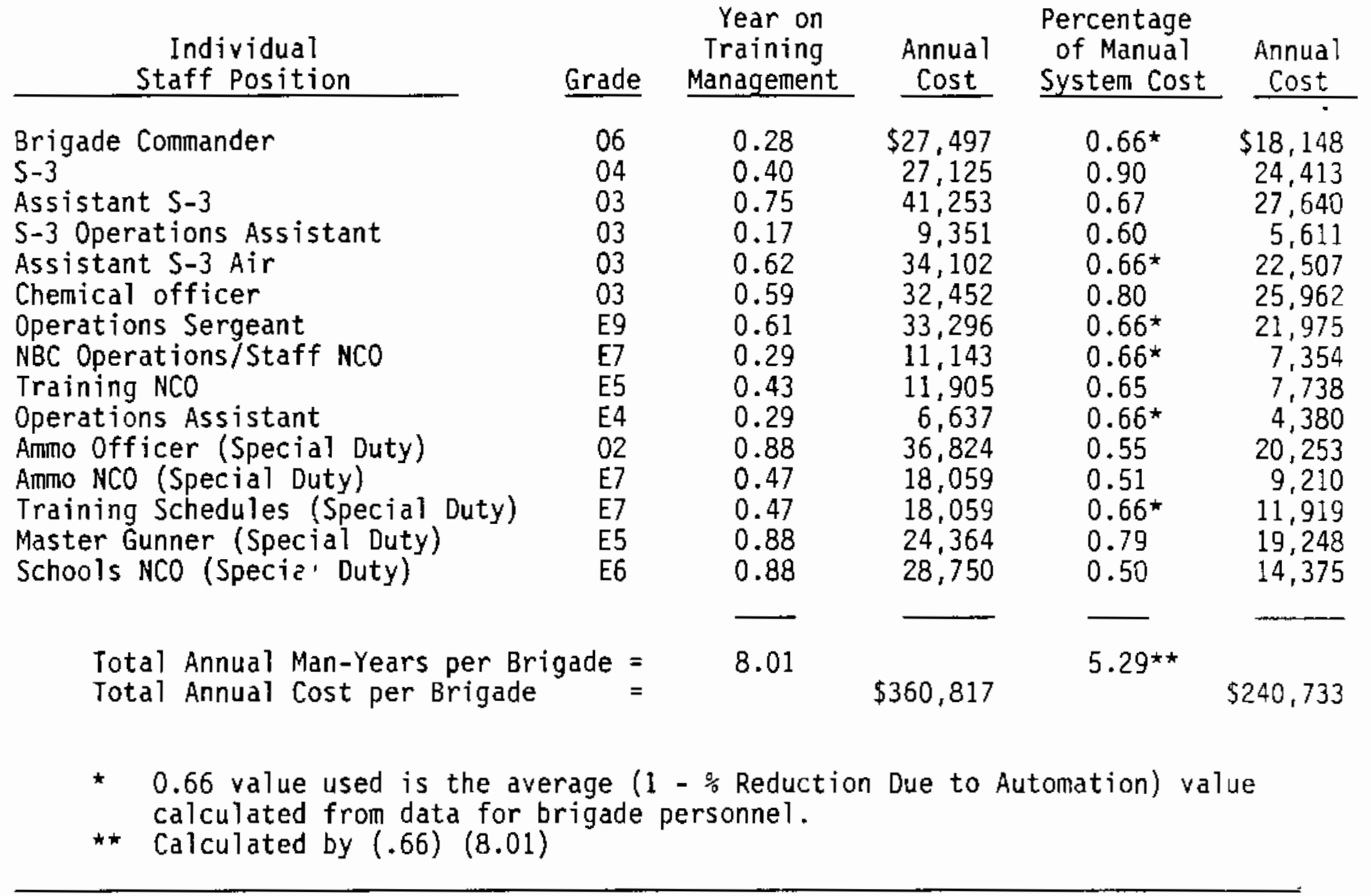


TABLE 4.18. Automated System Battalion Training Management Cost

Individual

Staff Position

Battalion Commander
S-3
S-3 - Air
S-3 - Assistant
Chemical Officer
Operations Sergeant
Operations Assistant
Fire Direction Officer
Training NCO
Operations Officer
Schools NCO
Assist. Security Manager
Supply Sergeant
Chemical NCO

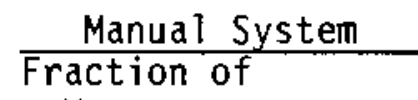

Year on

Training

$\frac{\text { Grade }}{05}$

04

03

03

02

$\mathrm{E} 8$

E6

03

E6

02

E6

E6

E7

E7
Management

0.30

0.48

0.76

0.38

0.56

0.30

0.57

0.19

0.84

0.59

0.84

0.04

0.15

0.09
Annual

$\frac{\text { Cost }}{\$ 24,744}$

32,550

41,803

20,901

23,433

13,641

18,622

10,451

27,443

24,689

27,443

1,307

5,763

3,458

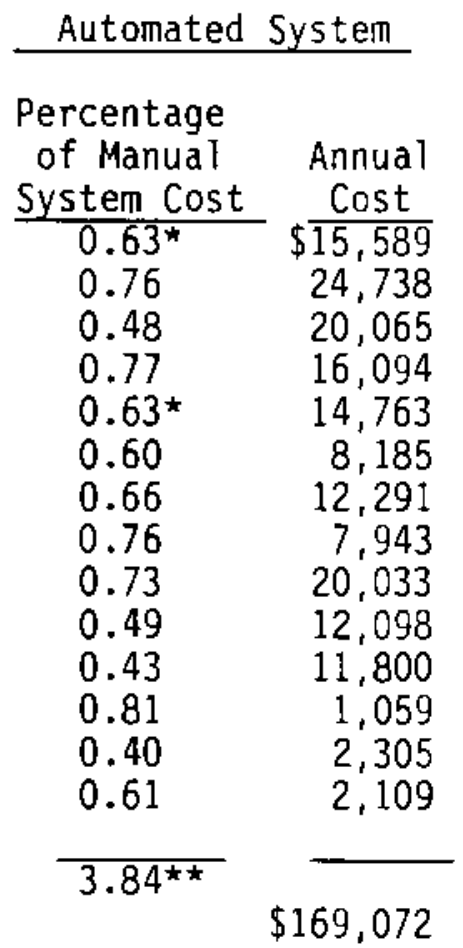

Total Annual Man-Years per Battalion =

Total Annual Cost per Battalion
6.09
$\$ 276,248$

* 0.63 value used is the average ( $1-\%$ Reduction Due to Automation) value calculated from data for battalion personnel.

** Calculated by $(.63)(6.09)$

TABLE 4.19. Automated Systems Company Level Training Management Cost

Individual Staff Position

Company Commander

Executive Officer

First Sergeant

Training $\mathrm{NCO} / \mathrm{Clerk}$

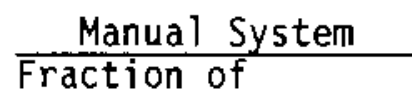

Year on

Training Annual

Grade

03

02

E8

E5

Management

Cost

Automated System

Percentage

of Manua 1

System Cost Cost

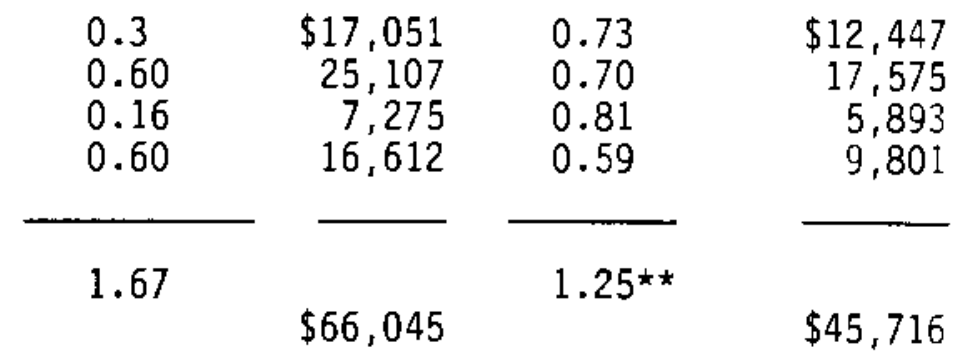

Total Annual Man-Years per Company =

Total Annual Cost per Company $=$

$\$ 66,045$

** Calculated By (1.67)(.75). The 0.75 value is the average (1 - \% reduction due to automation) value calculated from data for company personnel. 
TABLE 4.20. Labor Costs For Automated Training Management System From The Division Through Company Level

\begin{tabular}{|c|c|c|c|c|}
\hline \multirow[b]{2}{*}{ Unit } & \multicolumn{2}{|c|}{ Manual System } & \multicolumn{2}{|c|}{ Automated System } \\
\hline & $\begin{array}{c}\text { Annual Man-year } \\
\text { Required } \\
\end{array}$ & $\begin{array}{c}\text { Annual } \\
\text { Labor Cost }\end{array}$ & $\begin{array}{c}\text { Annual Man-Years } \\
\text { Required } \\
\end{array}$ & $\begin{array}{c}\text { Annual } \\
\text { Labor Cost }\end{array}$ \\
\hline Division & 156 & $\$ 7,339,032$ & 85 & $\$ 3,928,842$ \\
\hline Brigade & 729 & $32,834,347$ & 481 & $21,906,703$ \\
\hline Battalion & 3,088 & $140,057,736$ & 1,947 & $85,719,504$ \\
\hline Company & 4,235 & $167,490,120$ & 3,170 & $115,935,776$ \\
\hline & 8,208 & $\$ 347,721,235$ & 5,683 & $227,490,825$ \\
\hline
\end{tabular}

\subsubsection{Summary of Labor Costs}

Aggregating the task and work type across echelons provides an overall picture of where the major labor cost savings may be anticipated if the current Army TM activities are automated. Table 4.21 shows both dollar and man-year estimates for the calculated savings resulting from automating each TM task and work type. This table highlights major automation candidates based on current workload and procedures.

Based on current practice, automation ids the greatest prospect of affecting resourcing, near-term guidance, and training schedules. Because of the preponderance of company- and battalion-level respondents in the survey, the needs of these personnel tend to skew the findings. However, in terms of total costs associated with labor, these levels have the most profound overall cost impact.

\subsubsection{Automated Training Management Equipment Cost Estimates}

Cost estimates for an automated training management system depend on the type of equipment used and on system fielding requirements. There are two major scenarios regarding equipment type. The first scenario is that a TM system will be implemented entirely on existing Army equipment (i.e., no new equipment expenditures). The second scenario regarding equipment type is that additional equipment will be purchased to house the system. 
TABLE $4.21 .^{*}$ (A) Labor Savings in Thousands of Dollars for Each

TM Task and Type of Work for Active Army Units

(B) Labor Savings in Man-Years for Each TM Task and Type of Work for Active Army Units

\begin{tabular}{|c|c|c|c|c|c|c|c|c|c|c|}
\hline & & $\begin{array}{l}\text { Identify } \\
\text { Missions }\end{array}$ & $\begin{array}{l}\text { Training } \\
\text { Qbjectives }\end{array}$ & Resourcing & $\begin{array}{l}\text { Long-Range } \\
\text { Guidance }\end{array}$ & $\begin{array}{l}\text { Short-Range } \\
\text { Guidance }\end{array}$ & $\begin{array}{l}\text { Near-Tern } \\
\text { Guidance }\end{array}$ & $\begin{array}{l}\text { Training } \\
\text { Schedule }\end{array}$ & $\begin{array}{l}\text { Trainifig } \\
\text { Status } \\
\end{array}$ & SUMS \\
\hline \multirow[t]{8}{*}{ (A) } & Discussing and Planning & 852 & 885 & 2394 & 436 & 1157 & 2144 & 1268 & 1100 & 16174 \\
\hline & Obtaining Infornation & 263 & 538 & 1163 & 287 & 836 & 1048 & 1121 & 727 & 5769 \\
\hline & Conpiling Information & 1878 & 2579 & 7712 & 1261 & 3155 & 4701 & 5655 & 2877 & 29011 \\
\hline & Analyzing Information & 371 & 528 & 1240 & 235 & 538 & 1004 & 1211 & 1599 & 6725 \\
\hline & Conputing Nunbers $s$ & 721 & 1625 & 9111 & 810 & 2655 & 4484 & 1564 & 4439 & 24608 \\
\hline & Preparing Documents & 1578 & 3159 & 9855 & 1774 & 4594 & 9865 & 8284 & 6864 & 45682 \\
\hline & Supervising Others & 8 & 6 & $\theta$ & 6 & 6 & $\forall$ & 0 & 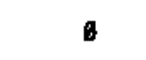 & o \\
\hline & sLes & 4855 & 9363 & 31413 & 4603 & 12129 & 22439 & 18962 & 17805 & 121309 \\
\hline \multirow[t]{8}{*}{ (日) } & Discussing and Planning & 18 & 19 & 51 & 9 & 25 & 45 & 26 & 23 & 218 \\
\hline & obtaining Information & B & 11 & 23 & 6 & 13 & 22 & 24 & 15 & 121 \\
\hline & Conpiling Inforuation & 23 & 55 & 164 & 27 & 67 & 168 & 120 & 61 & 616 \\
\hline & Analyzing Information & 8 & 11 & $2 B$ & 5 & 11 & 21 & 26 & 34 & 143 \\
\hline & Computing Numbers & 15 & 34 & 193 & 13 & 44 & 95 & 33 & 94 & 522 \\
\hline & Preparing Docunents & 33 & 67 & 209 & 38 & 97 & 192 & 174 & 146 & 958 \\
\hline & Supervising Others & $\theta$ & 0 & 0 & $\theta$ & a & $\theta$ & 8 & 6 & $\theta$ \\
\hline & suws & 104 & 199 & 669 & 102 & 262 & 482 & 409 & 381 & 2572 \\
\hline
\end{tabular}


The scenarios are further divided according to how far down the chain of command automated equipment is fielded. The first scenario assumes fielding an automated TM system from division through battalion levels. The second scenario extends automation through the company level.

Equipment costs for an automated system were obtained from the BDM Corporation. In accordance with TB 18-109, Army Automation Analys is Guidelines, the equipment cost data were translated into the three areas of life-cycle cost:

- Research and Development Cost

- Investment Cost

- Operations and Support Cost

It should be emphasized that automated equipment cost estimates are not well defined at this time. Army-wide fielding costs presented by the BOM Corporation are based on the use of equipment identical to their current ITMS prototype. These costs are based on current vendor prices for equipment needed to field an operational system incorporating all current features of the prototype.

Installation and system start-up costs are not available; thus, the cost analysis presented in the following sections concentrates on equipment and operating labor costs only.

\subsubsection{Training Management Automation Costs Using Existing Army Equipment and Dedicated Equipment}

Automation costs for fielding an automated TM system using existing equipment consist of research and development costs, software, system documentation, operator training, direct operating labor, and system maintenance costs. Only direct operator labor costs are presented in this analysis. No assumptions should be made about the comparability of functionality of the system using dedicated hardware and the system using existing equipment. (See Section 5.4 for a summary discussion of the functionality issue.) These costs for a system using existing equipment are currently estimated to differ from the dedicated hardware scenario only in the purchase of equipment. The system acquisition costs are shown in Table 4.22 on a per unit basis. 


\section{IABLE 4.22. Per Unit Equipinent And Supporting Software Costs}

For Automating Training Management (BDM Corporation) (Active Army)

Initial Acquisition Costs:

(1987 Dollars)

\begin{tabular}{|c|c|c|c|c|}
\hline Unjt & $\begin{array}{c}\text { ADPE } \\
\text { Purchase }\end{array}$ & $\begin{array}{l}\text { Comm. Equip } \\
\text { Purchase }\end{array}$ & $\begin{array}{l}\text { Software } \\
\text { Procurement }\end{array}$ & $\begin{array}{l}\text { Total } \\
\text { Initial } \\
\text { Cost }\end{array}$ \\
\hline $\begin{array}{l}\text { Division } \\
\text { Brigade } \\
\text { Battalion } \\
\text { Company }\end{array}$ & $\begin{array}{r}\$ 95,482.0 \\
40,437.0 \\
40,437.0 \\
5,870.0\end{array}$ & $\begin{array}{r}\$ 17,571.0 \\
2,521.0 \\
2,521.0 \\
166.0\end{array}$ & $\begin{array}{r}\$ 102,877.0 \\
0.0 \\
0.0 \\
0.0\end{array}$ & $\begin{array}{r}\$ 215,930.0 \\
42,958.0 \\
42,958.0 \\
6,036.0\end{array}$ \\
\hline
\end{tabular}

Annual Maintenance cost (1987 Dollars)

\begin{tabular}{|c|c|c|c|c|}
\hline Unit & $\begin{array}{c}\text { ADPE } \\
\text { Purchase }\end{array}$ & $\begin{array}{l}\text { Comm. Equip } \\
\text { Purchase }\end{array}$ & $\begin{array}{c}\text { Software } \\
\text { Procurement }\end{array}$ & $\begin{array}{c}\text { Total } \\
\text { Initial } \\
\text { Cost } \\
\end{array}$ \\
\hline $\begin{array}{l}\text { Division } \\
\text { Brigade } \\
\text { Battalion } \\
\text { Company }\end{array}$ & $\begin{array}{r}\$ 13,944.0 \\
5,688.0 \\
5,688.0 \\
1,380.0\end{array}$ & $\begin{array}{r}\$ 2,844.0 \\
180.0 \\
180.0 \\
0.0\end{array}$ & $\begin{array}{r}\$ 1,744.0 \\
0.0 \\
0.0 \\
0.0\end{array}$ & $\begin{array}{r}\$ 18,532.0 \\
5,868.0 \\
5,868.0 \\
1,380.0\end{array}$ \\
\hline
\end{tabular}

The total active Army-wide costs for dedicated equipment is shown in Table 4.23. Total initial equipment and software acquisition cost, as shown by Table 4.23 , is approximately $\$ 45,000,000$. This amount would provide equipment for training management automation from the division through company levels for all active Army units. The annual cost to maintain this equipment is approximately $\$ 7,300,000$ a year.

\subsection{AUTOMATED SYSTEM COST EFFECTIVENESS}

The cost effectiveness of an automated training management system is determined by comparing total expected life-cycle costs to the current costs incurred by the existing manual system. Life-cycle costs of the existing manual system consist essentially of direct operating labor costs as estimated in Section 4.2. Automated system life-cycle costs, as described in Section 4.3, consist of labor, research and development, investment, and operations and support costs. Only equipment investment costs, direct 


\section{TABLE 4.23. Army-Wide Equipment/Supporting Software Costs for an Automated Training Management System}

Total Initial Acquisition Cost:

\begin{tabular}{|c|c|}
\hline Unit & $\begin{array}{l}\text { Total Initial Cost } \\
\text { (In 1987 Dollars) }\end{array}$ \\
\hline $\begin{array}{l}\text { Division } \\
\text { Brigade } \\
\text { Battalion } \\
\text { Company }\end{array}$ & $\begin{array}{r}\$ 3,887,000 \\
3,909,000 \\
21,780,000 \\
15,307,000\end{array}$ \\
\hline Total & $\$ 44,883,000$ \\
\hline
\end{tabular}

Total Annual
Maintenance Cost
(In 1987 Dollars)

$\$ 334,000$

534,000

$2,975,000$

$3,500,000$

$\$ 7,343,000$

operating labor costs, and equipment maintenance costs have been quantified for the automated system at this time. Automated system research and development costs, etc. are currently being estimated with assistance from BDM Corporation personnel. A comparison of life-cycle costs, using available cost estimates, of alternative training management systems are shown in Table 4.24. These life-cycle cost estimates will be updated as additional litecycle cost information becomes available for automated training management system scenarios.

A summary of the expected 10-year 1 ife-cycle costs for alternative train ng management scenarios are presented at the bottom of Table 4.24. The cost categories shown in Table 4.24 consist of equipment acquisition costs, direct operating labor, and equipment maintenance costs. The life-cycle cost analys s assumes an equipment life of 10 years and a discount rate of 10 percent for present worth calculations. All yearly dollar figures have been discounted to account for the time value of money. In other words, it is assumed that the U.S. Army can obtain a 10 percent return on its money. In this manner, discounted dollar amounts for each year can be totaled to obtain the present worth of each alternative for the 10-year period.

Five alternative training management scenarios are presented in Table 4.24. These alternatives and their 10-year life-cycle costs present worth are as follows: 


\begin{tabular}{|c|c|c|c|c|c|c|}
\hline \multirow[b]{3}{*}{ Year } & \multirow[b]{3}{*}{$\begin{array}{c}\text { Cost } \\
\text { Category }\end{array}$} & \multicolumn{5}{|c|}{$\begin{array}{l}\text { Life-Cycle Costs for Alternative Training } \\
\text { Management Scenarios (Discounted at } 10 \% \text { Per Year) }\end{array}$} \\
\hline & & \multicolumn{5}{|c|}{ Scenarios - Costs In Millions of Dollars } \\
\hline & & $\begin{array}{l}\text { Manual } \\
\text { Systen }\end{array}$ & $\begin{array}{l}\text { Autonated } \\
\text { No. Add. Equip. } \\
\text { Dir. - Co. }\end{array}$ & $\begin{array}{l}\text { Autonated } \\
\text { Div. - Bn } \\
\text { No. Add. Equip. } \\
\text { Wanual at } \\
\text { Co. Level } \\
\end{array}$ & $\begin{array}{l}\text { Autonatod } \\
\text { Equip. Roq'd. } \\
\text { Div. - Co. }\end{array}$ & $\begin{array}{l}\text { Automated } \\
\text { Dir.-Bn } \\
\text { Equip. Req'd. } \\
\text { Manual at } \\
\text { Co. Lerel } \\
\end{array}$ \\
\hline \multirow[t]{2}{*}{1} & $\begin{array}{l}\text { Total Inicial Investment } \\
\text { Cost: Equipment }\end{array}$ & D & 1 & 6 & 45 & 30 \\
\hline & $\begin{array}{l}\text { Operations \& Support } \\
\text { Costs: Direct Labor } \\
\text { Equip. Maintenance(a) }\end{array}$ & $\begin{array}{r}348 \\
0\end{array}$ & 227 & $\begin{array}{r}279 \\
6\end{array}$ & 227 & $\begin{array}{r}279 \\
4\end{array}$ \\
\hline 2 & $\begin{array}{l}\text { Operations \& Support } \\
\text { Cost: Direct Labor } \\
\text { Equip. Maintenance(a) }\end{array}$ & $\begin{array}{r}317 \\
0\end{array}$ & 287 & 254 & $\begin{array}{r}207 \\
7\end{array}$ & $\begin{array}{r}254 \\
4\end{array}$ \\
\hline 3 & $\begin{array}{l}\text { Operations \& Support } \\
\text { Cost: Direct Labor } \\
\text { Equip. Haintenance(a) }\end{array}$ & $\begin{array}{r}289 \\
0\end{array}$ & $\begin{array}{r}188 \\
6\end{array}$ & $\begin{array}{r}232 \\
0\end{array}$ & $\begin{array}{r}18 B \\
6\end{array}$ & $\begin{array}{r}232 \\
3\end{array}$ \\
\hline 4 & $\begin{array}{l}\text { Operations I Support } \\
\text { Cost: Direct Labor } \\
\text { Equip. Maintenance(a) }\end{array}$ & $\begin{array}{r}261 \\
0\end{array}$ & $\begin{array}{r}170 \\
0\end{array}$ & $\begin{array}{r}209 \\
8\end{array}$ & $\begin{array}{r}170 \\
5\end{array}$ & $\begin{array}{r}209 \\
3\end{array}$ \\
\hline 5 & $\begin{array}{l}\text { Operations \& Support } \\
\text { Cost: Direct Labor } \\
\text { Equip. Maintenanceis }\end{array}$ & $\begin{array}{r}237 \\
6\end{array}$ & $\begin{array}{r}154 \\
0\end{array}$ & $\begin{array}{r}198 \\
8\end{array}$ & $\begin{array}{r}154 \\
5\end{array}$ & $\begin{array}{r}190 \\
3\end{array}$ \\
\hline 8 & $\begin{array}{l}\text { Operations \& Sugport } \\
\text { Cost: Oiract Labor } \\
\text { Equip. Maintenance(a) }\end{array}$ & $\begin{array}{r}216 \\
0\end{array}$ & 141 & $\begin{array}{r}173 \\
9\end{array}$ & 141 & $\begin{array}{r}173 \\
2\end{array}$ \\
\hline 7 & $\begin{array}{l}\text { Corations Support } \\
\text { Cust: Direct Labor } \\
\text { Equip. Maintenance(a) }\end{array}$ & $\begin{array}{r}195 \\
6\end{array}$ & 127 & $\begin{array}{r}156 \\
0\end{array}$ & $\begin{array}{r}127 \\
4\end{array}$ & $\begin{array}{r}158 \\
2\end{array}$ \\
\hline 8 & $\begin{array}{l}\text { Operations \& Support } \\
\text { Cost: Diroct Labor } \\
\text { Equip. Maintenance(a) }\end{array}$ & 177 & $\begin{array}{r}118 \\
0\end{array}$ & $\begin{array}{r}142 \\
\square\end{array}$ & $\begin{array}{r}116 \\
4\end{array}$ & $\begin{array}{r}142 \\
2\end{array}$ \\
\hline 9 & $\begin{array}{l}\text { Operations \& Stpport } \\
\text { Cost: Di rect Labor } \\
\text { Equip. Maintenance(a) }\end{array}$ & $\begin{array}{r}164 \\
0\end{array}$ & $\begin{array}{r}197 \\
6\end{array}$ & $\begin{array}{r}131 \\
6\end{array}$ & $\begin{array}{r}107 \\
3\end{array}$ & $\begin{array}{r}131 \\
8\end{array}$ \\
\hline 19 & $\begin{array}{l}\text { Operations \& Support } \\
\text { Cost: Diroct Labor } \\
\text { Equip. Waintenance(a) }\end{array}$ & $\begin{array}{r}146 \\
0\end{array}$ & $\begin{array}{r}95 \\
9\end{array}$ & 117 & $\begin{array}{r}95 \\
3\end{array}$ & $\begin{array}{r}117 \\
2\end{array}$ \\
\hline $\begin{array}{l}10 \mathrm{Ye} \\
0 f \mathrm{Se} \\
10 \mathrm{Pe} \\
\text { Rato }\end{array}$ & $\begin{array}{l}\text { ar Present Worth (Cost) } \\
\text { enario Asauaing } A \\
\text { reent Discount } \\
\text { (sWillion) }\end{array}$ & 2,350 & 1,532 & 1,883 & 1,625 & 1,940 \\
\hline
\end{tabular}

(a) No expected increase in existing equipoent mainterance cost. 
- Alternative 1: Manual System - The current manual training management system fron division through company levels.

10-Year Life-Cycle Cost: $\$ 2.35$ Billion Dollars

- Alternative 2: Automated/No Additional Equipment/Div.-Co. - An automated training management system requiring no additional U.S. Army equipment purchases. The system automates training management from division through company levels.

10-Year Life-Cycle Cost: $\$ 1.53$ Billion Dollars

- Alternative 3: Automated/No Additional Equipment/Div. - Bn/Manual at Company Level - The same alternative as Alternative 1, except that company level training management is not automated and the current manual system is assumed.

10-Year Life-Cycle Cost: \$1.88 Billion Dollars

- Alternative 4: Automated/Equipment Required/Div.-Co. - Training management is automated by purchasing equipment dedicated to training management from the division through the company level.

10-Year Life-Cycle Cost: \$1.63 Billion Dollars

- Alternative 5: Automated/Equipment Required/Div. - Bn/Manual at Company Level - The same as Alternative 4, except that training management is not automated at the company level, and the current manual training management system is assumed.

The resulting ranking of the five training management system alternatives by life-i,cle cost effectiveness is shown in Table 4.25 . As shown by Table 4.25, the most cost effective alternative for training managenent are those scenarios that automated training management at the company level. Not automating at the company level is expected to result in approximately $\$ 300$ million dollars in additional 10-Year Life-Cycle costs.

\subsection{COST IMPACTS ON INTANGIBLE ASPECTS OF ARMY OPERATION}

The cost impacts reported above are based on a tangible aspect of TM, i.e., the amount of personnel time spent on various TM tasks. It was possible to measure this quantity, based on a small sample of Army personnel, and to extrapolate it to the entire Army. There are a number of other areas, however, where automated TM is likely to have an impact on costs, that were not directly measured in the current study. These areas include fuel used during training, ammunition used during training, depreciation of vehicles, and range utilization. Obtaining unit level cost figures for these areas 


\section{TABLE 4.25. Ranking of Training Management System Alternatives by Life-Cycle Cost Effectiveness (in Millions of Dollars)}

\begin{tabular}{|c|c|c|}
\hline Alternative & Life-Cycle Cost & $\begin{array}{l}\text { Life-Cycle Savings } \\
\text { From Current System } \\
\end{array}$ \\
\hline $\begin{array}{l}\text { Alt. } 2 \text { - Automated/No } \\
\text { Add. Equip./Div.-Co. }\end{array}$ & $\$ 1530$ & $\$ 820$ \\
\hline $\begin{array}{l}\text { Alt. } 4 \text { - Automated/Equip. } \\
\text { Req'd./Div.-Co. }\end{array}$ & $\$ 1630$ & $\$ 720$ \\
\hline $\begin{array}{l}\text { Alt. } 3 \text { - Automated/Div. - } \\
\text { Bn/No Add. Equip./Manual } \\
\text { at Co. Level }\end{array}$ & $\$ 1880$ & $\$ 470$ \\
\hline $\begin{array}{l}\text { Alt. } 5 \text { - Automated/Div. - } \\
\text { Bn Equip. Req'd/Manual } \\
\text { at Co. Level }\end{array}$ & $\$ 1940$ & $\$ 410$ \\
\hline $\begin{array}{l}\text { Alt. } 1 \text { - Current Manual } \\
\text { System }\end{array}$ & $\$ 2350$ & \\
\hline
\end{tabular}

presents measurement problems that can be overcome in a study with expanded scope. In this section, a description is provided of the potential impacts of an automated TM system on selocted training-related consumable costs and equipment depreciation. Throughout this discussion it should be borne in mind that the approximate costs for personnel and equipment in the 1986-87 budget were roughly $\$ 60$ billion. Thus, even a 1 percent reduction in costs would be a substantial savings.

In order to assess the impact of an automated TM system on aspects of Army operation not directly measured in this study, two general types of effects were examined. The categories are (1) cost reductions in the overall expense of conducting training and (2) overall improvement in TM performance. Performance improvement involves both reduction of waste and inefficiency, and improvement of operational capability.

The following approach was used in defining the potential cost reductions that might be accomplished through an automated TM system. Gross categories of expenditure for various types of training related activities were identified, and calculations of the net savings that could be achieved 
through a very small percentage decrease in expenditures were made. The primary assumption is that some reductions in the procurement of equipment, ammunition, fuel, and repair parts can be made if all units in the Army are using their training time most effectively and efficiently. Additional cost savings can be realized in reducing the depreciation of existing equipment. For example, all Army aircraft and vehicles have finite lives. The length of the operational life of a given piece of equipment is governed by both operational obsolescence and the routine wear. To the extent that the life of various classes of Amy materiel can be extended through using high-cost vehicles exclusively for high-priority and necessary training activities, the overall impact on Amny procurement could be significant. Since the value of the Army's aircraft and vehicles is so high, even a modest improvement can yield significant savings in spare parts and equipment replacements.

\subsubsection{Cost Savings on Training-Related Consumables}

Producing the same (or improved) training with fewer resource dollar requirements will occur under an automated system if it is assumed that (1) automated systems increase the probability that all training conducted will be prioritized; and (2) automated systems permit a highly accurate means of forecasting needs for fuel, ammunition, and consumables required to accomplish needed training. Thtse improvements in resource management are characteristic of civilian applications where significant productivity improvements have been realized through computerized planning, resource management, and electronic information transfer (Tapscott, 1982). For example, accurately forecasting inventory needs in manufacturing is analogous to ammunition management. Current computer-based inventory control has dramatically reduced resources tied up in non-critical inventory. Net efficiency gains in manufacturing have ranged from 35 percent in computer hardware manufacture (Packard, 1980) to 15-20 percent gains in accuracy and efficiency in managerial productivity (Warren, 1986).

The purpose of the following discussion is to illustrate the magnitude of the actual dollar savings that could be realized with even a small reduction in the annual budgets for expendable items used in training. The savings identified are those that might be achieved through better planning, 
forecasting, and resource management resulting from automated TM. The percentage of savings is conservatively set at one percent annually.

Table 4.26 below shows the dollar savings which could be achieved through a one percent improvement in overall efficiency in managing current resources. The annual budget numbers are an average of the actual FY 1986 and 1987 budgets for the specific categories.

TABLE 4.26. Potential Savings Resulting from a One Percent Reduction in Cost of Training Resources (in Millions of Dollars)

$\begin{array}{lll}\text { Budget Category } & \text { FY 1986-87 Budget } & \frac{1 \% \text { Annual Savings }}{\$ 2100} \\ \text { Ammunition } & \$ 21\end{array}$

Operation \& Maintenance:

General Purpose

Supply \& Maintenance

Training, Medical, and General
7300

5100

4300
73

51

43

TOTAL POTENTIAL SAVINGS: \$188 Million

If even half of these estimated savings could be realized, an automated training management system with an expected life of ten years could be fully cost justified in Tess than one year. It should also be noted that the total of $\$ 188 \mathrm{million}$ potential savings on an annual basis does not include any savings from equipment depreciation, nor does it include any calculations for savings in the aircraft program. It is evident that an automated TM system that can produce even a modest increase in overall efficiency can be cost justified almost from the time it enters service.

\subsubsection{Cost Savings or. Equipment Depreciation}

If proper planning, scheduling and management can reduce the resources required for consumable training-related expenses, the Army should also be able to realize savings on the depreciation of vehicles and weapons used in training. Army vehicles have a finite life that is defined by both physical 
depreciation, and military obsolescence (AR 735-11 24 Nov 1986). In the discussion that follows, the impact of extending the cost effective life of vehicles and weapons by one percent will be considered.

It is assumed that proper planning and management of these resources will lower the use rate, thus lowering replacement, repair, and maintenance costs. In Table 4.27, calculations are presented that show the effect of a one percent increase in the operational life of vehicles and weapons. The calculation is extremely conservative in that it applies only to those vehicles and weapons that are being procured in the 1986 and 1987 fiscal years. In reality, the impact would accrue to the Army's entire vehicle stock. No improvements are forecast for the current vehicle or weapon inventory.

\section{TABLE 4.27. Potential Savings Resulting from Extending} the Life of Vehicles and Weapons

(in Millions of Dollars)

\section{Category}

Aircraft

Tracked Combat Vehicles

Tactical \& Support Vehicles

FY 1986

$\$ 1400$

4300

1100
FY 1987

$\$ 1500$

3400

700 $\underline{1 \% \text { Savings }}$

$\$ 29$

77

18

TOTAL FY 86 \& 87: \$12.4 Billion 1\% Savings $=\$ 124$ Million

As with potential savings that could be achieved in consumable resources, a one percent life extension of vehicles and weapons purchased in FY 1986 and 1987 yields a savings that is more than double the cost of a dedicated Army-wide automated TM system. Thus, if even half of the potential benefit is realized, the automated training management system is fully cost justified.

\subsubsection{Savings Resulting from Improved TM Performance}

There are many activities involved in training management that contribute either to the effective execution of necessary training, or promote confusion, waste and inefficiency. There are few of these activities that alone are of such prominence that they would justify implementing an automated training management system. Taken together, however, improving the overall performance 
of this myriad of individual activities and transactions will lead to a significant improvement in the efficiency of Army training.

Some of these intangible elements can have a significant impact. For example, if all training-related forms and report documents are printed out by a unit computer system, it will not be necessary to print or store blank forms. The net savings to the government for printing, distribution, and storage of forms could be substantial.

Data gathered in the survey conducted as part of this study indicate that there are several other areas where significant benefits could be obtained. These include the scheduling of training facilities, availability of references and training guidance, and the forecasting of training ammunition. Facility scheduling, particularly for firing ranges, is a situation where facilities are alternately underutilized or placed under heavy demand from units. When cancellations occur, many potential users are unaware of the change since scheduling information is not disseminated electronically. In this situation, ranges or training areas may go unused.

Ammunition usage is another area where considerable gains in efficiency appear possible based on better forecasting of needs related to missions, and better coordination of range times and the specific ammunition needed for a given exercise. Although this problem may vary in severity at different Army posts, the survey indicated that a major problem confronting training managers was the need to forecast ammunition requirements far in advance of the time when training schedules could be developed and ranges scheduled. Because of this delay, there was no clear relationship between the ammunition ordered, unit training needs, and the scheduling of firing ranges. This inefficiency promotes firing whatever ammunition is available to the units, whenever a range is available.

In Tables 4.28-4.34, a variety of intangible impacts of an automated TM system are listed. These points are based on the survey of training management personnel conducted as part of this study. The impact statements are drawn from responses obtained in the interviews concerning the most significant problems that the interviewees faced in conducting TM, and the potential improvements expected from automation. The list of potential benefits associated with automating training management is not all inclusive, 
TABLE 4.28. Potential Improvements in Training References Resulting from Automated TM

- Provides data base access to the 25-75 percent of references that are currently unavailable.

- Electronic storage and transmission of HQ training doctrine and guidance. Standardization of forms and reports.

- Reduces or eliminates printing costs by use of electronic forms and reports.

TABLE 4.29. Potential Improvements in Training Gujdance Resulting from Automated TM

- Immediate retrieval of current-year historical training guidance by subordinate units.

- Timely updates of perishable information.

- Provides means for subordinate unit feedback to higher $H Q$, with opportunity for electronic interchange (acknowledgement and clarification).

- Ensures uniform distribution of training guidance.

- Provides data base for BTMS workshop results.

- Provides means for preparation of training calendars--the most common form of written guidance at company level.

- Facilitates preparation and update of unit METL based on mission requirements. 
TABLE 4.30. Potential Improvements in Training Schedules Resulting from Automated TM

- Standardization of format from company through division.

- Provides more time for schedule preparation.

- Reduction in the variance of how far in advance schedules are prepared (currently 2-6 weeks).

- Faster notification of schedule changes.

- Faster higher HQ review of subordinate unit schedules.

- Provides means for higher HQ to assess impact of taskings to subordinate unit.

- Reduced need for company shadow clerks.

TABLE 4.31. Potential Improvements in Training Evaluation Resulting from Automation

- Provides means for closing evaluation gap in TM, permitting assessment of results.

- Provides means for recording training results for later evaluation.

- Provides means for use of systematic proficiency matrix to assess unit training status.

- Interface with TACCS-SIDPERS training records program.

- Links units to local ITEP offices for receiving SQT results and test dates.

- Provides tool for Deputy Training Standards Officer (DTSO). 
TABLE 4.32. Potential Improvements in Training Ammunition Resulting from Automation

- Electronic communication between DAO, G-3 training and account holders down to battalion level for forecasts, allocations, and requests.

- Reduces time spent by DAO manually accounting for training ammunition.

- Link to TAMIS will reduce time spent manually computing annual FORSCOM training ammunition allocations and reallocations.

- Provides an audit trail for requests submitted in advance.

- Standardization of the DA form 581 for ammunition request.

- Supports AR 710-2, Unit Supply Update No. 10, requiring units to maintain training ammunition status checks, which must be reconciled between DAO, IAMO (Installation Ammunition Management Office) and ASPs.

- Electronic notification of account holders regarding non-availability of supporting ASPs and ammunition shortfalls.

- Links the 90-120 day training ammunition forecast with the 35-day range request.

- Training ammunition allocations will precede forecasts and requests.

TABLE 4.33. Potential Improvements in Unit Status Reporting, Training Areas and Ranges, Training Aids Support and Training Funds Management

- Allows training distractors to be blocked during prime training time.

- Facilitates reporting of training readiness data.

- Speeded approval process for range/data requests.

- Better accumulation of range utilization data.

- Data link between TMACS event cost estimates and TUFMIS cost data.

- Speeded requests to Training Aids Support Center (TASC). 
IABLE 4.34. Potential Improvements in General Administration of TM Resulting from Automation

- Standardized forms and procedures.

- Reduced printing costs.

- Increased data storage and organization.

- Provides computers at levels where they are currently supplied from personal sources.

- Increased transaction speed.

- Reduced need for special duty personnel at all echelons.

- Increased availability of data critical for decision making.

but representative of the group surveyed. The listing also assumes that TM will be automated to the company level.

It is evident from these tables that improvements will occur in a variety of areas. It is also clear that the bulk of the comments refer to benefits that will occur as a result of improving the temporal relationships between planning activities, foracasting, and requesting of resources. By providing a better match between training needs assessment and resource allocation, automated TM will result in more effective training expenditures and substantially lower costs.

\subsection{SYNOPSIS OF POTENTIAL BENEFITS}

This chapter has approached the costs and benefits associated with automation from two perspectives. First, the costs and potential savings associated with labor savings were delineated. This analys is revealed that by automating those administrative activities, which currently consume a disproportionate amount of the training managers time, that 2525 man-years of labor may be saved on an annual basis. In practical terms, this figure means that 2525 man-years worth of labor will be made available for expenditure on activities of primary concern, i.e., mission-oriented training. Thus, the inefficiencies associated with the present TM system can be 
considered a secondary demand which drains labor resources from the primary task. By providing automated tools to reduce or eliminate these inefficiencies, the valuable labor resource can be redirected to higher priority activities.

The second approach to analyzing potential benefits was to compute savings, in training-related consumables by postulating a one percent increment in effectiveness, based on industrial studies. This analys is showed that, because of the magnitude of the Army budget, a one percent reduction in expenditures would fully cost justify an automated TM system within its first year of service. The magnitude of the savings is in the arena of $\$ 312$ million annually, based on 1986-87 budget figures. The following chapter examines previous and existing efforts for automating TM procedures. 


\subsection{AUTOMATED TRAINING MANAGEMENT}

\subsection{REVIEW OF MISSION ESSENTIAL NEEDS STATEMENT}

Development of an automated TM system will support a variety of objectives. Guidance from the DA initially focused on the need to provide a better means of justifying the Amy's budget requests for training, a means to better quantify the training elements of unit readiness, and a mechanism to integrate the existing and emerging automated systems that are being developed to support training. The draft Mission Essential Needs Statement (MENS) prepared by TRADOC expanded upon the initial criteria and emphasized additional requirements. These included more effective use of training resources; better identification of logistics, personnel, and administrative support requirements; and increased TM standardization. In addition, other objectives were discussed in the context of overall changes occurring in Army training management, such as facilitating the implementation of more precise standards of performance for combat proficiency and assisting the training manager by automating many of the principal administrative functions of the job.

This is a very broad range of objectives. At the time of this writing (January, 1988) the Army has not defined the objective system that would be developes! to manage training. Consequently, there has been no official statement of the relative priority that will be assigned to each of the objectives that have been defined in the initial tasking documents.

In Section 3.4, an empirical comparison was made between the formal doctrine for TM that was set forth in FC-25-100 and data obtained from a sample of Army units. This survey analysis provided systematically gathered evidence that supports the general contention that certain aspects of training management could benefit considerably from automation and linked data bases. In the sections that follow, previous and current TM automation efforts are discussed.

\subsection{PREVIOUS AUTOMATION EFFORTS}

The development of ITMS evolved from an effort by the Army that had been underway for more than ten years to improve unit TM. The Army Training 
Board developed the Battalion Training Management System (BTMS), which provided unit training management guidance and support at the battalion and lower echelons. Implementation of BTMS was achieved through development of a series of workshops oriented toward leaders within a battalion, from battalion commander through squad leader. BTMS tied together the major elements of the TM system with the flexibility for units to develop their own priorities for unit training. This approach has been enthusiastically received by unit leaders (Willison, 1980). The system is complex, however, and manual application is difficult.

While BTMS achieved general acceptance and recognition of its positive role in unit TM, the need for automation has also been recognized, particularly as computer technology has advanced and become more readily available to units. In the late 1970s, the Army Training Board initiated the development of the Battalion Training Model (BTM) (not to be confused with BTMS). BTM was an attempt to automate certain battalion TM functions, particularly training schedule development. The scheduling algorithm developed in BTM had technical shortcomings, was difficult to implement, and was subsequently abandoned. The concept of automation remained, however, and was subsequently pursued through the Advanced Technology Unit and Traininj Management System (ATUTMS).

The c: yelopment of ATUTMS was initiated by ARI and ADEA in 1982. ATUTMS was developed as a battalion-level integrated data base management system that combined knowledge gained from the development and use of BTMS with information concerning training detractors (Hiller, 1982). Lavin, Rosenberg, and Gray (1985) describe the user requirements used to guide system development. ATUTMS was developed and applied specifically within the context of the 1st Battalion, 11th Field Artillery (1/11 FA), 9th Infantry Division. While design and test results necessarily reflect the needs of a field artillery battalion (and to some extent those specific to the 1/11 FA), ATUTMS was intended to be applicable, with minor modifications, to all significant battalion-level units within FORSCOM. A users guide (Antczak, Benson, and Ibbott, 1985a) was developed to support the application of the system, and ATUTMS hardware and software design are documented in Antczak, Benson, and Ibbott (1985b). 
Subsequently, ATUTMS was expanded to include an electronic clipboard for data collection and entry (Perceptronics, 1985), and the system, then known as the Training Information Management System (TIMS), was subjected to a preliminary test. The test results, based primarily on user ratings, were encouraging, though objective data were lacking. Following ATUTMS and TIMS, the current ITMS prototype under development at ADEA (ADEA and BDM Corporation, 1987) has evolved.

\subsection{THE PROTOTYPE INTEGRATED TRAINING MANAGEMENT SYSTEM (ITMS)}

The prototype system is described in a functional specification prepared for ADEA by the BDM Corporation (ADEA and BDM Corporation, 1987). As this system will be used as a basis for evaluating many of the major propositions regarding improvement of $T M$, a brief discussion of the hardware system and functional features is presented here. It should be stressed that, in the following discussion, the system being described is the prototype that is scheduled for testing in 1988. There are many other features of an objective system that will ultimately link the DA and all levels of operational units that are not part of the current test bed system.

The prototype ITMS will be installed in a slice of the 1st Brigade of the 9ID (MTZ) during the latter part of 1987 and the early part of 1988. The system will be installed in B:'gade HQ, 3 Battalion HQs, and in 5 Company HQs within one of the battalions. In addition, terminals will be installed at the division level, and at the I Corps level (Installation Manager). This will constitute the test bed for the prototype system.

The prototype ITMS has seven functional areas which are used to manage training: (1) Requirements; (2) Calenders and Schedules; (3) Events;
(4) Funds;
(5) Training Ammunition;
(6) Training Areas, Ranges, and

Facilities; and (7) Training Aids and Devices.

The objective of the ITMS is to provide each level of command from division through company with two major outputs needed to achieve the maximal state of training readiness. The first output is a prioritized listing of the individual and unit training tasks each unit must accomplish to be ready to fight. The second output is a set of schedules that are developed through iteration with the pertinent units in the command to actually schedule and 
provide the necessary resources to conduct the needed training. The analysis of requirements and scheduling of needed training is performed in three time frames: the annual training plan for the fiscal year (long-range planning), the quarterly training plan (short-term planning), and the weekly training plan (near-term planning).

The requirements section of ITMS contains the vast majority of the data and information needed to operate the system. This information includes AMTP missions and unit Mission Essential Task Lists (METLs), Standards in Weapons Training (SWIT), Common Military Training Requirements (CMTR), Army Individual Training Evaluation Program (ITEP) requirements, Commanders Evaluation of individual tasks essential to the unit mission, Skill Qualification Test (SQT) requirements, and Common Task Test (CTT) requirements.

In order to develop a master schedule that takes account of the needs of all the various units within a command and the training needs of the various levels of the command hierarchy, an iterative process takes place where the desires and priorities of all elements are adjudicated, and a master schedule is devised for the command. Since time, funds for training, ammunition, and areas for conducting training are finite, and all desired training can rarely be accomplished, conflicts arise. Conflicting requests and priorities are formally resolved annually, and are refined on a quarterly basis.

The iteration of requests and the balancing of priorities into a final schedule for training is accomplished with the aid of sub-sections of ITMS that facilitate estimation of the costs of conducting various training exercises (the funds section) and the ammunition needed (ammunition section). The cost of various events is calculated in the funds area of the IrMS using an event-based costing approach similar to TMACs. This provides cost data on equipment, ammunition, supplies, support devices, and other budget items that are needed to develop an aggregated estimate of what training packages within a command will cost. As budget constraints limit the total training that can be done within a command, the funds data are essential in determining what training is scheduled. 
The ammunition segment of ITMS assists each level of command to estimate the ammunition that will be needed to carry out the training that is scheduled. This will permit a much more efficient and reliable means of assuring that the needed ammunition is available for training exercises, and that the proper ammunition is obtained and that the ammunition is positioned properly to support planned training evolutions.

The calenders that are published annually are calibrated to more current conditions on a quarterly basis. The updates permit commanders to reevaluate training scheduled for the coming quarter to account for changes in priorities, changes in missions, or to take account of the results of training accomplished in a previous period.

Near-term training guidance is generated by ITMS in the form of a weekly training calendar. This is the document which guides the actual conduct of training. Included in the weekly calendar outputs are aids to facilitate drawing the proper ammunition, going to the properly scheduled training area, and developing the necessary feedback data on the results of the training accomplished.

When training events are completed, or when tests or evaluations are conducted, the information on unit or individual performance is destined to be fed back into the requirements data base. This updated record should then represent the most current training status of the unit, and in some cases the individuals involved. As such, the current record has the potential to provide significant and accurate information about the training status of the units involved.

As noted earlier, the description of the prototype ITMS has been limited to the features that will be subjected to preliminary tests and proof of principal analyses during 1988. The focus of the test will be on a slice of units within a brigade, and thus the prospects of aggregating information up to higher levels of command will not be tested except by inference. It is evident that one critical aspect of system performance will be its ability to aggregate information to higher levels of command, and facilitate the resolution of competing requests for ranges, facilities, and resources. 


\subsection{ATCCS COMMON AS THE MEDIUM FOR AUTOMATED TRAINING MANAGEMENT}

Delivering automated TM on Army Tactical Command and Control System (ATCCS) hardware is a design approach that would not involve dedicated TM hardware. The arguments for it include simplified user training and more economical hardware. Questions arise, however, regarding the "force fit" of applications with very different requirements on the same hardware (and presumably operating system). It is useful to characterize the systems in several ways in order to examine the differing requirements and their impact on ATCCS hardware selection.

One way of approaching the applications requirements is to divide them into modules. These requirements are listed in Table 5.1, along with an estimate of how important each of these requirements is to the application. Note that the requirements of ATCCS hardware exceed the TM requirements in all but the communications and data base areas. The iconic interface of ITMS is not listed as a requirement because ease of use must be applicable to the Battlefield Applications as well as training management.

\begin{tabular}{|c|c|c|}
\hline Area & $\underline{I M}$ & ATCCS \\
\hline Data base & High & Medium \\
\hline Communications & High & Medium \\
\hline Word Processing & Medium & Medium \\
\hline Electronic Mail & Low & Low \\
\hline Graphics & Medium & Medium \\
\hline Security & Medium & High \\
\hline Mobility & Low & High \\
\hline Ruggedization & Low & High \\
\hline Ease of Use & High & High \\
\hline
\end{tabular}

Table 5.1 illustrates that the primary requirements that TM has for data base and data communications exceed those of ATCCS. In addition, the data base of ATCCS applications are distributed over many nodes, whereas the TM data base is more centralized. 
The implication of these requirements would be to greatly increase the storage on the ATCCS equipment and further provide a higher speed communications link between the units. The technology of current digital radio communications and the cost of the individual ATCCS systems may be taxed by these two requirements.

The Army also provides computer systems within the installation that could provide many of the additional requirements for the Training Management Application. These installation systems are equipped with high-speed networking for data communications and include minicomputer-class systems with large storage capabilities. The training management functions would necessarily be distributed over the ATCCS common hardware and the installation computers. Training requirements and funds, as well as the general user interface, would be provided by ATCCS. The resource allocation model (e.g., ammo, aids and devices, ranges, and schedules) could be provided by an installation system. These two systems would communicate via a gateway to the installation computing network. The ATCCS systems would be required to provide the connection point to this gateway. Such a system could deliver the Training Management function on ATCCS equipment with a minimum impact on ATCCS. Before such an approach is fully embraced, however, the impact of periodic removal of ATCCS equipment for field exercises on TM functions should be examined. 


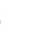




\subsection{DISCUSSION OF RESULTS AND POTENTIAL MEASURES OF EFFECTIVENESS}

\subsection{REVIEW OF MAJOR FINDINGS}

The study reported in this document used a structured analys is of Army training doctrine, a job analytic survey of a sample of units of the 9ID (MTZ), and cost effectiveness calculations to examine the impact of automating Anny TM. The major findings of these analyses are summarized below.

The job analysis demonstrated that for the respondents surveyed, approximately 47 percent of their time was spent on TM tasks. This is an average computed over all echelons and TM tasks. The largest proportion of time is spent on resourcing and forecasting (Task 3 ) at the division level. It is significant to note that echelons above companies currently have access to some form of automation (typically PC class machines); however, 48 percent of the respondents in the companies surveyed indicated the use of computers for various TM tasks. This indicates that computers are secured through personal means to assist with administrative activities.

A comparison of TM doctrine with practice revealed, generally, that TM tasks proceed according to doctrine, although there are a number of specific inadequacies in how tasks are performed. The most salient of these are (1) planning based on time and resources available rather than DA and FORSCOM guidance; (2) non-uniform development of METLs; (3) luck of formal mission analysis procedures at the company level; (4) heavy concentration of administrative work at companies without adequate personnel or ADP support; (5) turbulence resulting from external taskings introduced as units move from short-range to near-term plans; (6) increased workload at company levels during near-term planning without adequate personnel or ADP resources; and (7) low use of training results to plan future training activities at the company level. These problems have two general effects. The short term effect is excessive labor cost to accomplish TM tasks. The longer term, and clearly more harmful effect, is the lack of mission-oriented training, and its detrimental effects on unit readiness. Appropriate ADP solutions to conducting TM would reduce both of these effects, by saving labor on specific tasks, and by helping to orient the planning of training programs to unit missions and training status. 
The analysis of costs and savings associated with automating TM indicated that substantial savings would be obtained as a result of labor reduction in performing TM tasks. Over a 10-year life cycle, for example, the savings would amount to $\$ 720 \mathrm{milli}$ ion if new equipment were purchased. More important from the training standpoint is the gain of 2525 man-years that can be devoted to the primary task of training, rather than coping with the inadequacies of the current manual system. As with all projective cost analyses, these figures are predictions based on available data, and can be validated through fie]d testing and measurement.

The ITMS prototype under development at ADEA will provide a test bed for examining some of the estimates made in this study. The prototype will provide automated TM equipment within the 1st Brigade at Ft. Lewis, allowing specific issues to be examined within an appropriate experimental design. The remainder of this chapter discusses these evaluation considerations.

\subsection{COST EFFECTIVENESS AND EVALUATION}

The cost effectiveness calculations presented in the previous chapter are based on estimated reductions in personnel workload, based on previous studies of automation. This reduction in individual soldier workload would presumably provide more time for troops to concentrate on tasks other than TM. These figu, s should be viewed with some caution, since they are based on workload reduction factors that have been validated in similar, but not identical systems. Further, the workload reduction of 75 percent associated with the paper-based work types is actually a performance specification from the BDM functional description. Thus, such workload reductions would be expected only if the ITMS system successfully reduced the amount of paper flow by 75 percent. Nonetheless, the computations of savings presented in Chapter 4 do suggest that if certain performance benchmarks are achieved, workload reduction, hence cost savings, will accrue.

It is possible to obtain empirically-based estimates of cost effectiveness to support a decision to automate TM by using data from a field test. It is not necessary to conduct a test that is solely directed toward cost effectiveness; rather, this issue may be addressed as one of the issues in an independent evaluation. Thus, the evaluation exercise planned 
for the ITMS prototype will provide a good test bed for examining the potential cost savings resulting from automation. Such data can complement the more operationally-oriented information typically gathered in field tests, e.g., performance of the system, performance of TM tasks, and system availability statistics.

At a more general level, there are two basic issues of concern in an assessment of automated TM cost effectiveness. The first is concerned with the process of carrying out tasks, e.g., are they efficiently done, and are they done correctly? The second issue relates to the product of TM, i.e., military units that show a high level of readiness to perform their designated missions. The process issues are relatively easy to address in a brief duration field test, while the product issues are quite difficult to address. The assessment of the effectiveness of automated $T M$ on unit readiness requires objective measurements of unit performance, and a sufficient number of observations of various mission tasks. It is unlikely that the planned duration of the prototype field test will allow assessment of unit performance (other measurement problems notwithstanding). Thus, the following section discusses the general requirements for a field test that would address unit performance; this is followed by a more extensive section concerning potential MOEs for the process of conducting TM. The basic philosophy underlying measuring the effectiveness of TM processes is that they wi11 ultimately reflect the quality of the end product, i.e., unit performance based on training received.

\subsection{EVALUATION APPROACHES AND CANDIDATE MEASURES OF EFFECTIVENESS}

\subsubsection{The Ideal Test}

The ideal test of a change in how TM is conducted would invoive an assessment of the readiness of identical units that have been trained on the basis of plans generated with and without automation. There are obviously a number of variables that represent confounding sources of variance in such a test, such as unit home station, turnover in the pre-test time frame and general motivation levels. However, these factors would not be apparent to independent observer/evaluators, and so a blind test would be the result. 
Given the aforementioned conditions for testing, what would represent a true test of unit readiness? This is a difficult problem, since the performance standards currently specified by ARTEPs are quite subjective in nature. A more objective set of data can be obtained from performance in exercises at the National Training Center (NTC). Here, units could perform under highly challenging conditions that closely resemble those of their wartime missions. Also, data from sources such as MILES could be employed as an objective performance standard, on which units with similar or identical missions could be compared. Thus, units trained on the basis of activities generated with conventional TM methods and with automated TM methods would have numerical scores for comparison. This type of data would be necessary for a large number of unit pairs, e.g., 20, in order to make a statistical comparison. An even more powerful assessment would result if other elements of operational readiness of the units were considered, e.g., material readiness. Thus, if automated TM improved the C-rating of training readiness of the experimental group, but the $\mathrm{C}$-rating of material readiness stayed the same, and if there were no changes in the rating of training readiness of the control group (conventional TM methods), then the specificity of TM methods on training readiness would have been demonstrated. This is a variant of the "double dissociation" approach (Teuber, 1955).

While the evaluation approach descrithed above may be the most desirable from a scientific standpoint, there are numerous practical barriers to conducting such an exercise. These relate primarily to the time requirements for a test and the necessity to commit units to an evaluation for an extended period. At the very least, it would be necessary to commit two units for an entire training and NTC cycle. Given the difficulties of scheduling the facility, such a test may not be practical to consider for evaluation of ITMS. However, the framework described can be extended to a longitudinallyoriented study, and if the decision is made to automate TM Army-wide, statistics could be collected during and beyond the changeover period to assess differences in training readiness status based on TM methods employed for particular units. 


\subsubsection{The Practical Case}

It is likely that the independent evaluation of the ITMS prototype will be based on a field test that will be approximately one month in duration. Given this constraint, the issues that can be addressed will necessarily focus on TM processes, and the effectiveness with which they are performed. This section describes some general issues associated with the introduction of automated TM that may be effectively addressed within the constraints of a fairly brief test period. As with the scenario described above, the MOEs described in the following subsections assume a comparison of a unit using conventional TM methods, and one using autonated TM. The types of MOEs fall into three general classes: operator performance, operator ratings and self-report, and system performance. An extensive discussion of the human factors aspects of systems effectiveness testing is provided in Meister (1987).

\subsubsection{Operator Performance MOEs}

One of the primary issues to be concerned with when a new system is introduced is the extent to which there is transfer of training from previously learned tasks. It is often true that automated approaches are so different from more conventional means of task performance that much "unlearning" of old response patterns is necessary. This tends to manifest itself in the form of errors in performance. Thus, one general candidate MOE would be errors in the performance of various TM tasks. Error data can be gathered in a variety of ways. It is possible, for example, to make videotapes of operators as they use a computer terminal, and to count the number of typographical errors that result. This may not be an entirely meaningful measure, however, since it reflects the output side of the human information processing system rather than cognitive processing.

In order to address errors in how people are processing information, an analysis of key entry transcripts can be made. By noting the number of pauses between significant operations (in conjunction with video anilysis, if feasible), conclusions can be drawn regarding how operators are processing information in the tasks they perform. Another type of data would result from an analysis of the various forms that operators will be required to fill 
out electronically. Expert judges would be used to inspect completed forms, and to score them for errors. A comparison of errors made in an automated system with those made in a manual system is another candidate MOE.

Another type of performance measure is time on task. This served as the basis for the cost effectiveness calculations presented in Chapter 4, and should be an important consideration in the independent evaluation. Meaningful time-on-task measures can be obtained when a self-contained task is defined. That is, there must be a distinct beginning and end, and the task must be operationally defined. Thus, "filling out the unit status report" is a task that has an observable beginning and end, and would yield a useful time measure. In contrast, "identifying mission goals" is too abstract, since it involves a variety of component activities, such as compiling the relevant information to analyze, constructing lists, and selecting from the lists. If a time measure is desired for an abstract process, it will be necessary to break the process down into discrete component tasks. A comprehensive set of tasks of this type can be constructed, and repeated measurements of performance made across a number of operators; the data could then be used as input to cost calculations similar to those made in Chapter 4 to assess labor savings. A note of caution is warranted when using time measurements: it is important that there be assurances that the system has been learned to a level where "task acquisition time." i.e., Tearning the system, does not interfere with task performance time.

The last general class of operator performance measures concerns learning to use the automated system. In this case, a comparison with a similar group using non-automated methods is not necessary. Rather, a comparison of individual and group learning times for various aspects of system use can be made against system performance criteria. In the case of the ITMS prototype, there is a requirement that no more than 16 hours training be necessary to learn how to use the system. Thus, operators can be tested against this criterion for a variety of model tasks, such as constructing a METL and constructing a training schedule. By making repeated observations of time to perform a task during the initial learning phase, a learning curve can be constructed; when the curve reaches its asymptotic level, performance has 
stabilized, and time on task comparisons can then be made with the control group.

\subsubsection{Operator Rating and Self Report MOEs}

A variety of rating data were collected in the job analysis described in this report. Most of these data have not been reported here, since the focus was on global problems and labor involvement. However, an extensive series of ratings are available concerning the timeliness and accuracy of all of the classes of documents used in the eight TM tasks studied. Thus, one approach to collecting rating data would be to simply collect similar ratings from the unit that has been assigned to use the automated system in the test. These ratings could then be statistically compared with those obtained from the subjects interviewed in the present job analysis. Another approach would be to obtain ratings from both experimental and control groups in the test. This would be a somewhat more valid approach, since any "rating inflation" that might be operating because of the test would affect both groups.

Self report measures are frequently used in the evaluation of system effectiveness. These measures are useful for identifying problems that may not be readily apparent with global ratings or performance measures. Such problems include inconsistent relationships in the software-user interface, errors that occur under specific operational conditions, and inadequacies in organizational interfaces between system nodes. These types of responses are best elicited with questions that are tailored to a particular area of concern, such as the software-user interface. Additional information can be gained with open-ended questions.

A type of self report that can be validated by the time on task measurements is the TM task by work type inventory used in the present study. It can be predicted that if the automated system is successful, that the percentage of operator time spent on such activities as copying, compiling information, and computing numbers, will be greatly reduced. As with the rating scenarios described above, these data could be collected in a number of different ways, either using the existing data base for comparison, or in an experimental-control group comparison. 


\subsubsection{System Performance MOEs}

This general class of MOEs is concerned with the operation of the entire system, and how it affects the conduct of TM on a routine basis. Thus, issues such as system availability and maintainability are of concern, as well as the issue of the contents of the training program resulting from automated TM. While the independent evaluation and test of the ITMS prototyp: do not require the same rigorous standards in these areas as a system soon to be put in the field, an examination of them can illuminate problems that are much less expensive to correct than at a later stage of development.

System availability can be assessed through an analys is of the percentage of time that the prototype is actually operational, i.e., out of a typical duty week, how many hours is the system available to perform TM tasks? A somewhat more refined statistic, based on the mean time between fajlures and the mean time to repair, can be calculated if sufficient vendor data are available. This statistic can then be compared with empirical data obtained during system operation.

The issue of maintainability is generally concerned with the ease of repairing failures, and the requirements for preventive maintenance. Since this is a prototype system, the rigors of operational test and evaluation do not apply. Rather, observations of maintenance procedures can be made to asses ways in which design improvements can be made.

The final aspect of system operation is the one with the most direct bearing on unit readiness. This concerns the contents of the training schedules generated by automated and conventional means. Earlier in this report, it was conjectured that automated TM would improved readiness by more closely linking training activities with unit needs. This can be assessed in the independent evaluation by comparing the contents of the training schedules for the experimental and control groups (with all appropriate confounding variables controlled). Multiple independent raters, blind to the conditions in which the units served, could be used to rate the extent to which various training activities contained in the schedules correspond to the doctrinally-defined unit missions. The differences in these ratings can be used as an MOE for the results of automated TM, i.e, the training 
activities that it generates for units. Additionally, automated system operation should provide more timely scheduling information and more effective resource management. These benefits can be assessed through identification of appropriate data currently available in units, such as ammunition forecasts, and comparing them with actual ammunition expended. This approach of using unit documentation to assess training $p l a n s$ and resource forecasts with records of what is actually accomplished can provide a converging set of objective data that addresses TM effectiveness.

\subsection{CONCLUSIONS}

The existing manual process of TM follows Army doctrine in principle, but shows specific inefficiencies in how tasks are performed. This results in training activities that are tailored to schedules and resources rather than unit mission requirements and proficiency status. A significant potential benefit of automated TM will be the scheduling of training activities that are based on unit requirements. Cost effectiveness calculations indicate that 2525 man-years can be saved on an annual basis. Approximately half of these savings will result from automation at the company level, suggesting that computerization of $T M$ at this echelon be strongly considered. This translates to more time available for focusing on the primary task of mission-oriented training. The labor savings estimates presented in this report may be verified through an empirical test, using MOEs that capture operator performance, operator rating and self report, and system performance characteristics.

The impact of automation was also estimated on cost categories that were not directly measured in this study. These categories included trainingrelated consumables (e.g., fuel, ammunition) and vehicle depreciation. This analysis, based on the 1986-87 Army budget, showed that a one percent reduction in these cost categories could save $\$ 312$ million annually. As with the labor cost estimates, these potential savings can be verified through a test comparing automated and manual TM systems.

While the present study identified a number of areas where an automated TM system could potentially cut costs, the study was based on a small sample and 1 imited to subjective data. A more representative picture of Army TM 
practices and potential cost impacts can be obtained through further research with an expanded sample and objective data collection. The data from such a study would provide a substantial body of information concerning TM costs in a wider range of units, and would facilitate the design of an Army-wide automated TM system. 


\subsection{REFERENCES}

Alexander, J. J. Productivity Through Automation. In National Research Counci1, Managing Microcomputers in Large Organizations, National Academy Press, Washington, D.C., 1985, 101-114.

Antczak, T., Benson, A. and I. Ibbot. User's Guide for An Advanced Technology Unit Training and Management System (ATUTMS). Alexandria, VA: Defense Technical Information Center, 1985a.

Antczak, T., Benson, A. and I. Ibbot. Design Description of the Advanced Technology Unit Training and Management System (ATUTMS). ARI Field Unit at Presidio of Monterey, California. Alexandria, VA: Defense Technical Information Center, $1985 \mathrm{~b}$.

Army Development and Employment Agency, and BDM Corporation. Functional Description for ITMS, Volume I System Description; Volume II System Design (Draft). Army Development and Employment Agency, 1987.

Battelle Human Affairs Research Centers and Pacific Northwest Laboratory. Army Unit Effectiveness: Decisionmaking Requirements, Data Availability and Analytic Approaches. Research Concept Paper, September, 1987.

Booz, Allen, Hamilton, Inc. Why Automate? Cambridge, MA: Booz, Allen and Hamilton, Inc., 1980.

Carson, K. Memorandum for Record, Office of the Scientific Advisor, ADEA, May 11, 1987.

Curley, K. F. Are There Any Real Benefits from Office Automation. Business Horizons, July-August $1984,37-42$.

Czaja, S. J. Human Factors in Office Automation. In G. Salvendy (Ed.) Handbook of Human Factors, New York: Wiley, 1987, 1587-1616.

Demarco, T. Structured Analysis and System Specification. Englewood Cliffs, NJ: Yourdon Press, 1979.

Dyer, J. L. Annotated Bibliography and State-of-the-Art Review of the Field of Team Training as it Relates to Military Teams. Army Research Institute for the Behavioral and Social Sciences, Alexandria, VA, 1986.

Fearon, V. Successfully Evaluating and Implementing Office Automation, CA Magazine, August 1984, 106-114.

Fitts, P. M. Engineering Psychology and Equipment Design. In S. S. Stevens (Ed.) Handbook of Experimental Psychology, New York: Wiley, 1951, 1287-1340.

Fobes, J. L. National Training Center Data Handbook. U.S. Ariny Research Institute Field Unit, Presidio of Monterey, California. Alexandria, VA: Defense Technical Information Center, 1984. 
Hamza, A. N. Soldier's Guidebook to INGRES for Advanced Technology Unit Training and Management System. U.S. Army Research Institute Field Unit, Presidio of Monterey, California. Alexandria, VA: Defense Technical Information Center, 1985.

Hiller, J. H. United States Army Training Detractors and Proposed Solution. U.S. Army Research Institute for the Behavioral and Social Sciences, Alexandria, VA, December 1982.

Hiller, J. H. Deriving Useful Lessons From Combat Simulations. Defense Management Journal, Second and Third Quarter 1987, 29-33.

Holtzman, H. Justifying OA Costs, Modern Office Technology, June 1984, 130-136.

Kantowitz, B. H. and Sorkin, R. D. Allocation of Function. In G. Saivendy (Ed.) Handbook of Human Factors, New York: Wiley, 1987, 355-369.

Lavin, M. L., Rosenberg, L. S., and V. W. Gray, User Requirements for an Advanced Technology Unit Training Management System (ATUTMS). U.S. Army Research Institute for the Behavioral and Social Sciences. Alexandria, VA: Defense Technial Information Center, 1985.

Lieberman, M. A., Selig, G. J., and J. J. Walsh. Office Automation: A Manager's Guide for Improved Productivity, New York: Wiley, 1982.

Meister, D. System Effectiveness Testing. In G. Salvendy (Ed.) Handbook of Human Factors, New York: Wiley, 1987, 1271-1297.

Mullins, C. J. and T. W. West. The Office Automation Primer: Harnessing Information Technologies for Gre "er Productivity. Englewood Cliffs, N.J., 1982 .

Packard, David. Technology and Productivity in the United States. In Martin Feldstein (Ed.) The American Economy in Transition, Chicago: University of Chicago Press, $1 \overline{980}$, p. 606 .

Perceptronics, Inc. The Training Information Management System, (6 Volumes). woodland Hills, CA, $19 \overline{985}$.

Strassmann, P. A. Information Payoff; The Transformation of Work in the Electronic Age. New York: The Free Press, 1985.

Strassmann, P. A. The Real Cost of OA, Datamation. August, 1986, 82-94.

Tapscott, D. Office Automation: A User Driven Method. New York: Plenum Press, 1982.

Tueber, H. L. Physiological Psychology. Annual Review of Psychology. 1955, $\underline{6}: 267-296$. 
Willison, G. S., MAJ. U.S. The Battalion Commander's Guide to Successful Training Management. A Thes is Presented to the Faculty of the U.S. Army Command and General Staff College, Ft. Leavenworth, Kansas. Alexandria, VA: Defense Technical Information Center, 1980.

Word, L. E. Observations from. Three Years at the National Training Center. U.S. Army Research Institute for the Behavioral and Social Sciences, Alexandria, VA: Research Product 87-02, 1987. 


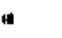

.

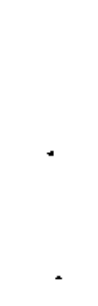


APPENDIX A

STRUCTURED INTERVIEW MATERIALS 


\section{APPENDIX A \\ STRUCTURED INTERVIEW MATERIALS \\ TRAINING MANAGEMENT INTERVIEW SCRIPT}

\section{PREPARATION}

To conduct training management interviews for the ITMS evaluation project, you should receive instruction in the use of:

- This interview script,

- The set of answer keys, and

- The set of data sheets.

After receiving the necessary instructions, you should familiarize yourself with the materials by either thoroughly reviewing all materials or observing an entire interview session.

To ensure a standardized mode of data collection, you should follow this script. Please note that throughout the script:

- Plain text provides general instructions which should not be read aloud

- Bold text provides questionnaire headings and specific instructions that you should follow during the interview, and

- Italicized text provides the interview script that should be read to the interviewee.

CONDUCTING THE INTERVIEW

Before you begin an interview:

(1) Determine and record on Data Sheet 1.0 the interviewer number for your interview. Your number:

$\begin{array}{ll}\text { Bettin } & 1 \\ \text { McCallum } & 2 \\ \text { Melber } & 3 \\ \text { Sanquist } & 4 \\ \text { Schuller } & 5 \\ \text { Seaver } & 6 \\ \text { Underwood } & 7\end{array}$

Then write the 2-digit sequence number of your interviews (e.g., 01 , $02 \ldots)$ after your number.

(2) Check the echelon level of the interviewee, and write in the interviewee's battalion unit name (for battalion and company level interviewees) and company unit name (for company level interviewees). 


\section{SUMMARY OF PROJECT BACKGROUND AND PURPOSE OF INTERVIEW}

The purpose of this project is to determine how training management is practiced in the Army. As you know, training management is defined as the process commanders, their staffs and other trainers use to plan training and to identify related resources needed to conduct ond evaluate training. It is the process of developing training programs with the goal of combining resources, materials guidance, and time to meet specific unit training requirements.

We want to identify areas which could benefit from improvements in the training management process. Our first step is to interview personnel, from all level:i, who are involved in any part of training management to get a description of the work they do. After we have an overview of training management tasks, we will be looking at some tasks in greater detail later on to identify specific improvements that could be made.

The information you provide will help us understand how training management is conducted here. All information will be canfidential; no names of individual staff or units will be used.

As you know, training management is very complex. The number of questions I ask you and the time required for this interview are dependent upon your leve? of involvement in training management. If you have a high level of involvement, we may spend over $11 / 2$ hours; if you have a more limited involvement it may last 30 minutes. I realize this is a significant imposition on your time; however, the information you provide today is critical in determining ways to improve training management procedures. If it is at all possible, I ask you to bear with me as we cover all questions pertinent to your rale in training management.

Let's begin the questions. Throughout this interview I'll be following a script. We're using this script to ensure that all important issues are covered in the same way for each interview. 


\section{BIOGRAPHICAL INFORMATION (DATA SHEET 1.0)}

I'd like to ask some biographical questions so we can know something about the range of people who provide information.

\section{(Record answers in Data Sheet, Part 1.)}

* 1.1 (Fill in on Data Sheet if known--go to 1.2) Would you tell me your rank?

* 1.2 How many years have you been in the Army?

- 1.3 (If interviewee is an officer): What Skill Indicators do you hold?

(If interviewee is an enlisted person): Whot MOSs do you hold?

- 1.4 What types of training monogement jobs have you held?

* 1.5 How mony years have you been involved in training management?

* 1.6 What is your present job title?

* 1.7 How long have you held your present job in training management?

- 1.8 Is training management your primary duty, or is it an additional duty or speciol duty assignment for you?

* 1.9 Whot percent of your duty time, not counting time spent in the field, is spent manoging training? This percentoge should not include time spent conducting training or in evaluation.

* 1.10 How many days in the past year did you spend in the field?

* 1.11 Excluding your time in the field, what are your normol number of duty hours per doy?

Now, I have a final question about who does training management in your unit.

- 1.12 Are there speciol duty personnel, or other personnel, who assist in troining monagement?

If so, could you identify them so that we can interview them briefly? (Record names and positions.) 
2. TRAining MANAGEMENt taSkS PERFORMed (DATA SHEEt 2.0)

Now I have some questions about your training management tasks.

Here is a sheet with the names and definitions of 8 training management tasks.

(Hand the data sheet 2.0 titled "TRAINING MANAGEMENT TASKS" to the interviewee.)

* Please check each task you wark on as part of your job.

(Wait for interviewee to check tasks.)

* Now, is there any other training management work that you do?

(If yes, continue. If no, go to next page.)

* Would you give me a brief one or two sentence description of each additional tosk?

(Limit descriptions to a maximum of three tasks (A, B, C). Write descriptions in spaces provided. Finally, review each additional task with the interviewee and develop a brief task name corresponding to the task description.)

(When completed, leave Data Sheet 2.0 in front of the interviewee for their reference.) 


\section{GENERAL PROBLEMS AND IMPROVEMENTS (DATA SHEET 3.0)}

\subsection{General Problems}

* Before we consider each of your training management tasks in detail, would you describe the three biggest problems you face in your training management work?

(Record descriptions.)

\subsection{General Improvements}

* Do you have any suggestions for improving training monagement?

(Record descriptions.) 


\section{DETAILED INFORMATION ABOUT INOIVIDUAL TASKS (DATA SHEET 4.0)}

Now I an going to ask you a series of questions about each of the tasks you work on.

I'll ask you the entire series of questions for the first task you checkec. Then, we' $l l$ begin the series again for the second task you checked. We'll continue until we have covered all of the tasks you work on.

* (Hrite task number in data sheet 4.0.)

* Here is an answer key we will be using for some of the questions about specific tosks. (Hand the answer key to interviewee.) 
BEGIN TASK QUESTIONS HERE (DATA SHEET 4.0)

4.1 Input Documentation and Data

* 4.1.1 What documents, forms, and other sources of information do you use in carrying out this task?

(Record title or description of each on data sheet.)

* 4.1.2 (For each listed ask:) Where do you get this information from?

(Record location on data sheet adjacent to each input description.)

* 4.1.3 Please turn to Page 1 of your answer key. Using the top answer key, which number best reflects how accurate and up-to-date this information is?

(Record number on data sheet for each input.)

* 4.1.4 Using the bottom answer key, which number best reflects how often you get this information when you need it to carry out this task?

(If interviewee cannot select number, record $N A$ on dato sheet.)

(Record number on data sheet for each input.)

\subsection{Outputs (DATA SHEET 4.0 )}

* 4.2.1 What products do you help generate in carrying out this task?

(Record title and description of each document on data set.)

* 4.2.2 Where do you send (name each product in turn)?

(Write location adjacent to each output description.)

4.2.3 Please turn to Page 2 of your answer key.

* Which number on the top scale best reflects the accuracy of (name each product in turn)?

(Record number in data sheet for each product.)

* 4.2.4 Which number on the bottom scale best reflects the adequacy of the time you have to produce (name each product in turn) on schedule.

(Record number in data sheet for each product.) 


\subsection{Type of Work (DATA SHEET 4.3)}

Now I have several questions about the type of work you do for this task.

Please turn to page 3 in your answer key.

I'd like you to consider seven types of work that may be part of this task. Let's run through each of these types of work.

1. Discussing and plonning ways to obtain, process, and document training management information.

2. Obtaining documents and information.

3. Copying and compiling information from available source documents.

4. Analyzing and interpreting documents and information.

5. Computing numerical dato.

6. Preparing tosk documents, including document revisions.

7. Supervising, directing, and leading others in carrying out this tosk.

* Now, for the work you do on this task, please write-in your estimates of approximate percentages of the time you spend on specific types of work. Note that the total should equal $100 \%$ of the time you spend on the task. 


\subsection{Problems Encountered (DATA SHEET 4.4)}

Please turn to Page 4 in your answer key.

- Now, I want you to briefly describe the kinds of problems you typically encounter in carrying out this task.

(Record answers in data sheet, as obtained.)

* 4.5.1 Are there any common problems in obtaining the information you need?

4.5.2 Preparing the products of the task?

* 4.5.3 Receiving feedback on the praducts you prepare?

* 4.5.4 Revising the products based on feedback?

RETURN TO PAGE 7 If ALL TASKS ARE NOT COMPLETED 


\section{TASK FREQUENCY AND TIME (DATA SHEET 5.0)}

Here's a form I'd like you to use to indicate how often you do each task and how much time you spend on each task.

(Hand a copy of Data Sheet 5.0 to the interviewee.)

* First, let's go through the form and check those tasks that you do.

(Copy information from Data Sheet 2.0)

\subsection{Frequency}

* Please write-in how often you work on this task.

\subsection{Percent of TM Time}

* Now I'd like to get some information on the total time you spend on training monagement.

* Considering only your time on training management tasks, please write-in your estimates of approximate percentages of time you spend on each of the tosks checked.

Note that the total should equal $100 \%$. 
6. SCHEDULED TRAINING ACCOMPLISHED (DATA SHEET 6.0)

Now I'd like to get some information concerning how often troining schedules must be modified and training exercises must be conducted in response to unexpected events.

* 6.1 Does your position allow you to compare the training that is actually conducted with the training that had been scheduled?

(If yes, hand "Example" sheet to interviewee. If no, go to next page.)

6.2 Based on the last three months, whot percent of scheduled training took place as planned on the training schedule?

6.3 What percent of scheduled training was rescheduled and conducted?

6.4 Whot percent of scheduled training was not conducted?

6.5 Over the past three months, what percent of all training was conducted without scheduling? 


\section{CURRENT USE OF AUTOMATED SYSTEMS (DATA SHEET 7.0)}

During this interview, you may have mentioned some types of automated systems you use during task work.

Here's a final answer sheet listing a number of automated systems and each of the tosks.

* 7.1 First, let's check those tasks that you do. Now, please check those boxes that show which systems, if any, you use in working on each task.

* Are there any other automated systems you use? If so, what ore they? (Check tasks performed by interviewee.)

\section{(If there is time, ask:)}

7.2 Do you hove ony suggestions for improving training management through automation?

7.3 Thank you very much for your time. Before I leave, are there any further comments you would like to make? 
8. INTERVIEWER OBSERVATIONS (DATA SHEET 8.0)

Interviewers should try to set aside a few minutes after the interview session to document their personal observations. Important factors that should be recorded include, but are not limited to, the following:

- The level of confidentiality permitted by interview conditions. Include mention of others intentionally over-hearing or participating in the interview.

- Any deviations from the established interview structure and sequence.

- Any observations concerning the level of the interviewee's attentiveness, the relative frequency of interruptions during the interview, and the relative length of the interview period.

- Willingness of the interviewee to show examples of his/her work. (Interviewers are encouraged to collect examples of all forms, spreadsheets, etc. and document this.)

- Explicit mention by the interviewee concerning his/her adherence to doctrine.' (Either high level of adherence or specific deviations.) 
ANSWER KEYS

A-14 


\section{ACCURACY OF TASK INFORMATION}

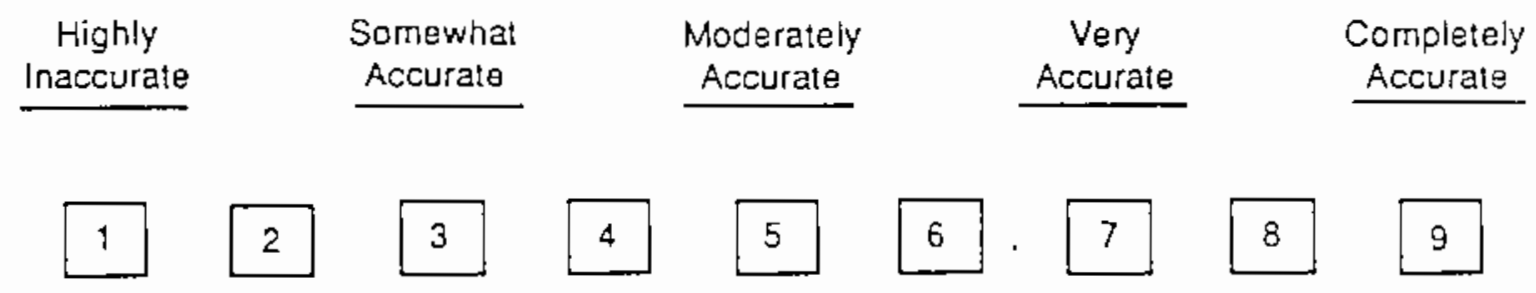

\section{AVAILABILITY OF TASK INFORMATION WHEN NEEDED}

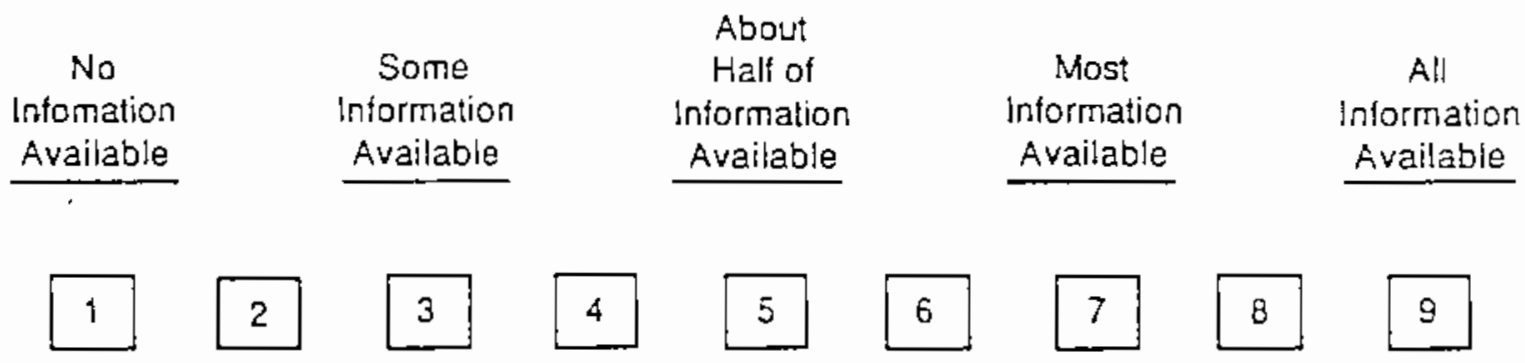


ACCURACY OF TASK INFORMATION PRODUCED

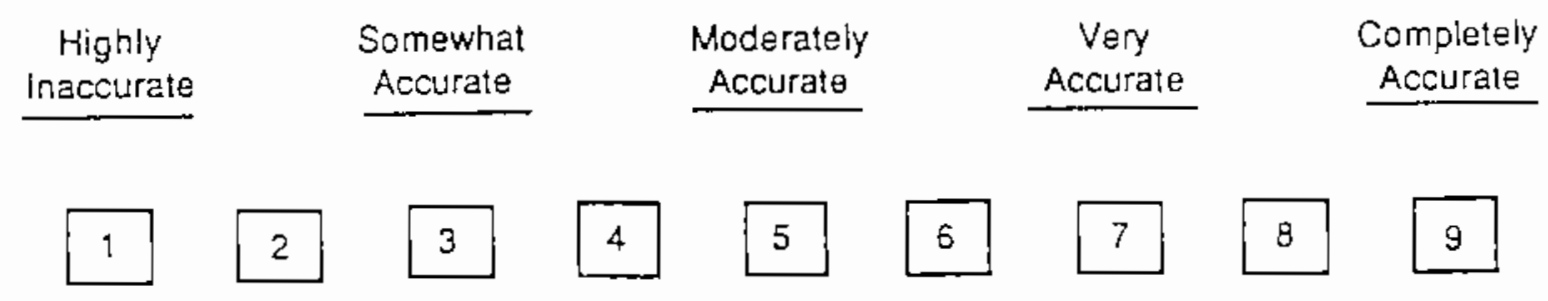

TIME AVAILABLE TO COMPLETE TASK IN A TIMELY MANNER

\begin{tabular}{|c|c|c|c|c|c|c|c|c|}
\hline $\begin{array}{c}\text { Never } \\
\text { Enough } \\
\text { Time } \\
\text { Available } \\
\end{array}$ & & $\begin{array}{c}\text { Seldom } \\
\text { Enough } \\
\text { Time } \\
\text { Available } \\
\end{array}$ & & $\begin{array}{c}\text { About } \\
\text { Half of } \\
\text { the Time } \\
\text { Enough } \\
\text { Time } \\
\text { Available } \\
\end{array}$ & & $\begin{array}{c}\text { Usually } \\
\text { Enough } \\
\text { Time } \\
\text { Available }\end{array}$ & & $\begin{array}{l}\text { Always } \\
\text { Enough } \\
\text { Time } \\
\text { Available }\end{array}$ \\
\hline 1 & 2 & 3 & 4 & 5 & 6 & 7 & 8 & 9 \\
\hline
\end{tabular}




\section{TYPES OF WORK:}

1. Discussing and Planning Task Work

2. Obtaining Documents and Information

3. Copying and Compiling Information

4. Analyzing and Interpreting Information

5. Computing Numbers

6. Preparing Task Documents

7. Supervising, Directing, and Leading Others 
TYPES OF PROBLEMS ENCOUNTERED IN CARRYING OUT TASK

1. Problems in Obtaining the Information You Need

2. Preparing the Products of the Task

3. Receiving Feedback on the Products You Prepare

4. Revising the Products Based on Feedback 


\subsection{DATA SHEET - BIOGRAPHICAL INFORMATION}

(Fill in information below prior to interview)

Interviewer Number:

Interviewer :

Date :

Time:

$\begin{array}{clll}\text { Echelon Level: } & \text { Division } & - & \text { 9th ID } \\ \begin{array}{c}\text { (Check level of } \\ \text { respondent's } \\ \begin{array}{c}\text { unit } \\ \text { assignment) }\end{array}\end{array} & \text { Brigade } & \text { Brd Brigade } \\ & \text { Company } & - & \text { Specify: } \\ & - & \text { Specify: }\end{array}$

1.1 Rank:

1.2 Years in Army:

1.3 MOS or Specialty:

1.4 Names of Training Management Jobs:

1.5 Years lnvolved in Training Management:

1.6 Present Job Tile:

1.7 Time in Present Job:

1.8 Type of Training Management Duty (Check one):

Assigned ] Primary:

Special:

Additional:

1.9 Percent TM Time:

1.10 Days in Field:

1.11 Typical Duty Hours:

1.12 Non-assigned Special Duty Personnel: 


\subsection{DATA SHEET - TRAINING MANAGEMENT TASKS PERFORMED}

\section{Interviewer Number:}

\section{CHE:CK IF \\ DONE}

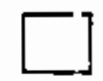

1. IDENTIFY UNIT MISSIONS, MISSION GOALS, METL, AND ENABLING (BATTLE) TASKS

2. IDENTIFY TRAINING OBJECTIVES, TASKS FOR TRAINING, AND TRAINING PROGRAM

3. FORECAST RESOURCE REOUIREMENTS AND PREPARE BUDGET INFORMATION

4. ISSUE LONG-PANGE (6-24 MONTH) TPAINING GUIDANCE

5. ISSUE SHORT-RANGE (3-6 MONTH) TRAINING GUIDANCE

6. ISSUE NEAR-TERM (3-12 WEEKS) TRAINING GUIDANCE

\section{ISSUE TRAINING SCHEDULE}

8. DETERMINE TASK TRAINING STATUS ANO FEEDBACK ANO REPORT TRAINING READINESS

A

B.

c.

\section{TASK DESCRIPTION}

Obtain and analyze relevant documents and information. then identify all of own unit's wartime missions; identify the goals for training, manning, and equipping the unit; develop the unit's METL and get Higher Commander's approval of this document; and identify enabling tasks that must be performed by own unit to support Higher Commander's mission.

Obtain and analyze relevant doocuments and information, then identify the unit's training objectives, consisting of tasks, conditions, and standards; identify the unit's tasks for training and the unit's training program.

Obtain and analyze reievant documents and information, then forecast training resource requirements for funds, ammunition, flying hours, ranges, training aids, fuel, etc.

Obtain and analyze relevant documents and information, then issue Long-Pange training guidance, coordinate training resources, and issue the Long-Pange Plan.

Obtain and analyze relevant documents and information, then issue Shon-Pange training guidance, coordinate training resources, and issue the Short-Range Plan.

Obtain and analyze relevant documents and information. then issue Near-Term training guidance, coordinate training resources, and issue the Near-Term Plan.

Obtain and analyze relevant documents and information, then develop and publish the unit's Training Schedule.

Obtain and analyze relevant documents and information, then determine task training status and provide unit feedback

(Use back of page, if necessary) 
3.0 DATA SHEET - GENERAL PROBLEMS AND IMPROVEMENTS

3.1 General Problems

A.

B.

C.

\subsection{General Improvements}

A.

B.

C. 


\subsection{DATA SHEET - DETAILED INFORMATION ABOUT INDIVIDUAL TASKS}

INTERVIEWER NUMBER:

4.1 Input Documentation and Data

4.1.1 Input Name/Description

4.1.2 Location

4.1.3

Accuracy

4.1.4

Availability

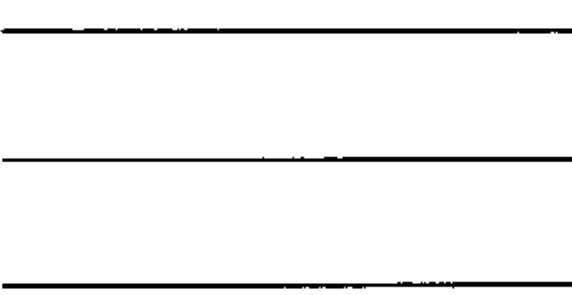

4.2.1 Productt Name/Description

4.2.2 Destination

4.2 .3

Accuracy

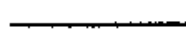

\section{A-22}

TASK NUMBER: 
4.3 DATA SHEET - COMPARISON OF TASKS

INTERVIEWER NUMBEA:

TYPES OF WORK
CHECXIF
DONE
TASK
IOENTIFY UNIT MISSIONS, GOALS METL AND ENABLING TASKS
$\square$ 2. OEVELOP TRAINING OQNECTIVES.
TASKS FOR TRAINING, AND TRAINING PROGRASM

\section{FORECAST REQUIREMENTS}

$\underset{\substack{1 \\ \sim}}{\sim}$ 4. LOMG-RANGE GUIDANGE

$\square$ 5. SHOFT-RANGE GUIOANCE

$\square$ 6. NEAR-TEPM GUIDANCE

$\square$ 7. ISSUE TRANING SCHEDULE

$\square$ 8. DETERMINE TRANING STATUS

$\square$ A.

$\square$ B

$\square \mathrm{c}$

A.

B.

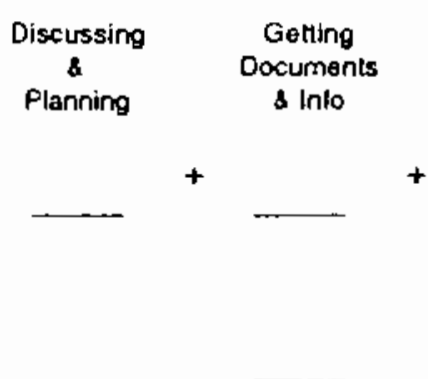

Copying

Compaing Interpreting

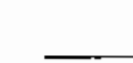

$=100 \%$ of time on task
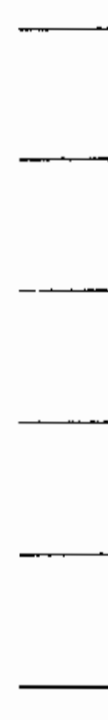


\subsection{DATA SHEET - DETAILED INFORMATION ABOUT INDIVIDUAL TASKS}

INTERVIEWER NUMBER:

TASK NUMBER:

4.4 Problems

4.4.1 Obtaining information

4.4.2 Preparation

4.4.3 Feedback

4.4.4 Revision/Completion 


\subsection{DATA SHEET - FREQUENCY AND TIME}

INTERVIEWER NUMBER:

- CHECKIF DONE

TASK

1. IDENTIFY UNTT MISSIONS, GOALS MET, AND ENABLING TASKS

2. DEVELOP TRAINING OBJECTIVES, TASKS FOR TAAINING, AND

TRAINING PROGRAM

3. FORECAST REQUIREMENTS

4. LONG-RANGE GUIDANCE

5. SHORT-RANGE GUIDANCE

6. NEAR-TERM GUIDANCE

7. ISSUE TRAINING SCHEDULE

8. DETERMINE TRAINING STATUS

A.

B.

c.

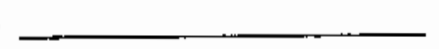

Number

of Times

Per Year

$$
\begin{aligned}
& \text { Percent } \\
& \text { Of TM } \\
& \text { Time }
\end{aligned}
$$
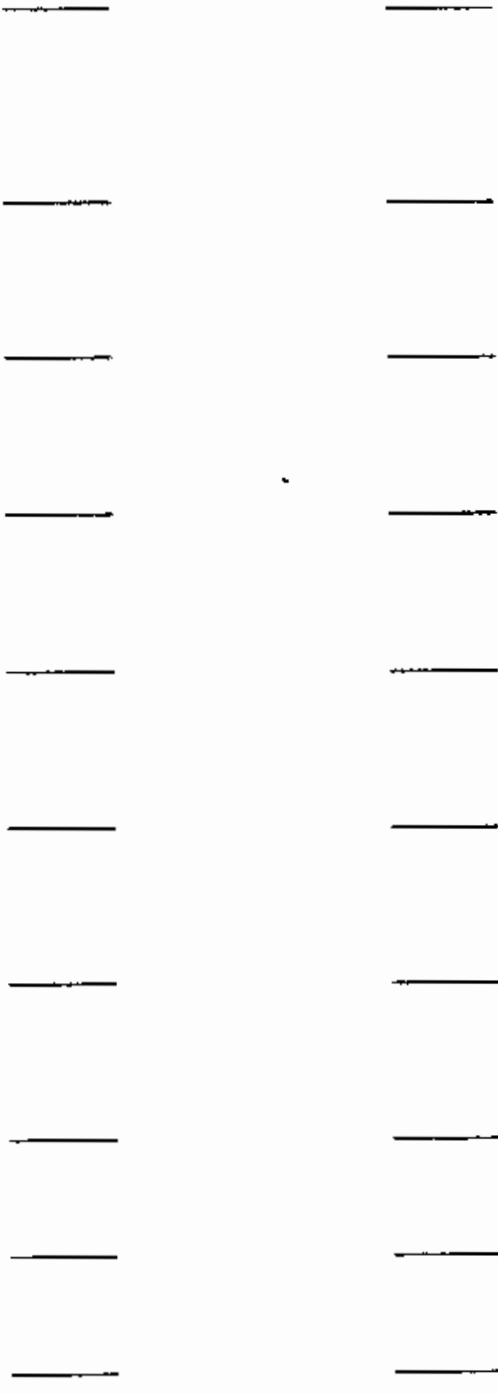

TOTAL TM $\%=100$ 
6.0 DATA SHEET - SCHEDULED TRAINING ACCOMPLISHED

6.1 Can Compare:

Yes

No

6.2 Percent:

6.3 Percent:

6.4 Percent: 
7.0 DATA SHEET - CURRENT USE OF AUTOMATED SYSTEMS

INTERVIEWER NUMBEA:

AUTOMATED SYSTEM NAME

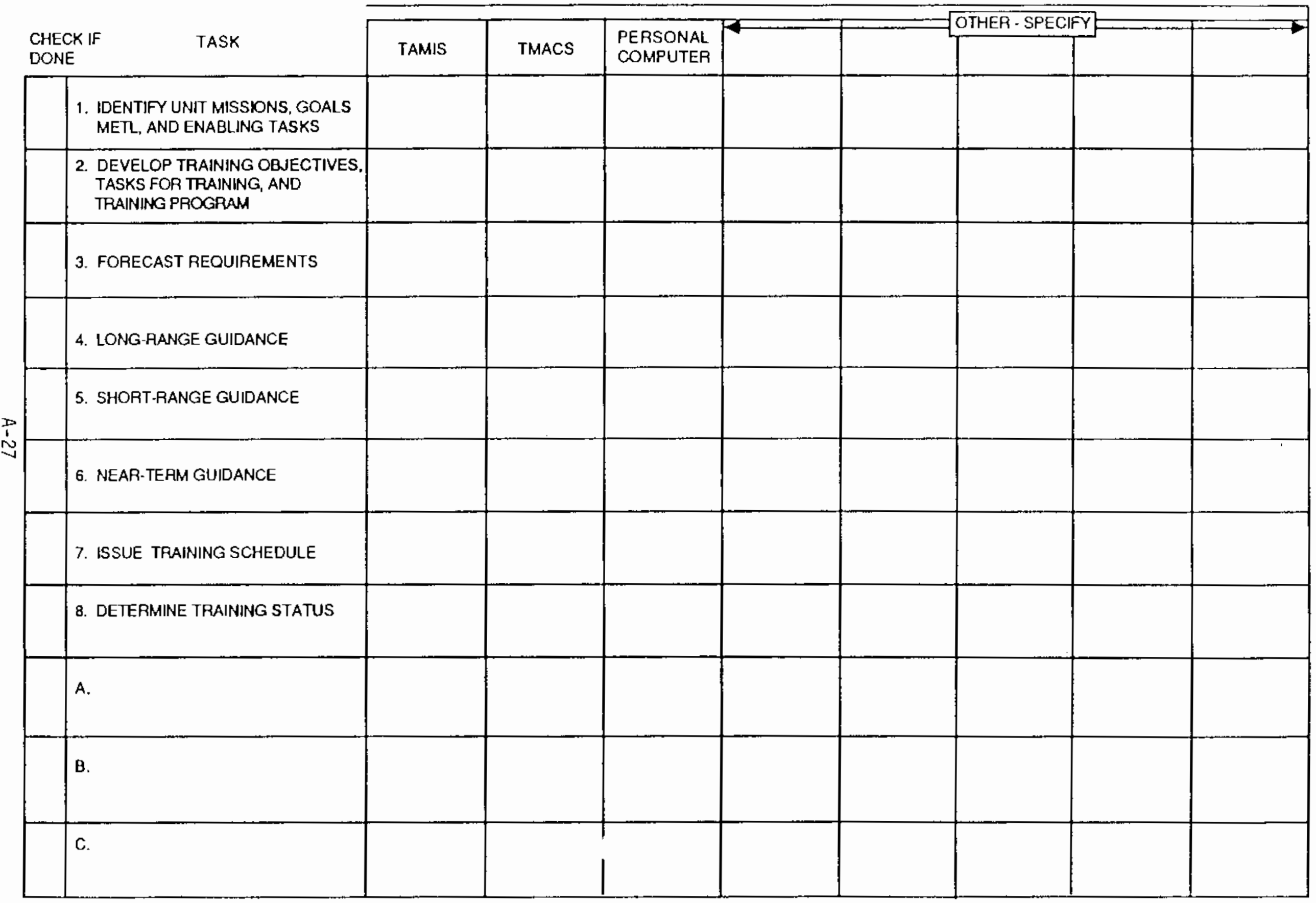


APPENDIX B

STRUCTURED SURVEY RESPONDENTS 
APPENDIX B

STRUCTURED SURVEY RESPONDENTS

$\begin{array}{lll}\text { Echelon } & \text { Unit } & \text { Job } \\ \text { Installation } & \text { Range Control } & \begin{array}{l}\text { Range Control Officer } \\ \text { Scheduling NCO }\end{array} \\ \text { Division } & \text { G3 Training } \\ & \text { G3 Assistant } \\ & \text { Assistant Training Officer, Ammo } \\ & \text { Data Training Resource Manager } \\ & \text { NCO In Charge } \\ & \text { Division Ammo NCO } \\ & \text { Operations NCO } \\ & \text { Training Inspector } \\ \text { Clerk Typist } \\ \text { Draftsperson }\end{array}$

Brigade

3rd BDE HQ

53

S3 Assistant (2)

S3 Assistant Operations

Chemical officer

Aпrno NCO

Schools NCO

Master Gunner

Training $\mathrm{NCO}$

Battalion

$2 / 60 \mathrm{CAB}(\mathrm{H})$

S3 Assistant Chemical officer Operations Assistant

$3 / 47$ CAB (L)

53

S3 Air Operations Sergeant Operations Assistant Schools NCO

3/11 FA

S3

Fire Direction Officer Operations officer BN Supply Sergeant Schools NCO Operations Sergeant

99 SB

53

S3 Assistant

Chemical NCO

Section NCO

Training NCO

Operations Sergeant 
Echelon

Company
Unit

3rd BDE HHC

$2 / 60 \mathrm{HHC}$

$2 / 60$ B CO

$2 / 60 \mathrm{C} \mathrm{CO}$

$2 / 60 \csc$

$3 / 47 \operatorname{CSC}$

$3 / 47$ A CO

$3 / 47$ B CO

$3 / 47$ C CO

$3 / 11$ HHB

$3 / 11$ A BT

3/11 C BT

$3 / 11$ SVC

99 HSC

99 A CO $\underline{\text { Job }}$

Company Commander

Training NCO

Company Commander

Company Commander 1st Sergeant

Company Commander Training NCO

Company Commander Training NCO

Company Commander Executive Officer Training NCO

Training NCO

Executive Officer Training NCO

Battery Commander Executive Officer Training $\mathrm{NCO}$

Battery Commander Chief, Firing Battery

Battery Commander Chief, Firing Battery Gunnery Sergeant

Battery Commander Training NCO

Company Commander 1st Sergeant

Company Commander Company Clerk 
APPENDIX C

SUMMARY OF CONTENT ANALYSIS 
This appendix provides a more detailed discussion of the results of the content analys is of the General Problems, Solutions, and Automated Features. Each discussion highlights the major findings and provides representative respondent comments in each response category.

General Problems

Resource Availability. Respondents provided 25 individual comments in this category, with the majority of those statements coming from company-level personnel. All types of training resources were mentioned by respondents, although comments about the lack of available ammunition and ranges were the most common. Two representative statements are provided below; the echelon of the respondent is provided in parentheses.

- Last-minute changes from [higher headquarters], especially in ammunition and equipment, cause training disruptions. (Battalion)

- Getting training areas that allow for employment of [the] unit under [the] motorized concept. (Company)

Administrative Procedures. Twenty-two comments regarding administrative procedural problems were provided by respondents. Such comments were most prevalent among battalion-level personnel, but were also relatively common among other echelons. Several comments focus on the level of paperwork, the need to hand-carry certain forms to obtain approval, and the brief periods of time available to process some types of information.

- Short time frame for brigade staff to process sub-unit training schedules, compile highlights for brigade, and pass to Division G-3. (Brigade)

- Constant change--no stability in Unit Status Reporting procedures imposed by higher echelons. (Battalion)

Adherence to Procedures. Twelve comments directed at the lack of adherence to established training management procedures were made by respondents. Eight of these comments were made by personnel at division level. 
- Incomplete requests [and] not following guidelines requires sending [the requests] back and forth. (Division)

- Units not adhering to the schedule for training aids and range utilization--no shows for scheduled areas and changes at the last minute. (Division)

Iraining Distractors. Respondents made 22 comments that focused on the problems associated with training distractors in managing training. iompany personnel provided the majority (15) of these comments, which often stressed the last-minute nature of imposed taskings. Readers should note that all units surveyed were in a support cycle during the time that these interviews were conducted.

- Taskings from division headquarters not given in time to react. [This causes] many problems at the company level where execution must be coordinated. (Company)

- Training distractors--taskings--they don't know about when training was scheduled. You get very short notice on division support cycle requirements [requiring] management time which would have been spent on training. (Company)

Resource Forecasts and Requests. Ten separate comments concerning zroblems in resource forecasting and requesting were made by respondents.

- [Ability] at brigade to monitor actual ammunition expenditures. The brigade is actually at the e' ' of the ammunition information flow. (Brigade)

- Last minute requirements from platoon leaders and sergeants, such as asking for ranges too late. Platoon personnel don't know how to look at resources available then determine training requirements. (Company)

Personnel Management. Eight comments regarding personnel management zroblems that disrupted training management were mentioned.

- Changes in personal assignments--basically juggling various responsibilities--results in conflicts in ability to support training. (Brigade)

- Incompatibility of training management personnel training and job requirements. (Battalion)

Schedule Changes and Conflicts. Respondents provided 14 comments regarding the disruptive effects of schedule changes and conflicts on 
training. As in the case where training distractors were explicitly mentioned, company personnel provided the majority (8) of these types of comments.

- Higher command changes which require battalion changes and the need to pass down changes in schedules to batteries. Major problems are weekly and daily changes. (Battalion)

- Placing events on the training schedule then having to cancel training. Either scheduling conflicts arise or there is an ammo problem. Some good training gets cancelled. (Company)

Higher Command Guidance. Thirteen comments identified higher command guidance as a problem in training management. The majority of these comments were provided by company personnel. Comments focused on various aspects of guidance, from identifying missions more precisely to an excess of directed training.

- Lack of clarity on missions from DA and above. [9th ID] needs a ciearer mission in Europe [it's uncertain] who we work for. Do we train for desert, jungle, or Europe? [Guidance] is unclear. (Brigade)

- Availability of time to complete DA- and Brigade-directed training. More directed training than time allowed [for training]. (Company)

Communications. Eight comments focused on the effect of sub-optimal communications on training management.

- Communication at all levels--communicating with separate sections within the unit to coordinate training. (Company)

- Communications--when the company receives notification of changes in training schedules, they are already outdated. (Company)

\section{Suggested Improvements}

Training Management Resources. Respondents provided 21 suggestions for improving training management through the introduction of resources to support the management process. Many of these comments suggested ways to improve or introduce automated procedures and computer operator training.

- Difficulty in operating current automated systems. Lack of training with new automated systems. (Division) 
- Would like some type of software program on line with Range Control listing what brigade subordinate units have scheduled. [These] units must place their [requests] through the brigade S-3 for approval anyway. (Brigade)

- Provide the company with more tools such as computers, typewriters, and photocopiers. (Company)

Training Management Procedures. Sixteen suggested solutions identified areas in which current training management procedures could be improved, or adherence to current procedures could improve the current process. No such suggestions were provided by respondents in companies.

- G-3 staff needs to review paperwork load and get rid of unnecessary work. (Division)

- Ammo system should be [managed as stated in doctrine]; it would work if followed. Ammo availability drives training rather than training needs driving ammo resources. (Brigade)

Communications. Seventeen suggestions were classified as dealing with improvements in training management communications. Over half of these zomments came from company-level personnel.

- Quicker flow of information past commanders at all levels. (Brigade)

- Better company training forecasting. SQT results and training tests are not being rolled back into determining training needs. (Company)

- Centralize materials request processing. (Company)

Personnel. Respondents provided eight comments focusing on improvements in current personnel management practices that would facilitate training nanagement.

- Increase tenure for job assignments. Reduce turnover. Keep same people at least one year. (Division)

- Increased number of personnel. (Brigade)

Division Organization. Eight comments concerning possible reorganization of training management responsibilities within the 9ID (MTZ) were provided by respondents.

- Keep training aids at battalion. (Brigade) 
- Central point of contact for clarification of questions at division level. (Battalion)

Training Resources. Respondents, predominately those at the company level, provided 13 suggestions for alleviating problems by increasing resources availability and quality. In general these suggestions focused more on the originally stated problem than on providing actual solutions to problems.

- Place more training aids in TASC. (Company)

- Better map supply and TASC items for class presentation. (Company)

Iraining Distractors. Sixteen comments made primarily by company-level respondents addressed the problem of training distractors.

- Reduce taskings, if possible, by spreading [them] between companies and looking for alternative support personne]. (Company)

- Reduce taskings. Division level control over taskings results in taskings that should be coordinated with the training cycle; but excessive taskings during cycles other than [support cycle] are made. So, better coordination between division and brigade.

Higher Command Guidance. Respondents provided 10 suggestions directed at changes in higher command guidance. These comments were made almost exclusive?y by personnel at the battalion- and company-levels.

- Have higher headquarters make clear their instructions contained in publications. Update their references more often than every few years. (Battalion)

- Make training a priority. (Company)

\section{Automation Features}

Network within Installation. Twenty-two suggestions indicated that some form of networking or electronic mail would improve the current training management process. These comments were made consistently across personnel from the four echelons.

- It would be good to have an integrated/networked system with links between battalion, brigade, and division. (Brigade) 
- Integrate a training management automation system with other systems on post. Would prefer on-line systems over transporting floppy or hard disks. (Battalion)

- With information from battalion that is currently on the GRID computer, the [company] could start planning much earlier.

Resources. Seventeen comments focused on ways in which the management of training resources could be automated. As in the identification of problems, the major areas identified were ammunition and training area information.

- [An automated system] would be especially useful for passing ammo information. If ammo information could be interrogated at brigade level to check battalion ammo requirements and determine division and installation ammo availability; then make the best use of resources. (Brigade)

- Want access to Range Control database--not to change data, but to see usage data. Want same type of data as Range Control [has] to influence subordinate units. Sometimes subordinate units bypass brigade and [we] are not aware of the total demands. (Brigade)

Provide to Companies. Although this was seldom an explicitly stated feature of suggested automated systems, the prevalence of suggestions for implementing automation was so high among company-level respondents (69\%), that this result deserves mention.

Training Records. Thirteen comments suggesting the automation of saining records were made by respondents.

- Would like to see a method established to access ITEP databases. Only want SQT test scores. (Brigade)

- Complete summary of individual status available at company and battalion level. (Battalion)

- SQT and CTT spreadsheets could be standardized and networked. (Company)

Scheduling. Respondents provided eleven comments suggesting improvements in the automation of training schedules. These suggestions were made zrimarily by personnel at the battalion- and company-levels.

- System to help plan training for the battalion and company commanders-just like he does ammo forecasting--get a computer-based worksheet/calendar. (Battalion) 
- All training schedules--but don't use a locked-in graphic format; use one that doesn't reflect unrealistically precise schedules. Automate [schedule] changes and network the schedules [between headquarters].

Forms. Eight respondents suggested the automation of procedures to reduce manual form preparation, or reduce paperwork. Again, suggestions came predominately from battalion-level and company-level personnel.

- Vast amounts (95\%) of AG blank forms could be done away with by automating the formats. The battalion has several cabinet drawers filled with blank forms ranging from often-used to seldom-used. Not all blank forms [are] compatible; for example casualty tags and $D X$ tags. (Battalion)

- Automated disposition forms. (Company)

Not Training Management-Specific. Nine comments were made by respondents who would prefer a general-purpose computer that was not dedicated to training management. The majority of these comments were made by company personnel.

- Would like an integrated hardware/software system that takes care of all administration. (Company)

- Would like automation in the context of total office automation for administration, supply, maintenance, and training management. (Company)

Store Training Manuals and Training Requirements. Respondents provided eight comments regarding decreasing paper requirements and facilitating retrieval of information through electronic storage of training manuals and training requirements. Most comments came from battalion and company personnel.

- ARTEP tasks--go beyond a listing and identify required areas of training. (Company)

- Would like a [database] cross referencing ARTEPS and individual level tasks. For example, Deliver Fire: tasks, standards, and training references, with aids available. (Company) 
APPENDIX D

COMPARISON OF DOCTRINE AND PRACTICE 
This section presents the results of the analys is of document category usage by each echelon for the eight TM tasks studied. The results are presented both for documents used as input for a particular task, and those produced or used for generating output. The specific documents contained in the categories analyzed are listed at the end of the appendix.

TASK 1: IDENTIFICATION OF UNIT MISSIONS, GOALS, METL, AND ENABLING (BATTLE) TASKS

Input

The development of unit missions, goals, METL and enabling tasks doctrinally begins with identifying wartime missions and developing supporting goals. Doctrinal reference sources cited were TOE/MTOE, OPLANS, contingency plans, directives and training guidance from higher headquarters, TRADOC doctrinal literature, installation guidance and directives, and Army and MACOM regulations. Structured interview results indicated no use of Army-level mission and training guidance above battalion, where the guidance was limited primarily to ITEP, weight control, and weapons qualifications. The same situation was noted for guidance from FORSCOM (MACOM-Ievel), installation, and corps (higher headquarters). Units reported using division, MSC, and battalion long-, short- and near-term planning guidance not normally considered doctrinal wartime mission and goal resources. The rationale offered by interviewees was a need to look at mission tasks in light of historical and current planning documentation published as mission and task guidelines. Battalion and companies also reported using previous training results as guides for prioritizing mission tasks.

\section{Output}

All echelons, division through company, reported preparing some form of goal and mission task list. Only the division, one MSC and one battalion had completed METL development; the others reported being in various stages 
TABLE D.1. Proportion of Respondents Citing Reference As Input for Task 1 - Identification of Unit Missions, Goals, METL, and Enabling (Battle) Tasks

\section{Proportion Citing Ref as Task Input}

$\underline{\text { Re }}$ erences

Army Mission

Guidance

Army Training

Gu dance

FORSCOM Training

Gu dance

TRADOC Training

Gu: dance

Comps Training

Guidance

Installation

Training

Gu dance

Division

Misision

Gu dance

Division

Training

Guidance

Division

Long-Range

plinning

Division

Short-Range

Guidance

MS: Training

Guidance
Div $\quad \underline{M S C} \quad \underline{B N} \quad \underline{C O}$

.14 Little cited use of TOE documentation for Task $\# 1$.

.22 .14 Consisted of program guidance such as ITEP, weight control and weapons qualification.

.22 Guidance principally FORSCOM Regulation 350-1.

1.00

.60

$.78 \quad .57$

Heavy reliance on TRADOC references such as ARTEP, CMTR and FMs in defining battle tasks.

Referenced during survey but no examples of corps guidance given by interviewees.

.11 .14 Program guidance on Individual Test and Evaluation (ITEP).

$\begin{array}{llll}.40 & .11 & .14 & \text { Division contingency OPLANS and }\end{array}$ moven. t plans.

1.00

$.56 \quad .29$

Consisted primarily of Division Regulation 350-1 and Division Commander's written guidance.

.14 Historical yardstick for mission analysis.

Same as above.

.40

.56

.43

MSC Commanders "visions" and goals along with METL and Cominander's focus as currently published. Heavy emphasis throughout division on MSC training guidance. 
TABLE D.1 (cont)

Proportion Citing Ref as Task Input

References

Div MSC $\underline{B N} \underline{C O}$

Comments

MSC Long-Range

.14 Historical yardstick for mission

Guidance

MSC Near-Term

Guidance

.11 analysis.

Battalion

.14

Mission

Guidance

Battalion

Training

$.22 .14 \quad$ Primary source was battalion commander's written guidance on training philosophy. Companies cited more reliance on MSC training guidance than battalion training guidance.

Battalion

.11

Historical yardstick for mission

Long-Range

analysis.

Guidance

.11

Same as above.

Battalion

Near-Term

Planning

Company Mission

.14

Guidance

Previous Training

.22

.14

Same as above.

Schools

Allocation

Not normally used to define missions and goals. 
TABLE D.2. Proportion of Respondents Citing Reference As Output for Task 1 - Identification of Unit Missions, Goals, METL, and Enabling (Battle) Tasks

Proportion Citing Ref as Task Output

References

Division Training .50

Guidance

Division Long-

Range Planning

MS: Training

Guidance

MSC Long-Range

Guidance

MSC Short-

Range Guidance

MSC Near-Term

Guidance

Battalion

Training

Gu: $r$ ence

Battalion Long-

Range Guidance

Battalion Near-

Term Guidance

Company Mission

Guidance

Company Training

Guidance

Ccmpany Short-

Range Guidance
.21 Company guidance normally consisted of a few goals and training objectives. Most guidance verbat-not found written at company.

.21 Same as comment on company mission guidance.

.07 Guidance results in planning changes to calendars. 
of the process. All echelons reported producing long-, short- or near-term planning guidance developed as results of Task 1 input. Though not doctrinally stated as part of the Task 1 process, this reflects the fact that planning is a continuous process and that whatever affects missions and goals affects planning.

TASK 2: IDENTIFICATION OF TRAINING OBJECTIVES, TASKS FOR TRAINING, AND TRAINING PROGRAM

Input

Doctrinally, commanders use enabling tasks to establish training objectives consisting of task, condition, and standards. With an established METL and training objectives, the training estimation process begins defining training programs. At battalion and company, previous training results were a key source of analysis input in accordance with doctrine, although rates were significantly lower than 100 percent usage. The results showed the usage rates of battalions and companies for previous training results are .55 and .21 respectively. One battalion used a form of proficiency worksheet for determining task status, while the others had no formatting procedures. The doctrinal practice of estimating training status with CAFS (combined arms functional systems) was not found in use anywhere. As reported in Task 1 , Input, units reported using long-, short- and near-term planning guidance in the task estimation process, which are not normally part of the doctrinal process. Again, there was a reported tendency to view current training status in light of historical and current planning.

Output

Doctrinally, the training objective and estimation process should result in a recommended training program identifying all METL and directed requirements. One MSC had developed a viable training program relating tasks to an ordered set of events. The output rate at MSC level for developing training programs was high, .75, which was an expected outcome. With the exception of one unit, most battalions and companies had no formal analysis procedures. MSC and subordinate echelons produced long-, short- and near 
TABLE 0.3. Proportion of Respondents Citing Reference As Input for Task 2 - Identification of Training Objectives, Tasks for Training, and Training Program

\section{Proportion Citing Ref as Task Input}

\begin{tabular}{|c|c|c|c|c|c|}
\hline References & Div & MSC & $\underline{B N}$ & $\underline{\mathrm{CO}}$ & Comments \\
\hline $\begin{array}{l}\text { Army Mission } \\
\text { Guidance }\end{array}$ & 1.00 & .25 & & .16 & $\begin{array}{l}\text { Extensive use at division level } \\
\text { of Army directed training guidance: } \\
\text { OPFOR, ITEP, NCO Development, etc. } \\
\text { Eventually translated into division } \\
\text { directed training guidance }(350-1) \text {. }\end{array}$ \\
\hline $\begin{array}{l}\text { FORSCOM Training } \\
\text { Guidance }\end{array}$ & 1.00 & & & & $\begin{array}{l}\text { Similar emphasis at division level } \\
\text { on FORSCOM training guidance as } \\
\text { on Army level guidance. }\end{array}$ \\
\hline $\begin{array}{l}\text { TRADOC Training } \\
\text { References }\end{array}$ & 1.00 & .25 & .57 & .63 & $\begin{array}{l}\text { Continued reliance on TRADOC- } \\
\text { produced doctrinal references. }\end{array}$ \\
\hline $\begin{array}{l}\text { Installation } \\
\text { Training } \\
\text { Guidance }\end{array}$ & & & .09 & & \\
\hline $\begin{array}{l}\text { Digision } \\
\text { Training } \\
\text { Guidance }\end{array}$ & 1.00 & 1.00 & .18 & .21 & $\begin{array}{l}\text { Subordinate echelons attach } \\
\text { importance to next higher } \\
\text { headquarter's training guidance. } \\
\text { MSC percentage very high for this } \\
\text { reason. }\end{array}$ \\
\hline $\begin{array}{l}\text { Dirision Long- } \\
\text { Rage Guidance }\end{array}$ & & .5 & .18 & & $\begin{array}{l}\text { Historical yardstick for training } \\
\text { status analysis. }\end{array}$ \\
\hline $\begin{array}{l}\text { Division Short- } \\
\text { Rarge Guidance }\end{array}$ & & & .09 & & Same as above. \\
\hline $\begin{array}{l}\text { MS: Missions } \\
\text { Guidance }\end{array}$ & & & & .05 & $\begin{array}{l}\text { Companies report rareiy considering } \\
\text { MSC mission in Task } 2 \text {. Reasons } \\
\text { offered ranged from missions not } \\
\text { seen to more reliance on battalion } \\
\text { training guidance. }\end{array}$ \\
\hline $\begin{array}{l}\text { MS: Training } \\
\text { Guidance }\end{array}$ & & .75 & .09 & .26 & $\begin{array}{l}\text { Data again show subordinate unit } \\
\text { reliance on next higher } \\
\text { headquarter's guidance, with the } \\
\text { exception of battalions. Their } \\
\text { reliance switched to previous } \\
\text { training results emphasis. }\end{array}$ \\
\hline
\end{tabular}






Proportion Citing Ref as Task Input

\begin{tabular}{|c|c|c|c|c|}
\hline References & $\underline{\mathrm{MSC}}$ & $\underline{B N}$ & $\underline{\mathrm{CO}}$ & Comments \\
\hline $\begin{array}{l}\text { MSC Long-Range } \\
\text { Guidance }\end{array}$ & .50 & .18 & .11 & $\begin{array}{l}\text { Historical yardstick for training } \\
\text { status analysis. }\end{array}$ \\
\hline $\begin{array}{l}\text { MSC Short- } \\
\text { Range Guidance }\end{array}$ & & .18 & .05 & Same as above. \\
\hline $\begin{array}{l}\text { Battalion Mission } \\
\text { Guidance }\end{array}$ & & & .05 & \\
\hline $\begin{array}{l}\text { Battalion Training } \\
\text { Guidance }\end{array}$ & .25 & .27 & .26 & $\begin{array}{l}\text { Same trend as training and long- } \\
\text { range guidance cited at MSC levei. } \\
\text { Note company rating same for MSC } \\
\text { and battalion. }\end{array}$ \\
\hline $\begin{array}{l}\text { Battal ion Long- } \\
\text { Range Guidance }\end{array}$ & .25 & & .11 & $\begin{array}{l}\text { Historical yardstick for training } \\
\text { status analysis. }\end{array}$ \\
\hline $\begin{array}{l}\text { Battalion Short- } \\
\text { Range Guidance }\end{array}$ & & & .05 & Same as above. \\
\hline $\begin{array}{l}\text { Battalion Near- } \\
\text { Term Guidance }\end{array}$ & & .09 & .05 & Same as above. \\
\hline $\begin{array}{l}\text { Company Mission } \\
\text { Guidance }\end{array}$ & & & .05 & \\
\hline $\begin{array}{l}\text { Company Training } \\
\text { Guidance }\end{array}$ & & & .05 & \\
\hline $\begin{array}{l}\text { Previous Training } \\
\text { Results }\end{array}$ & .55 & .21 & & $\begin{array}{l}\text { High battalion and moderate company } \\
\text { reliance on previous training } \\
\text { results. }\end{array}$ \\
\hline Training Schedules & & & .09 & $\begin{array}{l}\text { Historical yardstick for training } \\
\text { status analysis. }\end{array}$ \\
\hline
\end{tabular}


TABLE D.4. Proportion of Respondents Citing Reference As Output for Task 2 - Identification of Training Objectives, Tasks for Training, and Training Program

Proportion Citing Ref as Task Output

References

MSC Training

Guidance

MSC Long-Range

Pldnning

MSC Near-Term

Planning

Battalion

Training

Guidance

Battalion Long-

Range Planning

Battalion Short-

Range Planning

Battalion Near-

Tem Planning

Company Training

Guidance

Co:npany Long-

Range Planning

Conpany Short-

Range Planning

Company Near-

Term Planning

Training Schedules
$\underline{B N} \quad \underline{C O}$

.26 Few companies possessed written training guidance. Most guidance verbally disseminated.

.05 Analyzing the status of training results in planning changes.

.05 Same as above.

.05 Same as above.

.05 Training schedule not doctrinal output from Task 2. 
term planning guidance as results of Task 2 input. Again, though not doctrinally stated, this reflects that planning is a continuous process.

TASK 3: FORECAST, PROCESS AND MONITOR RESOURCE REQUIREMENTS AND PREPARE BUDGET INFORMATION

Input

Following the training estimate, resource requirements are identified. Doctrinally, throughout the planning phases of Task 3 and Tasks 4 through 6 resources are continually planned and coordinated. Fairly broad-based reliance was placed on resource forecasts and requests by all echelons. The survey data revealed that each echelon looked at the needs of subordinate units, approved and released the resource, or passed their approval on to the resource coordinator at installation level.

\section{Output}

Companies appear to be the primary source for generating resource requests, training aids, ranges, training areas, training ammunition, and general support.

\section{TASK 4: PROCESS LONG-RANGE (6-24 MONTHS) TRAINING GUIDANCE}

Input

Planning is continuous rather than a series of discrete events. Resource lead times that normally affect planning are frequently managed by phases: long-range (annual), short-range (quarterly), and near-term (weekly). The survey indicated a reliance from division through company on the next higher headquarter's training and planning guidance throughout all phases. Resource allocation, forecasting, requesting, and scheduling played a significant role in the planning process. From the survey results, planning and resourcing appear to be simultaneous processes. The key resource planning echelons were MSC and battalion. As planning moved from long-range through short-range to near-term, the impact of external taskings grew. Doctrinally, taskings represent external interference with training 
TABLE 0.5. Proportion of Respondents Citing Reference As Input for Task 3 - Forecast, Process and Monitor Resource Requirements and Prepare Budget Information

Proportion Citing Ref as Task Input

References $\quad \underline{\text { Div }} \quad \underline{M S C} \quad \underline{B N} \quad \underline{C O} \quad$ Comments

Army Mission

.06

Guidance

TRADOC Training

Moderate use of TRADOC references,

References particularly ARTEPs, for resource determination.

Installation

.25

Guidance

Division

Training

Guidance

Division Long-

Range Guidance

Dirision Short-

Range Guidance

MS: Training

Guidance

MS: Long-Range

Guidance

Battalion

Training

Guidance

Battalion Long-

Range Guidance

Battalion ShortRange Guidance
.13

.20

.07

Cited installation references primarily for training ammo, ranges, . and training areas. References several times criticized for being outdated and contradictory.

Division regulations, pamphlets, circulars, and memos cited as key to MSC and battalion. Recurring criticism for being outdated and contradictory.

Pattern develops from division long-range guidance through company short-range guidance. Not as much reliance on training guidance as opposed to increased importani? on resource forecasting and requesting.
.06

.06

$.13 \quad .07$

.13

$.20 \quad .11$

$.10 \quad .20 \quad .11$ 
TABLE 0.5 (cont)

\section{Proportion Citing Ref as Task Input}

References

Battalion Near-

Term Guidance

Company Training

Guidance

Company Long-

Range Guidance

Company Short-

Range Guidance

Training Aids

Request
Oiv $\quad \underline{M S C} \quad \underline{B N} \quad \underline{C O}$

.28 Companies highly dependent upon resource guidance from battalion.

.11

.07
Fairly broad-based reliance on resource forecasting and requesting throughout all echelons. Each echelon looks at the needs of subordinate units, then approves and releases resources or passes their approval on to the resource coordinator at installation level. Same holds true for training aids requests through funds management information input.
Range \& $T A$

Request

Range \& TA

Schedules

Range Control

References

Training Ammo

Allocation

Training Ammo

Forecast

Training Amino

Request

\section{$\begin{array}{llll}.25 & .10 & .20 & .11\end{array}$}

.13

.13

.20

.06

.13

.30

.06

.22

Oata reflect that MSCs are primary training ammo account holders. Companies generate training ammo needs, passing them to battalions for MSC approval. 
TABLE D.5 (cont)

\section{Proportion Citing Ref as Task Input}

\begin{tabular}{|c|c|c|c|c|c|}
\hline References & Div & $\underline{M S C}$ & BN & CO & Comments \\
\hline $\begin{array}{l}\text { Training Ammo } \\
\text { References }\end{array}$ & .13 & .20 & .33 & .11 & \\
\hline $\begin{array}{l}\text { Schools } \\
\text { Al ocation }\end{array}$ & .25 & .20 & .27 & .07 & \\
\hline Schools Request & .25 & .20 & .06 & .07 & \\
\hline $\begin{array}{l}\text { General Resource } \\
\text { Forecasts }\end{array}$ & .25 & & .06 & .07 & \\
\hline $\begin{array}{l}\text { General Resource } \\
\text { Request }\end{array}$ & & .10 & & .22 & \\
\hline $\begin{array}{l}\text { General Support } \\
\text { Refuests }\end{array}$ & .13 & .20 & .06 & & \\
\hline $\begin{array}{l}\text { Funds Management } \\
\text { In formation }\end{array}$ & & .30 & .40 & .17 & \\
\hline Taskings & .13 & & .13 & .07 & \\
\hline
\end{tabular}


TABLE D.6. Proportion of Respondents Citing Reference As Output for Task 3 - Forecast, Process and Monitor Resource Requirements, and Prepare Budget Information

Proportion Citing Ref as Task Output

\begin{tabular}{lllll} 
References & Div & MSC & SN $\quad$ CO & \multicolumn{1}{c}{ Comments } \\
$\begin{array}{lll}\text { Division Long- } \\
\text { Range Plan }\end{array}$ & .13 & & $\begin{array}{l}\text { Low resource output percentage } \\
\text { for division staff structured } \\
\text { interviews. Reflects their resource } \\
\text { monitoring roll versus the resource } \\
\text { operator roll of installation and } \\
\text { other resource coordinators. }\end{array}$
\end{tabular}

MSC Training $\quad .10$

Guidance

Battalion Near-

.07

Term Plan

Company Near-Term

.07

Plan

Training Aid

.13

Forecast

Training Aid

.25

$.13 \quad .22$ Companies appear to be the primary

Request source requesting training aids, ranges, training areas, training ammo, and general support throughout the outp. + process.

$\begin{array}{llllll}\begin{array}{l}\text { Range \& TA } \\ \text { Request }\end{array} & .13 & .30 & .40 & .61 & \begin{array}{l}\text { Same comment. Company key source } \\ \text { of requests. }\end{array} \\ \begin{array}{l}\text { Training Ammo } \\ \text { Allocation }\end{array} & .25 & .20 & & & \begin{array}{l}\text { Data reflect fact that training } \\ \text { ammo allocations come down from } \\ \text { division and MSC to battalion } \\ \text { where process ends. }\end{array} \\ \begin{array}{l}\text { Training Ammo } \\ \text { Forecast }\end{array} & .25 & .30 & .33 & .07 & \begin{array}{l}\text { Data reflect that companies are } \\ \text { not normally involved in } \\ \text { forecasting training ammo. } \\ \text { Distribution of effort fairly } \\ \text { even been division, MSC and } \\ \text { battalion. } \\ \text { Training Ammo }\end{array} \\ \text { Request }\end{array}$


IABLE D.6 (cont)

Proportion Citing Ref as Task Output

\begin{tabular}{|c|c|c|c|c|c|}
\hline References & $\underline{\text { Oiv }}$ & MSC & $\underline{B N}$ & $\underline{\mathrm{CO}}$ & Comments \\
\hline $\begin{array}{l}\text { Schools } \\
\text { Al?ocation }\end{array}$ & .38 & & .20 & & $\begin{array}{l}\text { School allocating efforts appear } \\
\text { primarily distributed between } \\
\text { division and battalion where } \\
\text { soldiers are assigned and a schools } \\
\text { NCO is on the battalion staff. } \\
\text { Lower percentages for MSC indicates } \\
\text { a monitoring role and company a } \\
\text { response role. }\end{array}$ \\
\hline Schools Request & & .10 & .13 & .11 & \\
\hline $\begin{array}{l}\text { General Resource } \\
\text { Forecast }\end{array}$ & & & .07 & & \\
\hline $\begin{array}{l}\text { General Resource } \\
\text { Request }\end{array}$ & & .20 & .07 & .07 & \\
\hline $\begin{array}{l}\text { General Support } \\
\text { Request }\end{array}$ & .13 & .40 & .07 & .33 & $\begin{array}{l}\text { Same comment. Company is key } \\
\text { source of requests. }\end{array}$ \\
\hline $\begin{array}{l}\text { Funds Management } \\
\text { Information }\end{array}$ & & .30 & .60 & .17 & $\begin{array}{l}\text { Budget development and management } \\
\text { (TUFMIS, TMACS) is primarily a } \\
\text { MSC and battalion function. Company } \\
\text { involvement limited to spending } \\
\text { dollar allocations under TUFMIS. }\end{array}$ \\
\hline Taskings & .13 & & & & \\
\hline $\begin{array}{l}\text { Training } \\
\text { Schedule }\end{array}$ & & & & .07 & $\begin{array}{l}\text { Low percentage response. Training } \\
\text { schedules follow near-term planning, } \\
\text { not processing of resource } \\
\text { requirements. }\end{array}$ \\
\hline
\end{tabular}


TABLE D.7. Proportion of Respondents Citing Reference As Input for Task 4 - Process Long-Range (6-24 Months)

Training Guidance

Proportion Citing Ref as Task Input

References $\quad \underline{\text { Div }} \quad \underline{M S C} \quad \underline{B N} \underline{C O}$ Comments

Army Mission

.20

Guidance

FORSCOM Training

.09

Guidance

TRADOC Training

.09

.13

Continued reliance at MSC level

References and below on TRADOC doctrinal references. Interviewees reported that percentages would have been higher had ARTEPs and motorized HTF doctrine been current.

Corps. Training

.09

Guidance

Division Training

.60

$.45 \quad .13$

Reliance indicated from division through company on next higher headquarter's training and planning guidance. Company reliance appears evenly distributed for division through battalion.

Division Long-

.40

$.91 \quad .13$

Range Guidance

$.09 \quad .13$

MSC Training

Guidance

MSC Long-Range

$.91 \quad .13$

Guidance

MSC Short-Range

Guidance

Battalion

$.27 \quad .13$

Training

Guidance

Battalion Long-

.20

$.18 \quad .13$

Range Guidance 
TABLE D.7 (cont)

Proportion Citing Ref as Task Input

References

Battalion Short-

Range Guidance

Company Training

Guidance

Range Control

References
$\underline{B N} \quad \underline{C O}$

.13

.13

Resource references, allocation, forecasting, requesting, and scheduling play a significant role in the planning process. Planing and resourcing appear to be simultaneous processes. Key resource planning echelons continue to be MSC and battalions.

Range \& TA

.09

Schedule

Training Ammo

.20

References

Tritining Ammo

.20

Al location

Training Ammo

.20

Forecast

Sc 10075

Allocation

.09

Ge'reral Support

.20

Rejuests

Tajkings

.25

.25 Regarding taskings, as planning moves from long-range through short-range to near-term, the impact of external taskings grows. They grow to the point that, during near-term planning, external taskings become a principal source of planning input. 
TABLE 0.8. Porportion of Respondents Citing Reference As Output for Task 4 - Process Long-Range (6-24 Months)

Training Guidance

\section{Proportion Citing Ref as Task Output}

References

Division Long-

Range Guidance

MSC Training

Guidance

MSC Long-Range

Plan

MSC Short-

Range Plan

MSC Near-Term

Plan

Battalion

Training

Guidance

Battalion Long-

Range Plan

Company Long-

Range Plan

Company Short-

Range Plan

.40

.60

.20

.20

20
.09

.82

.38 Company long-range plan normally not written, usually verbal or a collection of training calendars.

.25 Same for company as other echelons. One planning phase affects another. 
TABLE D.8 (cont)

Proportion Citing Ref as Task Output

References

Range \& TA

Request

Training Ammo

Aliocation

Training Ammo

Request

School

Allocation

General Resource

Forecast

Training

Schedule

Taskings
Div $\underline{M S C} \quad \underline{B N} \quad \underline{C O}$

.13 Few resources are coordinated for in long-range planning. As planning moves through short-range to nearterm, percentages increase reflecting an increase in activity.

.20

.13

.09

.09

.25
.09 Low percentage response. Training schedules follow near-term planning, not long-term planning.

Division often initiates subordinate unit planning with taskings. Percentage increases from longrange through short-rann: to nearterm planning. 
execution. The survey data indicated that taskings grew to a point that, during near-term planning, they became a major source of planning input.

Output

Table 0.8 proportions for Task 4 Output reflect that planning was continuous and according to doctrine. Changing and updating one plan often resulted in changes to another. Few resources were actually coordinated during long-range planning. As the process moved towards short-range and near-term planning, resource percentages increased, indicating an increase in activity. Division taskings also increased as planning moved towards the near-term. Taskings were often used by division to initiate subordinate unit planning.

IASK 5: PROCESS SHORT-RANGE (3-6 MONTHS) TRAINING GUIDANCE.

$\underline{\text { Input }}$

Unit reliance on division training and long-range guidance began dropping off during short-range planning. The trend continued through nearterm planning. The impact of external taskings grew during short-range planning.

output

Resource coordination activity increased during short-range planning over long-range planning percentages along with division use of external taskings. At this point, the units began citing external taskings as being disruptive to planning.

TASK 6: PROCESS NEAR-TERM $(3-12$ WEEKS $)$ TRAINING GUIDANCE

$\underline{\text { Input }}$

Reliance on division training and long-range guidance continued dropping off during near-term planning. The emphasis switched to MSC, battalion and company short-term planning, such as quarterly calendars and training meet ings . 
TABLE D.9. Proportion of Respondents Citing Reference As Input for Task 5 - Process Short-Range (3-6 Months)

Training Guidance

Proportion Citing Ref as Task Input

\begin{tabular}{|c|c|c|c|c|c|c|}
\hline References & Div & MSC & $\underline{B N}$ & $\underline{\mathrm{CO}}$ & Comments & \\
\hline $\begin{array}{l}\text { TRADOC Training } \\
\text { References }\end{array}$ & & .25 & .09 & .10 & $\begin{array}{l}\text { Continued moderate use of TRADOC } \\
\text { references, particularly ARTEPS, } \\
\text { for planning. Interviewees reported } \\
\text { that percentages would have been } \\
\text { higher had ARTEPS and motorized } \\
\text { doctrine been current. }\end{array}$ & ? \\
\hline $\begin{array}{l}\text { Division Training } \\
\text { Guidance }\end{array}$ & & .50 & .36 & .10 & $\begin{array}{l}\text { Continued reliance on Division } \\
\text { training guidance as seen in long- } \\
\text { range planning. Division Regulation } \\
350-1 \text { key reference. }\end{array}$ & \\
\hline $\begin{array}{l}\text { Division Long- } \\
\text { Range Guidance }\end{array}$ & & .25 & & .18 & $\begin{array}{l}\text { Reliance on Division training and } \\
\text { long-range guidance begins dropping } \\
\text { off durino short-range olanning }\end{array}$ & \\
\hline $\begin{array}{l}\text { Division Short- } \\
\text { Range Guidance }\end{array}$ & & & .27 & & $\begin{array}{l}\text { Trend continues through near-term } \\
\text { planning. }\end{array}$ & \\
\hline $\begin{array}{l}\text { MSC Training } \\
\text { Guidance }\end{array}$ & & .50 & & .20 & $\begin{array}{l}\text { MSC self-initiated training and } \\
\text { long-range planning guidance appear } \\
\text { to be of great importance within } \\
\text { the MSC and to subordinate } \\
\text { Battalions. }\end{array}$ & \\
\hline $\begin{array}{l}\text { MS: Long-Range } \\
\text { Guidance }\end{array}$ & & .25 & .45 & .05 & & \\
\hline $\begin{array}{l}\text { MS: Short-Range } \\
\text { Guidance }\end{array}$ & & & .55 & .15 & & \\
\hline $\begin{array}{l}\text { Battalion } \\
\text { Training } \\
\text { Guidance }\end{array}$ & & & .09 & .05 & & \\
\hline $\begin{array}{l}\text { Battalion Long- } \\
\text { Range Plan }\end{array}$ & & & .36 & .10 & & \\
\hline $\begin{array}{l}\text { Battalion Short- } \\
\text { Range Guidance }\end{array}$ & & & .27 & .50 & $\begin{array}{l}\text { Company reliance on Battalion short- } \\
\text { range guidance takes a significant } \\
\text { percentage increase over Battalion } \\
\text { long-range guidance. The change } \\
\text { is understandable since companies } \\
\text { plan more in the short- and near- } \\
\text { term. }\end{array}$ & - \\
\hline
\end{tabular}


IABLE D.9 (cont)

Proportion Citing Ref as Task Input

\begin{tabular}{|c|c|c|c|c|c|}
\hline References & $\underline{\text { Div }}$ & MSC & $\underline{B N}$ & $\underline{\mathrm{CO}}$ & Comments \\
\hline $\begin{array}{l}\text { Battalion Near- } \\
\text { Term Guidance }\end{array}$ & & & & .05 & \\
\hline $\begin{array}{l}\text { Company Long- } \\
\text { Range Plan. }\end{array}$ & & & & .05 & \\
\hline $\begin{array}{l}\text { Company Short- } \\
\text { Range Guidance }\end{array}$ & & & & .05 & \\
\hline $\begin{array}{l}\text { Training Aids } \\
\text { Forecast }\end{array}$ & & & .09 & & \\
\hline $\begin{array}{l}\text { Range \& TA } \\
\text { Request }\end{array}$ & & & .09 & & \\
\hline $\begin{array}{l}\text { Range \& TA } \\
\text { Schedule }\end{array}$ & & & .09 & & \\
\hline $\begin{array}{l}\text { Training Ammo } \\
\text { References }\end{array}$ & & .25 & & & \\
\hline $\begin{array}{l}\text { General Resource } \\
\text { Forecast }\end{array}$ & & & .09 & & \\
\hline $\begin{array}{l}\text { General Resource } \\
\text { Request }\end{array}$ & & & & .05 & \\
\hline Training Schedule & & & & .05 & \\
\hline $\begin{array}{l}\text { Previous Training } \\
\text { Results }\end{array}$ & & & & .05 & \\
\hline
\end{tabular}

$\begin{array}{llllll}\text { Taskings } & .33 & .25 & .18 & .05 & \text { Note growing influence of external }\end{array}$ taskings on short-range planning. 
TABLE D.10. Proportion of Respondents Citing Reference As Output for Task 5 - Process Short-Range (3-6 Months)

Training Guidance

Proportion Citing Ref as Task Output

\begin{tabular}{|c|c|c|c|c|c|}
\hline$\underline{\text { References }}$ & $\underline{\text { Div }}$ & $\underline{\mathrm{MSC}}$ & BN & $\mathrm{CO}$ & Comments \\
\hline $\begin{array}{l}\text { MSC Training } \\
\text { Guidance }\end{array}$ & & .25 & & & \\
\hline $\begin{array}{l}\text { MSC Short-Range } \\
\text { Plan }\end{array}$ & & .75 & .09 & & $\begin{array}{l}\text { Higher percentage of battalion input } \\
\text { to MSC short-range planning over } \\
\text { MSC long-range plan. }\end{array}$ \\
\hline $\begin{array}{l}\text { MSC Near-Term } \\
\text { Guidance }\end{array}$ & & .25 & & & \\
\hline $\begin{array}{l}\text { Battalion Short- } \\
\text { Range Plan }\end{array}$ & & & .73 & .05 & \\
\hline $\begin{array}{l}\text { Company Mission } \\
\text { Guidance }\end{array}$ & & & & .05 & \\
\hline $\begin{array}{l}\text { Company Short- } \\
\text { Range Plan }\end{array}$ & & & & .60 & \\
\hline $\begin{array}{l}\text { Company Near- } \\
\text { Term Guidance }\end{array}$ & & & & .05 & \\
\hline $\begin{array}{l}\text { Training Aids } \\
\text { Request }\end{array}$ & & & .09 & .05 & $\begin{array}{l}\text { Resource coordination activity } \\
\text { increases during short-range } \\
\text { Dlannina. }\end{array}$ \\
\hline $\begin{array}{l}\text { Range \& TA } \\
\text { Request }\end{array}$ & & & .09 & .05 & \\
\hline $\begin{array}{l}\text { General Resource } \\
\text { Forecast }\end{array}$ & & & .27 & .10 & \\
\hline $\begin{array}{l}\text { General Resource } \\
\text { Request }\end{array}$ & & & .09 & .05 & \\
\hline Training Schedule & & & .09 & & \\
\hline Taskings & .33 & & .09 & & $\begin{array}{l}\text { Division use of taskings to initiate } \\
\text { subordinate unit short-range } \\
\text { planning over long-range planning } \\
\text { increased. }\end{array}$ \\
\hline
\end{tabular}


IABLE D.11. Proportion of Respondents Citing Reference As Input for Task 6 - Process Near-Term (3-12 Weeks)

Training Guidance

\section{Proportion Citing Ref as Task Input}

\begin{tabular}{|c|c|c|c|c|c|}
\hline References & $\underline{\text { Div }}$ & $\underline{M S C}$ & $\underline{B N}$ & $\underline{\mathrm{CO}}$ & Comments \\
\hline $\begin{array}{l}\text { TRADOC Training } \\
\text { References }\end{array}$ & & & .09 & .04 & $\begin{array}{l}\text { Reliance on TRADOC references drops } \\
\text { off during near-term planning. } \\
\text { Trend continues through Task } 8 \text {. }\end{array}$ \\
\hline $\begin{array}{l}\text { Division } \\
\text { Training } \\
\text { Guidance }\end{array}$ & & & .18 & .04 & $\begin{array}{l}\text { Reliance on division training and } \\
\text { long-range guidance continues } \\
\text { dropping off during near-term } \\
\text { planning. Emphasis placed on } \\
\text { MSC, battalion, and company short- } \\
\text { term planning, such as quarterly } \\
\text { calendars and training meetings. }\end{array}$ \\
\hline $\begin{array}{l}\text { Division Long- } \\
\text { Range Plan }\end{array}$ & & & .09 & & \\
\hline $\begin{array}{l}\text { Division Short- } \\
\text { Range Plan }\end{array}$ & & & .09 & & \\
\hline $\begin{array}{l}\text { MSC Training } \\
\text { Guidance }\end{array}$ & & & & .08 & \\
\hline $\begin{array}{l}\text { MSC Long-Range } \\
\text { Plan }\end{array}$ & & & .09 & & \\
\hline $\begin{array}{l}\text { MSC Short-Range } \\
\text { Plan }\end{array}$ & & .50 & .09 & .08 & $\begin{array}{l}\text { MSCS reported placing greater } \\
\text { emphasis on their own planning } \\
\text { guidance versus division planning } \\
\text { guidance. It appears that, at the } \\
\text { MSC level, definitive facts about } \\
\text { events are initially formulated. }\end{array}$ \\
\hline $\begin{array}{l}\text { MSC Near-Term } \\
\text { Guidance }\end{array}$ & & & .27 & & \\
\hline $\begin{array}{l}\text { Battalion } \\
\text { Training } \\
\text { Guidance }\end{array}$ & & & .09 & .04 & \\
\hline $\begin{array}{l}\text { Battalion Long- } \\
\text { Range Plan }\end{array}$ & & & .09 & .08 & \\
\hline
\end{tabular}


TABLE 0.11 (cont)

Proportion Citing Ref as Task Input

\begin{tabular}{|c|c|c|c|c|c|c|}
\hline References & $\underline{0 i v}$ & $\underline{M S C}$ & $\underline{B N}$ & $\underline{\mathrm{CO}}$ & Comments & \\
\hline $\begin{array}{l}\text { Battalion Short- } \\
\text { Range Plan }\end{array}$ & & & .64 & .25 & $\begin{array}{l}\text { Company reliance on battalion short- } \\
\text { range plan grows larger in near-term } \\
\text { planning. Companies are in the next } \\
\text { stage before drafting training } \\
\text { schedules, requesting resources, } \\
\text { and designating unit trainers. }\end{array}$ & 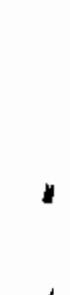 \\
\hline $\begin{array}{l}\text { Battalion Near- } \\
\text { Term Plan }\end{array}$ & & & .18 & .17 & & ? \\
\hline $\begin{array}{l}\text { Company Long- } \\
\text { Range Plan }\end{array}$ & & & & .04 & & - \\
\hline $\begin{array}{l}\text { Company Short- } \\
\text { Range Plan }\end{array}$ & & & .09 & .42 & $\begin{array}{l}\text { Company near-term planning is } \\
\text { normally verbal guidance to } \\
\text { subordinate trainers. }\end{array}$ & \\
\hline $\begin{array}{l}\text { Company Near-Term } \\
\text { Guidance }\end{array}$ & & & & .21 & & \\
\hline $\begin{array}{l}\text { Range \& TA } \\
\text { Requests }\end{array}$ & & & .09 & .04 & & \\
\hline $\begin{array}{l}\text { Training Ammo } \\
\text { Forecast }\end{array}$ & & & & .04 & & \\
\hline $\begin{array}{l}\text { General Resource } \\
\text { Forecast }\end{array}$ & & .50 & .18 & .04 & & \\
\hline $\begin{array}{l}\text { General Resource } \\
\text { Request }\end{array}$ & & & & .04 & & \\
\hline $\begin{array}{l}\text { General Support } \\
\text { Request }\end{array}$ & & & & .04 & & \\
\hline Training Schedules & & & .18 & .08 & & \\
\hline $\begin{array}{l}\text { Previous Training } \\
\text { Results }\end{array}$ & & & & .08 & & \\
\hline Taskings & .50 & .50 & .09 & .08 & $\begin{array}{l}\text { Note impact of external taskings } \\
\text { on near-term planning. Taskings } \\
\text { become one of the principal inputs. } \\
\text { Each echelon percentage has } \\
\text { generally increased. }\end{array}$ & • \\
\hline
\end{tabular}


TABLE D.12. Proportion of Respondents Citing Reference As Output

for Task 6 - Process Near-Term (3-12 Weeks)

Training Guidance

Proportion Citing Ref as Task Output

References

MSC Near-Term

Plan

Battalion Near-

Term Plan

Company Training

Guidance

Company Near-

Term Plan

Training Aids

Request

Range \& TA

Request

Training Ammo

Request

General Resource

Forecast

General Resource

Request

General Support

Request

Training Schedule $\underline{\text { Div }} \quad \underline{M S C} \quad \underline{B N} \quad \underline{C O}$ .50

$.73 \quad .04$

.04

.54

Emphas is placed on verbally directing actions with trainers in the company.

.13 Percentages of resource coordination activity during near-term planning by echelon increases during nearterm planning.

Taskings .50

$.18 \quad .13$

.04

$.09 \quad .29$
.50

.09

.08

.04

.50

29

End product of most company nearterm planning is a draft training schedule. Percentages reflect observations that companies draft training schedule, battalions review and publish in final form.

Percentage of division taskings initiating subordinate unit planning has increased from .25 to .25 from long-term planning. 
The MSCs reported placing greater emphasis on internal planning guidance versus division planning guidance because MSC guidance contained more definitive guidance about forthcoming training events. Company reliance on battalion short-range planning guidance grew during near-term planning since they were in the next phase before drafting training schedules, requesting resources and designating trainers. The percentage of interviewees reporting taskings as a source of near-term planning input grew substantially.

\section{Jutput}

The principal output cited by MSC and battalions during near-term planning was the event LOI/MOI. The end product of most company near-term planning was a draft training schedule. Fifty percent of the division's output during near-term planning were taskings.

\section{TASK 7: PROCESS TRAINING SCHEDULE}

\section{$\underline{\text { Input }}$}

During Task 7, the bulk of planning moved to company, where training schedules were being prepared. The workload for event execution steadily shifted downward during Tasks 4-6 from MSC to company.

\section{Output}

The survey data indicated reported levels of effort and the attached importance of training schedules. Companies draft training schedules while battalions publish. Training schedules are important to battalion and company operations since they guide daily activities. Training schedules are important to MSC and division, but not nearly as important as they are to battalion and company, as they are used for monitoring subordinate unit activities. 
TABLE D.13. Proportion of Respondents Citing Reference As Input for Task 7 - Process Training Schedule

Proportion Citing Ref as Task Input

References $\quad \underline{\text { Div }} \quad \underline{M S C} \quad \underline{B N} \quad \underline{C O} \quad \underline{\text { Comments }}$

TRADOC Training

.11 Reliance on TRADOC references

References

diminishes during training schedule processing with the exception of some companies, where references are cited on training schedules.

Division Training $.08 \quad .07$

Guidance

MSC Training

Guidance

MSC Long-Range

Plan

Battalion

$.08 \quad .07$

Training

Guidance

Battalion Long-

Range Plan

Battalion Short$.08 \quad .07$

Range Plan

Battalion Near-

Company emphasis placed on internal

Term Plan near-term guidance when writing schedules. Planning now at company level.

Company Training

Guidance

Company Long-

Range Plan

Company Short-

Range Plan

.22 Preponderance of planning at company level, being translated into draft training schedules. Workload for event execution has steadily shifted downward during Tasks 4-6 from MSC to company. 
TABLE D.13 (cont)

Proportion Citing Ref as Task Input

\begin{tabular}{|c|c|c|c|c|c|}
\hline References & $\underline{\text { Div }}$ & $\underline{M S C}$ & $\underline{B N}$ & $\underline{\mathrm{CO}}$ & Comments \\
\hline $\begin{array}{l}\text { Company Near- } \\
\text { Term Plan }\end{array}$ & & & & .33 & \\
\hline $\begin{array}{l}\text { Range \& TA } \\
\text { Requests }\end{array}$ & & & .08 & & \\
\hline $\begin{array}{l}\text { General Support } \\
\text { Requests }\end{array}$ & & & & .04 & \\
\hline $\begin{array}{l}\text { Training } \\
\text { Schedules }\end{array}$ & .50 & .33 & 1.00 & & $\begin{array}{l}\text { Oata indicate division, MSC, and } \\
\text { battalion reliance on company } \\
\text { drafted training schedules. }\end{array}$ \\
\hline $\begin{array}{l}\text { Previous Training } \\
\text { Results }\end{array}$ & & & & .04 & \\
\hline
\end{tabular}


TABLE D.14. Proportion of Respondents Citing Reference As Output for Task 7 - Process Training Schedule

\section{Proportion Citing Ref as Task Output}

\begin{tabular}{|c|c|c|c|c|c|}
\hline References & Div & $\underline{M S C}$ & BN & $\underline{\mathrm{CO}}$ & Comments \\
\hline $\begin{array}{l}\text { Company Mission } \\
\text { Guidance }\end{array}$ & & & & .04 & \\
\hline $\begin{array}{l}\text { Range \& TA } \\
\text { Request }\end{array}$ & & & .08 & & \\
\hline $\begin{array}{l}\text { General Resource } \\
\text { Request }\end{array}$ & & & & .04 & \\
\hline $\begin{array}{l}\text { General Support } \\
\text { Request }\end{array}$ & & & .08 & .04 & \\
\hline $\begin{array}{l}\text { Training } \\
\text { Schedules }\end{array}$ & .50 & .67 & .92 & .96 & $\begin{array}{l}\text { Data indicate reported levels of } \\
\text { effort and attached importance of } \\
\text { training schedules. Companies draft } \\
\text { the schedules, battalions publish. } \\
\text { Training schedules are very } \\
\text { important to battalion and company } \\
\text { operations. Importance drops } \\
\text { away at MSC and division where } \\
\text { schedules are used more for } \\
\text { monitoring subordinate unit } \\
\text { activities. }\end{array}$ \\
\hline
\end{tabular}

Taskings 
input

Doctrinally, training results are to be systematically assessed and incorporated into the training estimate process. The assessment process forms a bridge, so that training management can become a continuous process. -ew interviewees at any echelon understood this process or had a systematic procedure for analyzing and incorporating training results. Most previous training results consisted of data collected from individual training records.

The principal input for analyzing training cited by interviewees was the training quality checklist (TQC), originally designed to evaluate a trainer's performance, not measure results.

\section{Output}

The division staff was found to be heavily involved in command inspections of subordinate unit training guidance compliance. During command inspections, the division evaluated unit ITEP proficiency by administering tests to a small sampling of soldiers. Data from the sampling was an ludicator to the division of a unit's overall individual training proficiency. 
TABLE D.15. Proportion of Respondents Citing Reference As Input for Task 8 - Process Information on Task Training

Status and Report Training Readiness

\section{Proportion Citing Ref as Task Input}

\begin{tabular}{|c|c|c|c|c|c|}
\hline References & $\underline{\text { Div }}$ & MSC & $\underline{B N}$ & $\underline{\mathrm{CO}}$ & Comments \\
\hline $\begin{array}{l}\text { Ariny Mission } \\
\text { Guidance }\end{array}$ & & & .25 & .07 & $\begin{array}{l}\text { Emphasis switched from guidance and } \\
\text { planning to inspecting, checking, } \\
\text { and reporting training readiness. }\end{array}$ \\
\hline $\begin{array}{l}\text { Army Training } \\
\text { Guidance }\end{array}$ & & & .07 & .05 & \\
\hline $\begin{array}{l}\text { TRADOC Training } \\
\text { References }\end{array}$ & & & & .14 & \\
\hline $\begin{array}{l}\text { MSC Training } \\
\text { Guidance }\end{array}$ & & & & .09 & \\
\hline $\begin{array}{l}\text { Battalion } \\
\text { Training } \\
\text { Guidance }\end{array}$ & & & & .09 & \\
\hline $\begin{array}{l}\text { Company Mission } \\
\text { Guidance }\end{array}$ & & & & .09 & \\
\hline $\begin{array}{l}\text { Company Near- } \\
\text { Term Plan }\end{array}$ & & & & .09 & \\
\hline $\begin{array}{l}\text { Range Control } \\
\text { References }\end{array}$ & & .25 & & & \\
\hline $\begin{array}{l}\text { Unit Readiness } \\
\text { Reporting }\end{array}$ & & .25 & .14 & .09 & $\begin{array}{l}\text { Primarily AR } 220-1 \text { and FORSCOM } \\
\text { Supplement to AR } 220-1 \text { reporting. }\end{array}$ \\
\hline $\begin{array}{l}\text { Training } \\
\text { Evaluation } \\
\text { Guidance }\end{array}$ & .50 & & & & $\begin{array}{l}\text { Division staff conducts command } \\
\text { inspection of subordinate Battalion } \\
\text { compliance with Oivision training } \\
\text { directives. }\end{array}$ \\
\hline $\begin{array}{l}\text { Previous } \\
\text { Training } \\
\text { Results }\end{array}$ & .50 & .25 & .50 & .45 & $\begin{array}{l}\text { Previous results input consisted } \\
\text { primarily of data collected from } \\
\text { individual training records. } \\
\text { Another source was individual } \\
\text { soldier reports from ITEP. }\end{array}$ \\
\hline $\begin{array}{l}\text { Training } \\
\text { Schedules }\end{array}$ & & & .57 & .45 & $\begin{array}{l}\text { Key training schedule events are } \\
\text { highlighted by battalion and company } \\
\text { for possible higher headquarters } \\
\text { training inspection visits. }\end{array}$ \\
\hline
\end{tabular}


TABLE D.16. Proportion of Respondents Citing Reference As Output for Task 8 - Process Information on Task Training

Status and Report Training Readiness

Proportion Citing Ref as Task Output

\begin{tabular}{|c|c|c|c|c|c|}
\hline References & Div & $\underline{M S C}$ & BN & $\underline{\mathrm{CO}}$ & Comments \\
\hline $\begin{array}{l}\text { Unit Readiness } \\
\text { Report }\end{array}$ & & .25 & .14 & .18 & $\begin{array}{l}\text { Primarily AR } 220-1 \text { and FORSCOM } \\
\text { Supplement to AR } 220-1 \text { reporting. }\end{array}$ \\
\hline $\begin{array}{l}\text { Training } \\
\text { Evaluation } \\
\text { Report }\end{array}$ & 1.00 & & & & $\begin{array}{l}\text { Division staff found heavily } \\
\text { involved in command inspections } \\
\text { of subordinate unit training } \\
\text { guidance compliance. }\end{array}$ \\
\hline $\begin{array}{l}\text { Previous } \\
\text { Training } \\
\text { Results }\end{array}$ & 1.00 & .75 & .93 & .73 & $\begin{array}{l}\text { Principal output was training } \\
\text { quality checks (TQC) Little } \\
\text { feedback of results into Task } 2 \\
\text { found. }\end{array}$ \\
\hline
\end{tabular}


APPENDIX E

INPUT AND OUTPUT DOCUMENT TAXONOMY 
Following is a list of documents that have been identified in the course of reviewing the completed ITMS staffing/job surveys.

Numbers in the left column are the numerical code for the name that will be used to identify the documents.

Names in the center column are the document category, or general name that will be used for a group of documents.

Names in the right column are specific documents, as well as alternative names for the same document, that belong to the corresponding document category.

\section{$\underline{\text { Code }}$}

01

02

03

04
Document Category

ARMY MISSION GUID.

ARMY TRNG GUID.

FORSCOM TRNG GUID

TRADOC TRNG GUID
Document Names

TOE (Table of Organization \& Equipment) MTOE (Modified Table of Org. \& Equip.)

Army Training, DA Reg 350-1 Opposing Force Program, AR 350-2 Army Individual Training Evaluation Program, AR 350-37

Army Physical Fitness and Weight Control Program, AR 600-9

Qualification and Instructional Firing with Weapons and Weapons Systems, AR 3504

NCO Development Program, AR 350-17

DA Messages

DA Pam 350-8

AR $220-58$

DA Circ. 350-87-1, ITEP Announcement

Active Component Training, FORSCOM 350-1

FORSCOM 350-2, Appendix $C$

Five Year Exercise Plan

NTC Objectives

SQTs (Skills Qualification Tests), 11HSQT, 11 BSQT

SMs, Soldier's Manuals

CTT, Common Task Test

ITPT, Individual Training Proficiency Test MOS Manuals

ARTEPS

AMTPS

TRADOC PAM 350-1

Field Manuals (FMS) 
Code

05

50

i) 6

37

38

09

49

10

12
Document Category

HOW TO FIGHT DOCS

CORPS TRNG GUID.

INSTALL. TRNG GUID

DIV MISSION GUID

DIV TRNG GUID

DIV LONG-RANGE

PLANNING

DIV SHORT-RANGE

PLANNING

BDE MISSIONS

BDE LONG-RANGE

PLANNING
Document Names

FC 7-54, CAB How to Fight

FC 7-53, Assault Gun Company Doctrine

Higher Headquarter's Planning

FL Reg 350-1

FL PAM 350-2

SQT Testing

FL Reg 350-14

FL Pam 350-2

HFL Reg 350-3

FL Cir 350-1

Reserve Component

ITEP Testing

9th ID Operations Plans

910 (Motorized) Reg. 350-1

9th ID Master Gunnery Training Requirements

G-3 Training Guidance for External Eval. of Crews

9ID Commanders Training Guidance

Division-Directed Training

910 Command Training Guidance

9ID Circular 350-2

Octofoil Focus Training Goals

9ID Enabling Tasks

Division METL

Div Battle Tasks/Book

FLW Pam 350-2

Div Focus

HFL Reg 350-3

910 Cir 725-2

ROTC Planning Meetings

9th ID Master Training Calendar

Division Long-Range Calendar

gth ID Annual Training Guidance

Div Long-Range Guidance

Division Quarterly Training Guidance

Division G3 Training Notes

Division Quarterly Training Meeting

3rd BDE Missions Statement

3rd BDE Training Calendar/Guidance

BDE Long Range Calendar/Guidance

Brigade Annual Training Calendar

BDE Master Training Calendar

BDE Long-Range Plan 
$\underline{\text { Code }}$

11

13

14

15

16

17

18
Document Category

BDE TRNG GUIDANCE

BDE SHORT-RANGE

PLANNING

BDE NEAR-TERM

. PLANNING

BN MISSION GUIDANCE

BN TRNG GUID.

BN LONG-RANGE

PLANNING

BN SHORT-RANGE

PLANNING
Document Names

Brigade Annual Training Guidance

3rd Brigade FY Training Guidance

Brigade Commander's Training Guidance

Brigade Mission Essential Task List (METL)

3rd BDE Vision Statement

BDE Commander's "Visions" Goals

BDE Gunnery LOI

BDE Internal SOP

BDE Battle Book

BDE Commander's Focus

BDE Quarterly Calendar/Guidance

BDE Mid-Range Planning

BDE Quarterly Training Focus

BDE Quarterly Training Meeting

BDE Event LOI/MOI

BDE WeekTy Training Meeting

BN Missions Guidance

BN Goals

BN Mission Essential Task List

Letters Specifying BN Training

Objectives

BN Critical Missions Task List

BN Battle Book

BN Historical Files

BTMS

NCODP

NCO Development Program

Battalion Annual Iraining Calendar/

Guidance

BN Training Calendar

BN Long-Range Goals

BN Long-Range Calendar

BN Master Training Calendar

BN Long-Range Training Meeting

Battalion Quarterly Training Guidance

Battalion Short Range Calendar

BN Quarterly Training Meeting

BN Mid-Range Planning 
Code

19

20

21

$-2$

23

24

25

TRNG SCHEDULES

BN NEAR-TERM

PLANNING

CO MISSION GUID.

CO TRNG GUID.

CO LONG-RANGE

PLANNING

CO SHORT-RANGE

PLANNING

CO NEAR-TERM

PLANNING
TASKINGS
Document Names

BN LOI/MOI

Battalion Monthly Training Calendar

Battalion Weekly Training Meeting

BN Weekly Training Notes

8N Training Plans

Last Minute BN S3 Guidance

Company Battle Book

Company Tactical SOP

Company Goals

C0 Commander's Out look

Enabling Battle Task List

List of Critical \& Non-Critical Trng Tasks

CO Training 0bjectives

C0 Long Range Plan

18 Month CO Trng Guidance Calendar

Company Quarterly Training Calendar/ Guidance

Company Short Range Calendar

Company Training Board

Company Training Plans

Company Weekiy Training Meeting

Company Daily Status Report

CO Training Brief to $\mathrm{BN}$

CO Commander Guidance

CO Files

Prepare Platoons for Training

Verbal Guidance to Leaders

Battalion Training Highlights

Draft Company Training Schedule

2-4 Week Out Training Schedule

Revised Company Training Schedule

Company Training Schedule

HFL Form 823-DG3

3 BDE Training Hightights Memo

Division Taskings

Brigade Taskings

Divarty Taskings

Battalion Taskings

Directed Event

CG Directed Events

ADEA Appraisal \& Test Worksheets

OTEA Worksheets

Test and Appraisal Summaries 
SQT Test Results

Weapons Qualification Results

PT Test Results

CTT Results

Collective Training Results

Training Visit Report, HFL Form 362

After Action Report

Verbal Results to Unit Leaders

Training Management Evaluation Report Form

Training Quality Checks

Mission Request \& After Action Report, HFL Form 1063

Battalion ARTEP Training Status

BN Individual Training Proficiency Test Results

BN SQT List (Who needs to take test)

CO SQT List (Who needs to take test)

Company Dragon Night Fire Scorecard

Company Range Report

Individual Soldier Report (ISR)

Subjective Evaluation/Notes on Training

CO ARTEP Results

Job Books

Training Records

T.P. or U. Assessment Matrix

ITEP Results

EDRE Results

Identified Training Weaknesses

Future Training Recommendations

Evaluate Training Readiness

Color Code Task Readiness by Percent

READINESS REPORTING

AR 220-1

FORSCOM Supplement to AR 220-1

DA Form 2715 Report

DA Form 2406

Personnel Worksheets

Equipment on Hand Worksheets

Commander's Cover Letter

Monthly USR Briefing

Major Training Event (FTX, Live Fire) Plans

CI (Command Inspection) Checklist, FC 20-3 Command Inspection Meetings

CI (Command Inspection) Review of Training Eval.

Training Meeting Inspection Checklist 


\begin{tabular}{|c|c|c|}
\hline Code & Document Category & 0ocument Names \\
\hline 31 & FUNDS MGMT INFO. & $\begin{array}{l}\text { COB, Command Operating Budget } \\
\text { Expenditure Summaries } \\
\text { TMACS } \\
\text { TUFMIS } \\
\text { AR } 350-31 \\
\text { FORSCOM PAM } 350-31 \\
9 \text { ID LOI for TMACS } \\
\text { BN Budget for Classes of Supplies } \\
\text { CO Guidance on Budget }\end{array}$ \\
\hline 32 & SCHOOLS ALLOCATION & $\begin{array}{l}\text { FL Circ. 350-4, Schedule of Schools } \\
\text { STRAMS } \\
\text { Off-Post Schools Info. } \\
\text { OA Schools Slots Available } \\
\text { Division On-Post Schools Allocation } \\
\quad \text { Notice } \\
\text { Div. Comptroller Schools Budget } \\
\text { CASS Course }\end{array}$ \\
\hline 33 & SCHOOLS REQUEST & $\begin{array}{l}\text { HFL Form } 888 \\
\text { Off-Post Schools Request Form } \\
\text { On-Post Schools Request } \\
\text { DA Form } 4187 \\
\text { Approval/Disapprov of Schools Request }\end{array}$ \\
\hline 34 & AMMO ALLOCATIONS & $\begin{array}{l}\text { Division Ammunition Annual Allocation } \\
\text { Report } \\
\text { I-Corps Ammo Allocation } \\
\text { Brigade Ammunition Allocation } \\
\text { HFL Form } 82 \\
\text { Battalion FY Expended Ammunition Summary } \\
\text { TAMIS } \\
\text { Expenditure Report } \\
\text { Monthly Reconciliation }\end{array}$ \\
\hline 35 & AMMO REFERENCES & $\begin{array}{l}\text { Division Weapons Density } \\
\text { DA Pam } 710-2 \\
\text { FL Reg. } 700-20 \\
9 \text { ID Pam } 350-1 \\
\text { FORSCOM } 700-4 \\
\text { DA Ammo Reg. } \\
\text { DA Pam } 350-85-4 \text {, Ammo STRAC Guide } \\
\text { TB } 9-1300-385\end{array}$ \\
\hline 36 & AMMO FORECASTS & $\begin{array}{l}\text { Army Short Supply Ammo Report } \\
\text { Monthly Ammo Forecast } \\
\text { Brigade Ammunition Requirements Forecast } \\
\text { DA } 5514-R \\
\text { TAMIS Forecast Report } \\
\text { CO Ammo Forecast }\end{array}$ \\
\hline
\end{tabular}

E- 6 
$\underline{\text { Code }}$

37

38

39

40

41

42
Document Category

AMMO REQUESTS

TRNG AIDS FORECAST

TRNG AIDS REQUESTS

AVIATION REQUEST

RANGE CONTROL REFS.

RANGE \& TRNG AREA REQUESTS

RANGE \& TRNG AREA
Document Names

Ammunition Requests

Request for Ammunition

DA Form 581

Scheduled MILES Forecast, HFL Form 585

Request for MILES Support, HFL Form 584 Approved/Disapproved MILES Request Form TASC Information

Training Aids List

HFL Form 1063

Army Aviation Support Request

Flight Cost Analys is

Aircraft Request

Approval/Disapprov. of Aviation Request

Ft. Lewis Reg. 350-30, Range Control Reg.

Ft. Lewis Reg. 350-31

6-Month Trng Area Conference

Monthly Training Area Conference

90-Day Range Scheduling Conference

Letter Identifying Range \& TAs

Range \& TA Discussion

Installation (Ft. Lewis) Range, Facility, and Training Area Request

HFL Form 473

HFL Form 99

Off-Post Training Area Request

Response to Off-Post Training Area Request

Request for Training Area

Request for Range

BN Range Request Approval from Range Control

Range Forecast

Informal Info. on Range \& Training Area Availability from Range Control Cancellation of Training Facility HFL Form 2035

Range Control Projected Scheduling Projected Training Range Schedule

Ft. Lewis Range Control Unit Scheduling 2-Week Forecast of Training Area Usage Weekly Range Bulletin Headquarters, I Corps, and Fort Lewis Daily Bulletin Notice to Airmen (NOTAM)

Range/Training Area Controi Log Ft. Lewis Daily Range Schedule Ft. Lewis Range Control Outreach Program $E-7$ 
Code

$\$ 4$

45

46

47

48
Document Category

RANGE USAGE RPT

RANGE CONTROL RESOURCES

SUPPORT REQUESTS

RESOURCE FORECASTS

RESOURCE REQUESTS
Document Names

Monthly Range Conference

Outreach Program

ROTC Coordination

Monthly Range Usage Report

Range and Training Area Mandays Report Information re Range Usage \& Restrictions Area Surface Danger Zones

Resource Requirements Specifications Guidance to Target Makers

Supply Orders

Request for EOD (Explosive Ordinance Demolition) Support

DEH Engineering Workorders

Request for Fuel

Request for Chemical Items

Request for Food

Request for Medical Support

Request for Equipment

Request for Facilities

Request for Transportation

Personne] Roster

HFL Form 424

HFL Form 744

Request for Battle Simulators

Request for Aviation Support

NBC Eq Status Report

CDE Repi ${ }^{-t}$.

Resource Forecast

Mid-Range Resource Forecast

Ask Commander for Resource Needs

BN Resource Forecast

CO Additional Resource Requirements

Previous Year Resource Expenditure Info.

Identify Resource Requirements

Resource Allocations

Resource Constraints

Resource Request

Commander's Note/Memo to Get a Resource

Resource DF

Platoon Leader's Resource Requests 
No. of

Copies

\section{OFFSITE}

Deputy Commander, U.S. Army

Development \& Employment Agency

ATTN: MODE-DCDR (Col. Burlingame)

Ft. Lewis, WA 98433-5000

Deputy Commander, U.S. Army

Development \& Employment Agency

ATTN: MODE-FDD (LTC MCCAa)

Ft. Lewis, WA 98433-5000

7 Deputy Commander, U.S. Army

Development \& Employment Agency

ATTN: MODE-FDD-TB (LTC Behncke)

Ft. Lewis, WA 98433-5000

Deputy Commander, U.S. Army Development \& Employment Agency

ATTN: MODE-SA (Mr. Fuchs)

Ft. Lewis, WA 98433-5000

President, CDEC Board

U.S. Army Development \& Employment Agency

ATTN: ATEC-B (LTC O'Mara)

Ft. Lewis, WA 98433-5000

ITMS Project Manager

U.S. Army Development \& Employment Agency

ATTN: BDM (Mr. Madden)

Ft. Lewis, WA 98433-5000

Commander

Combined Arms Training Activity

ATTN: ATZL-TAI-TM (Col. MCWain)

Ft. Leavenworth, KS 66027-7000

Commander

Combined Arms Training Activity

ATTN: ATZL-TAI-TM (Maj. Burton)

Ft. Leavenworth, KS 66027-700D
Commander

TRADOC

ATTN: ATT6-UI (Col. Probesdorfer)

Monroe, VA 23651-5000

Project Manager

Army Communicative Systems

ATTN: AMCPM-TND-ACS (LTC Drews)

P.0. Box 4337

Ft. Eustis, VA 23604-0337

Department of the Army

ATTN: HQDA-DAMO-TRS (LTC Millard)

The Pentagon

Washington, D.C. 20310

Dr. Jack Hiller, Director

Training Research Laboratory

U.S. Army Research Institute

5001 Eisenhower Avenue

Alexandria, VA 22333-56D0

Dr. Stan Halpin

ARI Field Unit - Leavenworth

P.0. Box $H$

Ft. Leavenworth, KS 66027-0347

Dr. Howard McFann

Chief, ARI Field Unit

P.0. BOX 5787

Presidio of Monterey, CA 93944-5011

DOE/Office of Scientific and

Technical Information 
No. of

Copies

ONSITE

10 Pacific Northwest Laboratory

C. J. Hostick

D. A. Seaver

T. A. Williams

Publishing Coordination (2)

Technical Report Files (5)

\section{Human Affairs Research Centers}

P. J. Bettin

C. L. Geisendorfer

R. L. Hooper

J. L. King

M. C. McCallum

B. D. Melber

M. Morgenstern

T. F. Sanquist (10)

C. R. Schuller

R. Shikiar

A. Slavich

J. L. Toquam

J. A. Underwood

W. A. Wheeler

Library (2) 